\title{
The biopychosocial approach to chronic pain: scientific advances and future directions.
}

Citation for published version (APA):

Gatchel, R. J., Bo Peng, Y., Peters, M. L., Fuchs, P. N., \& Turk, D. C. (2007). The biopychosocial approach to chronic pain: scientific advances and future directions. Psychological Bulletin, 133(4), 581624. https://doi.org/10.1037/0033-2909.133.4.581

Document status and date:

Published: 01/01/2007

DOI:

10.1037/0033-2909.133.4.581

Document Version:

Publisher's PDF, also known as Version of record

Document license:

Taverne

Please check the document version of this publication:

- A submitted manuscript is the version of the article upon submission and before peer-review. There can be important differences between the submitted version and the official published version of record.

People interested in the research are advised to contact the author for the final version of the publication, or visit the DOI to the publisher's website.

- The final author version and the galley proof are versions of the publication after peer review.

- The final published version features the final layout of the paper including the volume, issue and page numbers.

Link to publication

\footnotetext{
General rights rights.

- You may freely distribute the URL identifying the publication in the public portal. please follow below link for the End User Agreement:

www.umlib.nl/taverne-license

Take down policy

If you believe that this document breaches copyright please contact us at:

repository@maastrichtuniversity.nl

providing details and we will investigate your claim.
}

Copyright and moral rights for the publications made accessible in the public portal are retained by the authors and/or other copyright owners and it is a condition of accessing publications that users recognise and abide by the legal requirements associated with these

- Users may download and print one copy of any publication from the public portal for the purpose of private study or research.

- You may not further distribute the material or use it for any profit-making activity or commercial gain

If the publication is distributed under the terms of Article $25 \mathrm{fa}$ of the Dutch Copyright Act, indicated by the "Taverne" license above, 


\title{
The Biopsychosocial Approach to Chronic Pain: Scientific Advances and Future Directions
}

\author{
Robert J. Gatchel and Yuan Bo Peng \\ The University of Texas at Arlington
}

Perry N. Fuchs

The University of Texas at Arlington

\author{
Madelon L. Peters \\ Maastricht University
}

Dennis C. Turk

University of Washington, Seattle

\begin{abstract}
The prevalence and cost of chronic pain is a major physical and mental health care problem in the United States today. As a result, there has been a recent explosion of research on chronic pain, with significant advances in better understanding its etiology, assessment, and treatment. The purpose of the present article is to provide a review of the most noteworthy developments in the field. The biopsychosocial model is now widely accepted as the most heuristic approach to chronic pain. With this model in mind, a review of the basic neuroscience processes of pain (the bio part of biopsychosocial), as well as the psychosocial factors, is presented. This spans research on how psychological and social factors can interact with brain processes to influence health and illness as well as on the development of new technologies, such as brain imaging, that provide new insights into brain-pain mechanisms.
\end{abstract}

Keywords: biopsychosocial, chronic pain, neuroscience of pain, pain and cognition, pain and emotion

During the past decade, there has been an explosion of research on chronic pain, with significant advances in understanding its etiology, assessment, and treatment (Gatchel, 2004a, 2004b, 2005; Turk \& Monarch, 2002). This research has important health care implications. Epidemiological research has shown that chronic pain (loosely defined as prolonged and persistant pain of at least 3 months in duration) and chronic recurrent pain (recurrent episodes of pain interspersed with pain-free periods extending over months or years) affects $10 \%-20 \%$ of adults in the general population (Blyth et al., 2001; Gureje, Von Korff, Simon, \& Gater, 1998; Verhaak, Kerssens, Dekker, Sorbi, \& Bensing, 1998). For example, in a large-scale epidemiological study, Von Korff et al. (2005) estimated a $19 \%$ prevalence for chronic spinal pain (neck and back) in the United States in the previous year and a 29\% lifetime rate. The American Academy of Pain Management (2003) asserted that approximately $57 \%$ of all adult Americans reported experiencing recurrent or chronic pain in the past year. About $62 \%$ of those individuals reported being in pain for more than 1 year, and

Robert J. Gatchel and Yuan Bo Peng, Department of Psychology, The University of Texas at Arlington; Madelon L. Peters, Department of Medical, Clinical and Experimental Psychology, Maastricht University, The Netherlands; Perry N. Fuchs, Department of Psychology and Department of Biology, The University of Texas at Arlington; Dennis C. Turk, Department of Anesthesiology, University of Washington, Seattle.

Preparation of this article was supported by National Institutes of Health Grants 1K05-MH071892, 2R01 DE 010713, and 2R01 MH 046452; Department of Defense Grant DAMD17-03-1-0055; and National Institute of Arthritis and Musculoskeletal and Skin Diseases Grants AR44724 and AR47298.

Correspondence concerning this article should be addressed to Robert J. Gatchel, Department of Psychology, University of Texas at Arlington, Box 19528, Arlington, TX 76063. E-mail: gatchel@uta.edu
$40 \%$ noted that they were constantly in pain. Indeed, as Gatchel (2004a, 2004b) has summarized, pain is a pervasive medical problem: It affects over 50 million Americans and costs more than $\$ 70$ billion annually in health care costs and lost productivity; it accounts for more than $80 \%$ of all physician visits. Moreover, chronic pain is often associated with major comorbid psychiatric disorders and emotional suffering.

As the above factors attest, the prevalence and cost of chronic pain is a major physical and mental health care problem in the United States. Moreover, individuals 50 years of age and older are twice as likely to have been diagnosed with chronic pain (Gatchel, 2004, 2005). Currently, there are approximately 35 million Americans aged 65 years or older, accounting for $12.4 \%$ of the total population. The proportion of the population aged 65 and over is expected to increase by $57 \%$ by the year 2030 , with Americans now having an average life expectancy of 77 years (Social Security Administration, n.d.). Awareness of these population trends has contributed to an increased concern about health care issues of older Americans, including chronic pain problems. With these estimates in mind, it is not surprising that the U.S. Congress designated 2001-2010 as the Decade of Pain Control and Research and that the Joint Commission on Accreditation of Healthcare Organizations now requires physicians to consider pain as the fifth vital sign (added to the other vital signs of pulse, blood pressure, core temperature, and respiration).

The statistics cited above and population trends have fueled a great deal of research on chronic pain. The purpose of the present article is to provide a review of some of the most noteworthy scientific advances in this area. As is initially discussed, the biopsychosocial model has proved to be the most widely accepted and most heuristic perspective to the understanding and treatment of chronic pain. Subsequently, reviews 
of important biobehavioral mechanisms and psychosocial factors are provided.

\section{The Biopsychosocial Model of Chronic Pain}

The traditional approach embraced a dualistic viewpoint that conceptualized the mind and body as functioning separately and independently. The inadequacy of the dualistic model contributed to a growing recognition that psychosocial factors, such as emotional stress, could impact the reporting of symptoms, medical disorders, and response to treatment. George Engel (1977) is credited as one of the first to call for the need of a new approach to the traditional biomedical reductionistic philosophy that dominated the field of medicine since the Renaissance. This subsequently led to the growth of the field of behavioral medicine and health psychology (Gatchel \& Baum, 1983). A major outgrowth, in turn, was the development and evolution of the biopsychosocial model. This model has been especially influential in the area of chronic pain.

The biopsychosocial model focuses on both disease and illness, with illness being viewed as the complex interaction of biological, psychological, and social factors (Gatchel, 2005). As succinctly summarized by several authors (e.g., Gatchel, 2004a, 2004b; Turk \& Monarch, 2002), disease is defined as an objective biological event involving the disruption of specific body structures or organ systems caused by either anatomical, pathological, or physiological changes. In contrast, illness refers to a subjective experience or self-attribution that a disease is present. Thus, illness refers to how a sick person and members of his or her family live with, and respond to, symptoms of disability.

The distinction between disease and illness is analogous to the distinction that can be made between nociception and pain. Nociception involves the stimulation of nerves that convey information about potential tissue damage to the brain. In contrast, pain is the subjective perception that results from the transduction, transmission, and modulation of sensory information. This input may be filtered through an individual's genetic composition, prior learning history, current psychological status, and sociocultural influences. For pain to be registered, the organism must be conscious. To the best of our knowledge, completely anesthetized patients do not perceive pain; however, nociception can be detected following a surgical incision even in the absence of any subjective report.

Loeser (1982) originally formulated a general model that delineated four dimensions associated with the concept of pain: the dimensions of nociception and pain reviewed above, suffering (the emotional responses that are triggered by nociception or some other aversive event associated with it, such as fear or depression), and pain behavior (those things that people say or do when they are suffering or in pain, such as avoiding activities or exercise for fear of reinjury). Pain behaviors are overt communications of pain, distress, and suffering.

Waddell (1987) has emphasized that pain cannot be comprehensively evaluated without an understanding of the individual who is exposed to the nociception. Waddell also made a comparison between Loeser's (1982) model of pain and the biopsychosocial model put forth by Engel (1977). In particular, Engel proposed the important dimensions of the physical problem, distress, illness behavior, and the sick role, which corresponded to Loeser's dimensions of nociception, pain, suffering, and pain behavior, re- spectively. In order to fully understand a person's perception and response to pain and illness, the interrelationships among biological changes, psychological status, and the sociocultural context all need to be considered (see Figure 1). Any model that focuses on only one of these dimensions will be incomplete and inadequate.

Many of the individual dimensions depicted in Figure 1, and the complexities involved with their interactions, are discussed in subsequent sections of this article, particularly the neurobiology of the nociception process and other basic neuroscience processes of pain (the bio part of biopsychosocial), as well as psychological and social factors. The psychosocial factors involve both emotion and cognition. Emotion is the more immediate reaction to nociception and is more midbrain based. Cognitions then attach meaning to the emotional experience and can then trigger additional emotional reactions and thereby amplify the experience of pain, thus perpetuating a vicious circle of nociception, pain, distress, and disability. We then review the implications of the new insights for better understanding the etiology, assessment, treatment, and prevention of chronic disability.

\section{The Nociceptive Process}

\section{Early Biomedical Models}

Historically, 19th and 20th century models of nociceptive processing followed the traditional biomedical model of disease. The ideas followed a Cartesian view that there was an isomorphic relationship between pain and tissue injury. The early biomedical models can, in general, be divided into two general perspectives. One perspective, "specificity theory," generally stated that there were unique receptor mechanisms and pathways that transduced and transmitted specific painful information from the periphery to the spinal cord and then to the brain. This direct transmission line model can be traced back to views expressed by the ancient Greeks. One of the earliest and best known of the modern specificity theorists was von Frey (see Finger, 1994). His work revolved around the identification and description of mechanical and thermal receptive fields on the skin. On the basis of his work, it was suggested that specialized nerve endings were involved in the transduction and transmission of painful information.

Another general theoretical perspective has been referred to as the "pattern response" (Nafe, 1934; Sinclair, 1955; Weddell, 1955). According to this perspective, nociceptive information was not primarily due to activation of specific receptors and pathways but rather was due to the pattern of responses in afferent systems It was the stimulus intensity and the processing of the pattern of responses that determined the perceptual response to the nociceptive input, namely, pain. Although these two general perspectives explained much of the literature and prompted a wealth of scientific literature, both perspectives had limitations, and many issues and potential explanations related to pain and suffering remained elusive.

Another perspective, harkening back to Aristotle and challenging the pure sensory models described, conceptualized pain as a "quality of the soul" - an emotion in contrast to a pure sensory event. This competing viewpoint was carried forward to more recent times. For instance, Livingston $(1943,1998)$ was one of the first to expose the weaknesses of specificity theory and argue for pain as a subjective state that arises from activation of aversive 
BIO • PSYCHO • SOCIAL

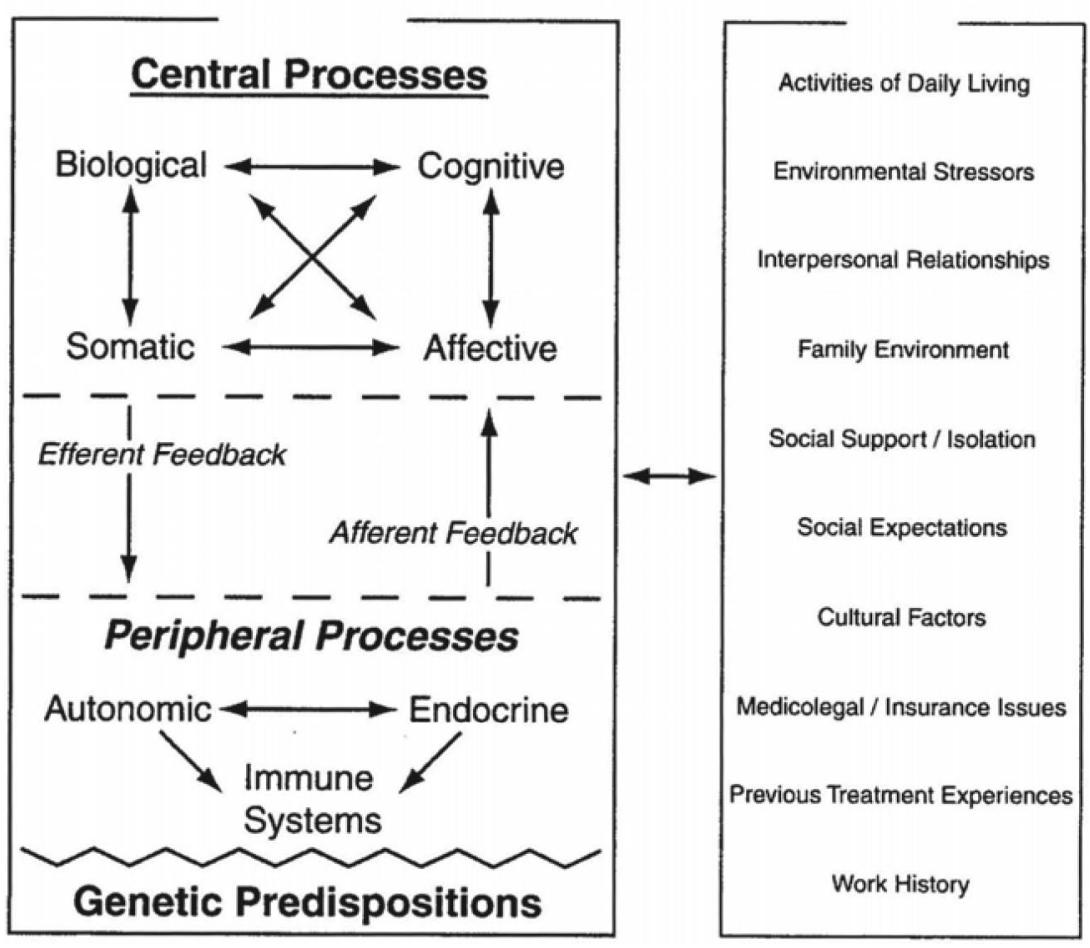

Figure 1. A conceptual model of the biopsychosocial interactive processes involved in health and illness. From "Comorbidity of Chronic Mental and Physical Health Conditions: The Biopsychosocial Perspective," by R. J. Gatchel, American Psychologist, 59, 792-805. Copyright 2004 by the American Psychological Association.

networks in the brain. His concept of "appetites," with pleasure and pain as the motivating attributes, was a dramatic shift in thought and reflected Hebb's (1949) belief that pain was a factor motivating behavior. The failure of these unidimensional sensory and affective models to explain much of what was observed experimentally and clinically (Beecher, 1959) and the inadequacy of treatments based on these models served as the impetus for a more complex, integrative model. In particular, the seminal gate control theory of pain postulated by Melzack and colleagues (Melzack \& Casey, 1968; Melzack \& Wall, 1996).

\section{The Gate Control Theory of Pain}

The initial framework for the gate control theory of pain, which built on the ideas of the Dutch surgeon Nordenbras (1959), was developed to ensure that the known properties of clinical pain conditions at the time were explained. Melzack and Wall (1965) sought to combine the properties of the specificity theories with the best features of the pattern response theories and the affectivemotivational view in order to generate the more inclusive gate control theory of pain. They recognized that there was a certain degree of specificity for peripheral nerve function. They also realized that there was a certain degree of pattern recognition that was responsible for the underlying peripheral and central processing of noxious information. Moreover, they acknowledged that a comprehensive model must take into consideration the amplifiying effects of emotion and the interpretive role of cognitive evaluation.
As outlined by Melzack and Wall (1996), the gate control theory of pain had to account for a number of facts such as the following:

(1) the variable relationship between injury and pain; (2) non-noxious stimuli can sometimes produce pain; (3) the location of pain and tissue damage is sometimes different; (4) pain can persist long after tissue healing; (5) the nature of the pain and sometimes the location can change over time; (6) pain is a multi-dimensional experience; and (7) there is a lack of adequate pain treatments. (p. 165)

It is precisely these facts that no theory at the time could explain.

The initial formulation proposed that there are five stages that compose the mechanism by which noxious signals enter the spinal cord from the periphery and then proceed to higher level brain areas. The first stage consisted of the small diameter peripheral nerve fiber transmission of signals to cells in the spinal cord. The second stage included facilitatory interneurons in the region of the spinal cord to account for the fact that cells in the spinal cord can show prolonged afterdischarge following the arrival of a signal from the peripheral nerve (Wall, 1960). The afterdischarge was accounted for by an excitatory interneuron. The third stage incorporated a large-fiber, low-threshold input. This third stage focused attention on a group of additional peripheral fiber inputs to the spinal cord that could be involved in pain processing. As they indicated, most research prior to the gate control theory focused on nociceptive specific neurons, or those cells that responded only to high-threshold peripheral stimulation. The fourth stage included inhibitory interneurons to account for the fact that postsynaptic 
inhibition was likely to occur in the spinal cord. The fifth stage was the inclusion of a descending modulatory system to account for the finding that there was an inhibitory influence from the brainstem to the spinal cord (Wall, 1967). The final stage was the inclusion of a loop system, with the assumption that ascending signals to the brain engage and influence descending modulatory systems. Therefore, Figure 2 illustrates the final diagram of the gate control theory. There is little doubt that the gate control theory, with a focus on the multidimensional and variable relationship between pain and tissue damage, was a major advancement in the field of pain research and management, prompting much research and ultimately increasing researchers' understanding of pain mechanisms. As the field of pain research and management evolves, the adequacy of the gate control theory of pain to explain different factors has also continued to be examined.

\section{The Neuromatrix Theory of Pain}

The neuromatrix theory of pain proposes that pain is a multifaceted experience that is produced by a characteristic neurosignature of a widely distributed brain neural network, called the body-self neuromatrix (Melzack, 2001, 2005; see Figure 3). The body-self neuromatrix integrates cognitive-evaluative, sensorydiscriminative, and motivational-affective components proposed by Melzack and Casey (1968). The theory proposes that the output patterns of the neuromatrix engage perceptual, behavioral, and homeostatic systems in response to injury and chronic stress. A critical component of the neuromatrix theory of pain is the recognition that pain is the consequence of the output of the widely distributed brain neural network rather than a direct response to sensory input following tissue injury, inflammation, and other pathologies (Melzack, 2001).

The development of such a hypothetical system stems primarily from reports and research in patients with spinal cord injuries and in patients that experience phantom limb and phantom limb pain. In a large number of cases, paraplegics will continue to experience body sensations and pain below the level of the spinal section. A significant proportion of individuals who lose a limb or sensation

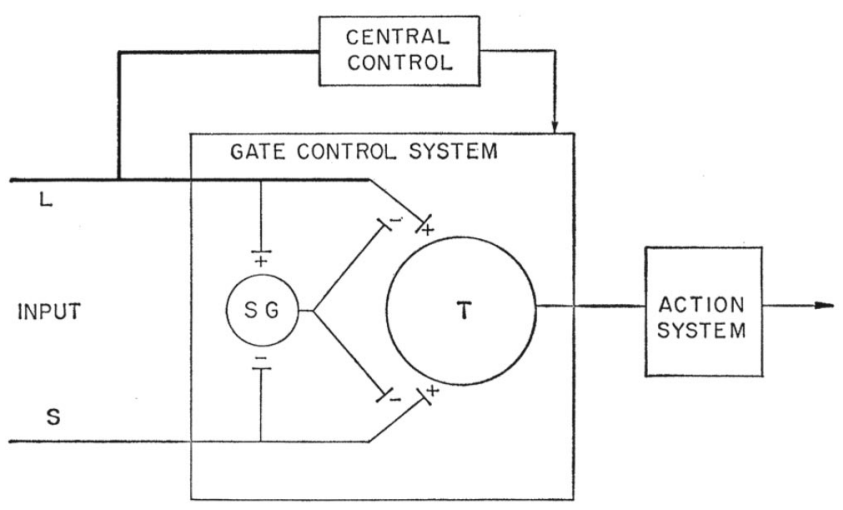

Figure 2. $\mathrm{L}=$ large diameter fibers; $\mathrm{S}=$ small diameter fibers; $\mathrm{SG}=$ substantia gelatinosa; $\mathrm{T}=$ first central transmission cells; $+=$ excitation; $-=$ inhibition. Melzack and Wall's gate control theory of pain. From "Pain Mechanisms: A New Theory," by R. Melzack and P. D. Wall, 1965, Science, 150, p. 975 . Copyright 1965 by the American Association for the Advancement of Science. Reprinted with permission. in other body regions will continue to experience the presence of the limb or the otherwise anesthetic area (e.g., below a spinal lesion). Although the experience of the phantom limb might be in some cases maintained by altered peripheral nerve activity in the region of the stump (Hunter, Katz, \& Davis, 2005), there is sufficient evidence indicating that peripheral mechanisms do not fully account for such phenomena (Katz \& Melzack, 1990; Ramachandran, 1998; Ramachandran \& Hirstein, 1998; Wu et al., 2002). Traditional specificity and pattern theories of pain, in particular, have difficultly accounting for these phenomena. The body-self neuromatrix, however, requires no actual sensory input to produce experiences of the body.

\section{Homeostasis, Allostatic Load, and Hypothalamic- Pituitary-Adrenal (HPA) Axis Dysregulation}

It is becoming clear that the pain experience is determined by a multitude of factors. Although the focus has historically been directed at sensory mechanisms, more attention is being placed on factors related to cognitive, affective, behavioral, and homeostatic factors. The primary basis for including discussions of homeostatic factors is that chronic pain threatens the organism and produces a cascade of events that eventually contributes to the maintenance of such conditions even after the original tissue damage has been resolved or in the absence of any objectively determined pathology. If one views pain as a primary threat to the organism, similar to the stress of extreme hunger and thirst, then mechanisms should be present to engage and motivate the organism to restore basic homeostatic function (LaGraize, Borzan, Rinker, Kopp, \& Fuchs, 2004). The major consequence of homeostatic imbalance is stress. Regardless of the source, stressors activate numerous systems such as the autonomic nervous system and the HPA axis. Prolonged activation of the stress system has disastrous effects on the body (cf. Selye, 1950; Korte, Koolhaas, Wingfield, \& McEwen, 2005) and sets up a condition of a feedback loop between pain and stress reactivity.

During periods of short-term stress and homeostatic imbalance, the hypothalamus activates the pituitary gland to secrete adrenocorticotropic hormone, which acts on the adrenal cortex to secrete cortisol. Secretion of cortisol elevates blood sugar levels and enhances metabolism, an adaptive response that allows the organism to mobilize energy resources to deal with the threat and restore homeostatic balance (i.e., fight or flight response). The situation is much more serious during prolonged periods of stress and homeostatic imbalance that is associated with long-term psychological stress, including chronic pain and other pathological conditions. Prolonged, elevated levels of cortisol are related to the exhaustion phase of Selye's (1950) General Adaptation Syndrome. The negative effects of this stage of the adaptation syndrome include atrophy of muscle tissue, impairment of growth and tissue repair, immune system suppression, and morphological alterations of brain structures, which together might set up conditions for the development and maintenance of a variety of chronic pain conditions (Chrousos \& Gold, 1992; McBeth et al., 2005; McEwen, 2001; McLean et al., 2005). The concept of allostatic load, and the factors that contribute to physiological burden, is becoming increasingly recognized as an important component of disease and disabilities (Seng, Graham-Bermann, Clark, McCarthy, \& Ronis, 


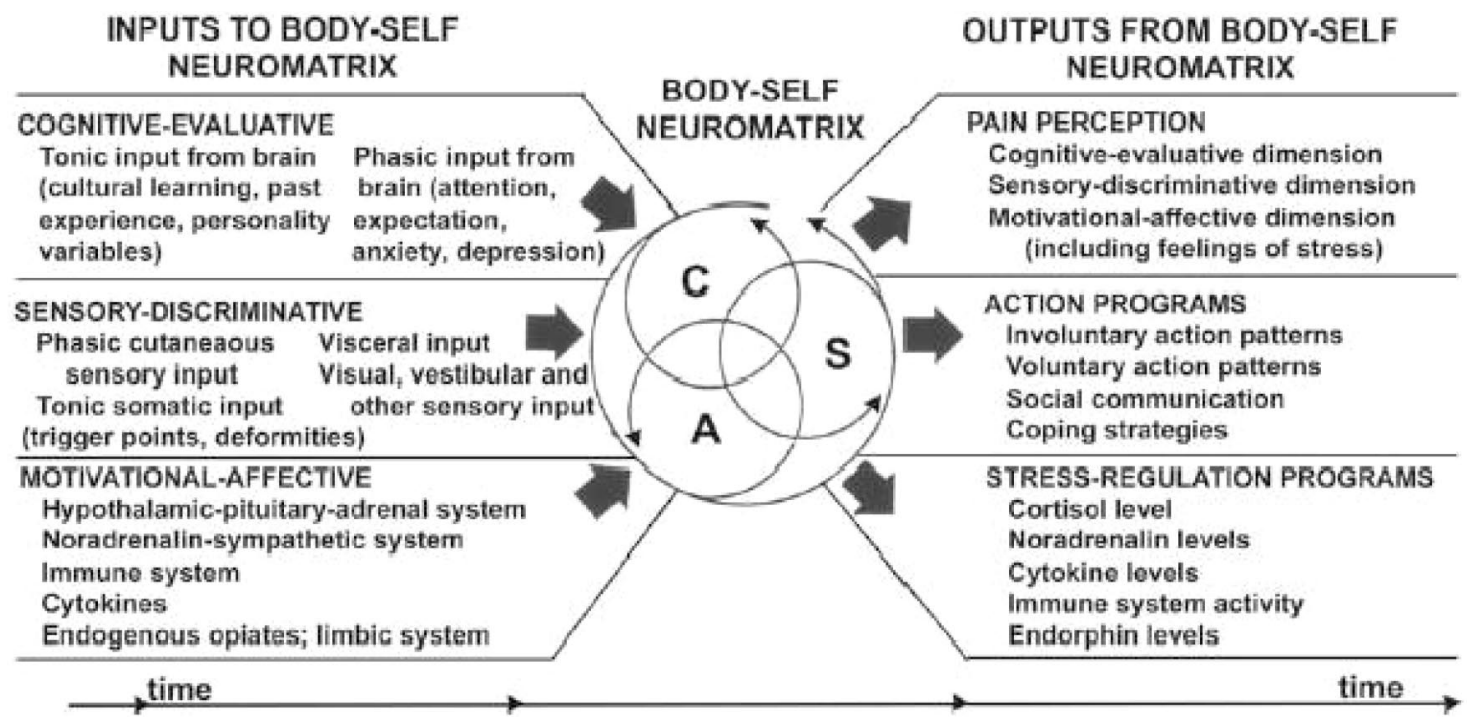

Figure 3. Melzack's body-self neuromatrix model of pain. From "Pain and the Neuromatrix in the Brain," by R. Melzack, 2001, Journal of Dental Education, 65, p. 1382. Copyright 2001 by the American Dental Education Association. Reprinted with permission.

2005; Singer, Friedman, Seeman, Fava, \& Ryff, 2005; Tucker, 2005).

According to Melzack (2005), psychological stress, as well as sensory and cognitive events, modulates the neurosignature of the body-self neuromatrix which, as a consequence of altered neuromatrix output, is associated with chronic pain conditions. The concept of the neuromatrix has potentially important explanatory implications for brain function in general and, together with the concepts of allostasis and homeostasis, provides a theoretical framework for the biopsychosocial perspective of chronic pain. As is discussed later, there is a growing literature demonstrating the importance of psychosocial factors (emotion and cognition) in this neuromatrix conceptualization.

\section{The Neuroscience of Pain}

The field of neuroscience has contributed to a better delineation of basic mechanisms in pain processing by conducting carefully controlled experimental studies. In doing do, several experimental pain models have been proposed involving inflammatory pain, neuropathic pain, and cancer pain. These models, in turn, have led to important clinical applications, such as the development of analgesic agents for improved management of chronic pain. A summary of research related to these three models is presented in Table 1. The purpose of this section is to simply provide a general overview of the wide breadth of neuroscience research of chronic pain that is ongoing. Research on inflammatory, neuropathic, and cancer pain models is reviewed.

Inflammatory mediators and their action on pain pathways have a direct effect on pain states through stimulation or potentiation of nociceptive transduction at peripheral terminals and central changes contributing to hypersensitivity (Levine \& Reichling, 1999; Raja, Meyer, Ringkamp, \& Campbell, 1999). As noted in Table 1, inflammatory pain models have been tested with a number of different techniques, such as experimental arthritis by intra- articular injections of certain substances, cutaneous inflammation by application of certain extracts, and so forth. In addition to the somatic pain models, several visceral pain models have been developed, including writhing test by intraperitoneal injection of phenylquinone or acetic acid or injection of formalin into the colon wall. Other methods used have been intracolonic application of mustard oil or capsaicin, colorectal distention, and intrabladder injection of xylene, to mention some of the more commonly used ones.

Neuropathic pain results from damage to the nervous system, including peripheral nerves, spinal cord, and certain central nervous system (CNS) regions. As seen with many other clinical pain conditions, the clinical symptoms of neuropathic pain include spontaneous pain, allodynia (i.e., pain due to a stimulus that does not normally produce pain, such as soft touch), and hyperalgesia (i.e., an exaggerated response to a stimulus that is normally somewhat painful). It may spread to the neighboring cutaneous distribution of the injured nerve or develop bilaterally in mirror image sites with the quality of burning, shooting, stabbing, piercing, and electric shock.

Following trauma, inflammation or infection causes almost half of human neuropathies. Sciatic inflammatory neuritis models have been developed to address this issue by injection of zymosan around the sciatic nerve. As a further model for two of the major human diseases that cause peripheral neuropathy, there has been the development of the postherpetic neuralgia model, involving reactivation of a primary infection with varicella-zoster virus, and the diabetic neuropathic pain model, involving injection of streptozocin or use of animal strains (such as insulin-deficient rats and mice, insulin resistant mice, and Mongolian gerbil).

Cancer pain is an increasingly devastating problem affecting the quality of life for patients undergoing active treatment and advanced cancer stages. Cancer-related pain can be caused directly by tumor infiltration or compression of peripheral nerve, plexus, or 
Table 1

Summary of Experimental Pain Models

\begin{tabular}{|c|c|c|c|}
\hline Category & Models & Procedures & References \\
\hline \multirow[t]{19}{*}{$\begin{array}{l}\text { Inflammatory } \\
\text { pain }\end{array}$} & \multirow[t]{2}{*}{ Experimental arthritis } & $\begin{array}{l}\text { Intra-articular injection of kaolin and } \\
\text { carrageenan }\end{array}$ & $\begin{array}{l}\text { Schaible \& Schmidt (1985); Schaible \& Schmidt (1988a, 1988b); } \\
\text { Neugebauer \& Schaible (1990); Schaible \& Grubb (1993) }\end{array}$ \\
\hline & & $\begin{array}{l}\text { Intra-articular injection of Freund's } \\
\text { adjuvant }\end{array}$ & Butler et al. (1992); Grubb et al. (1993); L. F. Donaldson et al. (1993) \\
\hline & \multirow[t]{6}{*}{$\begin{array}{l}\text { Cutaneous } \\
\text { inflammation }\end{array}$} & Topical application of mustard oil & $\begin{array}{l}\text { Woolf \& King (1990); Koltzenburg et al. (1992); Koltzenburg \& } \\
\text { Handwerker (1994) }\end{array}$ \\
\hline & & Injection of carrageenan & Traub (1996); Ren, Williams, et al. (1992); Meller et al. (1994) \\
\hline & & $\begin{array}{l}\text { Injection of complete Freund's } \\
\text { adjuvant }\end{array}$ & $\begin{array}{l}\text { Ren, Hylden, et al. (1992); Ren \& Dubner (1993); Ren et al. (1994); } \\
\text { Ren \& Dubner (1996); Ruda et al. (2000) }\end{array}$ \\
\hline & & Injection of formalin & $\begin{array}{l}\text { Dubuisson \& Dennis (1977); Dickenson \& Sullivan (1987); Coderre et } \\
\text { al. (1990); Coderre \& Melzack (1992a, 1992b); Coderre et al. (1993); } \\
\text { Abbott et al. (1995) }\end{array}$ \\
\hline & & Injection of bee venom & $\begin{array}{l}\text { Lariviere \& Melzack (1996); J. Chen et al. (1998); J. Chen et al. (1999); } \\
\quad \text { Lariviere \& Melzack (2000) }\end{array}$ \\
\hline & & $\begin{array}{l}\text { Injection or topical application of } \\
\text { capsaicin }\end{array}$ & $\begin{array}{l}\text { Bodnar et al. (1983); Simone et al. (1989); LaMotte et al. (1991, 1992); } \\
\text { Torebjörk et al. (1992); Sluka et al. (1997) }\end{array}$ \\
\hline & \multirow[t]{2}{*}{ Myofascial pain } & Injection of acidic saline & $\begin{array}{l}\text { Sluka et al. (2001); Hoeger-Bement \& Sluka (2003); Radhakrishnan et } \\
\text { al. (2003); Skyba, et al. (2005) }\end{array}$ \\
\hline & & Injection of carrageenan & Radhakrishnan et al. (2003); Skyba et al. (2005) \\
\hline & \multirow[t]{9}{*}{ Visceral pain } & $\begin{array}{l}\text { Intraperitoneal injection of } \\
\text { phenylquinone }\end{array}$ & Hendershot \& Forsaith (1959); Taber et al. (1964) \\
\hline & & $\begin{array}{l}\text { Intraperitoneal injection of acetic } \\
\text { acid }\end{array}$ & Taber et al. (1969) \\
\hline & & $\begin{array}{l}\text { Injection of formalin into the colon } \\
\text { wall }\end{array}$ & Miampamba et al. (1994) \\
\hline & & $\begin{array}{l}\text { Intracolonic application of mustard } \\
\text { oil or capsaicin }\end{array}$ & Laird, Martinez-Caro, et al. (2001) \\
\hline & & Colorectal distention & Ness et al. (1991); Al-Chaer et al. (1996) \\
\hline & & Intrabladder injection of xylene & Abelli et al. $(1988,1989)$ \\
\hline & & Intrauterine injection of mustard oil & Wesselmann et al. (1998) \\
\hline & & $\begin{array}{l}\text { Vaginal hyperalgesia through } \\
\text { endometriosis }\end{array}$ & Berkley et al. (2001) \\
\hline & & Artificial ureter stone & Giamberardino et al. (1995) \\
\hline \multirow[t]{8}{*}{$\begin{array}{l}\text { Neuropathic } \\
\text { pain }\end{array}$} & \multirow[t]{2}{*}{ Deafferentation } & Spared root paradigm & $\begin{array}{l}\text { Liu \& Chambers (1958); Loeser \& Ward (1967); Goldberger \& Murray } \\
\text { (1974); Basbaum \& Wall (1976); Wall et al. (1979); Pubols \& } \\
\text { Goldberger (1980); Brinkhus \& Zimmerman (1983) }\end{array}$ \\
\hline & & Nerve transaction & $\begin{array}{l}\text { Devor \& Wall (1981a, 1981b); Woolf \& Wall (1982); Hylden et al. } \\
\quad \text { (1987) }\end{array}$ \\
\hline & \multirow[t]{3}{*}{$\begin{array}{l}\text { Peripheral } \\
\text { neuropathic pain } \\
\text { (Kim et al., 1997) }\end{array}$} & Bennett model & Mosconi \& Kruger (1996); Bennett \& Xie (1988); Maves et al. (1993) \\
\hline & & Seltzer model & Seltzer et al. (1990) \\
\hline & & Chung model & $\begin{array}{l}\text { S. H. Kim \& Chung (1992); Palecek et al. (1992); Carlton et al. } \\
\text { (1994); Yoon et al. (1996); Ali et al. (1999) }\end{array}$ \\
\hline & Sciatic cryoneurolysis & Freezing of the sciatic nerve & $\begin{array}{l}\text { DeLeo et al. (1994); Imamura \& Bennett (1995); Willenbring et al. } \\
\text { (1995) }\end{array}$ \\
\hline & Sciatic demyelination & Topical application of lysolecithin & Wallace et al. (2003) \\
\hline & $\begin{array}{l}\text { Central neuropathic } \\
\text { pain (Boivie et al., } \\
\text { 1989; Leijon et al., } \\
\text { 1989. Boivie }\end{array}$ & Cordotomy & $\begin{array}{l}\text { White et al. (1950); Levitt \& Levitt (1981); Lenz et al. (1987, 1989); } \\
\text { Vierck et al. (1990); Ovelmen-Levitt et al. (1995); Vierck \& Light } \\
\text { (1999); Weng et al. (2000) }\end{array}$ \\
\hline
\end{tabular}

1989

1990; Willis, 2002)

Contusion

Spinal cord hemisection Injection of quisqualic acid Injection of kainate Ischemia

Sciatic
inflammatory neuritis

Injection of zymosan around the sciatic nerve

Placing proinflammatory gut suture Placing dead bacteria or carrageenan

Postherpetic neuralgia model
Schaible \& Schmidt (1985); Schaible \& Schmidt (1988a, 1988b); Neugebauer \& Schaible (1990); Schaible \& Grubb (1993)

Woolf \& King (1990); Koltzenburg et al. (1992); Koltzenburg \&

Ren, Hylden, et al. (1992); Ren \& Dubner (1993); Ren et al. (1994); al. (1990); Coderre \& Melzack (1992a, 1992b); Coderre et al. (1993);

Lariviere \& Melzack (2000)

Bodnar et al. (1983); Simone et al. (1989); LaMotte et al. (1991, 1992);

al. (2003); Skyba, et al. (2005)

adhakrishnan et al. (2003); Skyba et al. (2005)

Ness et al. (1991); Al-Chaer et al. (1996)

Alli et al. $(1988,1989)$

Giamberardino et al. (1995)

\& Chambers (1958); Loeser 1974); Basbaum \& Wall (1976); Wall et al. (1979); Pubols \& (1987)

S. H. Kim \& Chung (1992); Palecek et al. (1992); Carlton et al

(1994); Yoon et al. (1996); Ali et al. (1999)

Co Wallace et al. (2003)

Vierck et al. (1990); Ovelmen

Siddall et al. (1995); Basso et al. (1995); Hulsebosch et al. (2000)

Christensen et al. (1996); Christensen \& Hulsebosch (1997a, 1997b)

Yezierski \& Park (1993); Yezierski et al. (1993, 1998)

LaBuda et al. (2000)

Hao, Xu, Yu, et al. (1991); Hao, Xu, Aldskogius, et al. (1991); Hao, $\mathrm{Xu}, \mathrm{Yu}$, et al. (1992); Xu et al. (1992); Hao, Xu, Aldskogius, et al. (1992)

Gazda et al. (2001); Chacur et al. (2001)

Maves et al. (1993)

Eliav et al. (1999)

Sadzot-Delvaux et al. (1990, 1995); Fleetwood-Walker et al. (1999) 
Table 1 (continued)

\begin{tabular}{|c|c|c|c|}
\hline Category & Models & Procedures & References \\
\hline & Diabetic neuropathic & Injection of streptozocin & Wuarin-Bierman et al. (1987); Courteix et al. $(1993,1994)$ \\
\hline & & Insulin deficient BB rat NOD mice & Sima $(1980)$ \\
\hline & & & Mosseri et al. (2000); Pieper et al. (2000) \\
\hline & & $\begin{array}{l}\text { Insulin resistant } \mathrm{ob} / \mathrm{ob} \text { and } \mathrm{db} / \mathrm{db} \\
\text { mice }\end{array}$ & Meyerovitch et al. (1991); Takeshita \& Yamaguchi (1998) \\
\hline & & Mongolian gerbil & Vincent et al. (1979); Shafrir et al. (2001) \\
\hline \multirow[t]{6}{*}{ Cancer pain } & Chemotherapy- & Injection of vincristine & Aley et al. (1996); Nozaki-Taguchi et al. (2001); Tanner et al. (1998) \\
\hline & & Injection of taxol & $\begin{array}{l}\text { Apfel et al. (1991); Cavaletti et al. (1995); Cliffer et al. (1998); Boyle et } \\
\text { al. (1999); Authier et al. (2000); Dina et al. (2001); Polomano et al. } \\
\text { (2001) }\end{array}$ \\
\hline & & Injection of cisplatin & $\begin{array}{l}\text { de Koning et al. (1987a, 1987b); Verdu et al. (1999); ter Laak et al. } \\
\text { (2000) }\end{array}$ \\
\hline & $\begin{array}{l}\text { Cancer invasion pain } \\
\text { model }\end{array}$ & $\begin{array}{l}\text { Implantation of Meth A sarcoma } \\
\text { cells around the sciatic nerve in } \\
\text { BALB/c mice }\end{array}$ & Shimoyama et al. $(2002,2005)$ \\
\hline & $\begin{array}{l}\text { Bone cancer pain } \\
\text { model }\end{array}$ & $\begin{array}{l}\text { Injection of osteolytic mouse } \\
\text { sarcoma NCTC } 2472 \text { cells into the } \\
\text { femur bone marrow }\end{array}$ & $\begin{array}{l}\text { Schwei et al. (1999); Honore et al. (2000); Mantyh et al. (2002); Luger } \\
\text { et al. (2005) }\end{array}$ \\
\hline & & $\begin{array}{l}\text { Injection of MRMT-1 rat mammary } \\
\text { gland carcinoma cells into the tibia } \\
\text { bone marrow of Sprague-Dawley } \\
\text { rats }\end{array}$ & Medhurst et al. (2002); Walker et al. (2002) \\
\hline
\end{tabular}

roots; indirectly by immunoreactive and pronociceptive substances released from tumors; or by treatment (chemotherapy, radiation, or surgery). In order to model human cancer pain, several cancerrelated pain models have been developed, including the chemotherapy-induced peripheral neuropathy model by injection of vincristine, taxol, and cisplatin; the cancer invasion pain model by implantation of Meth A sarcoma cells around the sciatic nerve; and the bone cancer pain model by injection of osteolytic mouse sarcoma NCTC2472 cells into the femur bone marrow or by injection of MRMT-1 rat mammary gland carcinoma cells into the tibia bone marrow of rats.

With the establishment of these pain models, the biological mechanisms of pain can be further studied by application of various techniques. For example, following the L5 spinal nerve ligation, in combination with behavioral observation, electrophysiological techniques can be applied to study the peripheral single fiber response properties and change of excitability of central dorsal horn neurons; genetic expression of target proteins (such as different voltage sensitive sodium channels, opioid receptors, early response genes) can be evaluated during the acute phase and chronic phase of the neuropathic pain. In addition to anatomical, behavioral, psychophysical, and computational neural modeling tools, genetic, electrophysiological, and imaging techniques can be widely used in the investigation of these three models of pain. They are discussed next.

\section{Genetics}

With the rapid advances in molecular biology and genetics, the human genome was mapped out in 2001 (Jasny \& Kennedy, 2001). Biological functions of every system, organ, and each individual cell depend on genetic expression to produce peptides or proteins, which either contribute to the structure of the cell or participate in metabolism through various enzymes. Overexpression or elimination of a gene results in functional changes. The neuronal activities involved in pain transmission can be influenced by activities of immediate, early genes as well as transcriptional factors, all of which may result in changes in gene expression. With the understanding of the gene expression in response to noxious stimuli, genetic engineering can be applied in experimental or potential clinical conditions. Examples of this are "knock-out" mice or antisense oligonucleotides and viral transfection of neurons locally at various levels along the ascending or descending pathways of noxious signal transmission (Mogil, Yu, \& Basbaum, 2000).

A recent new technique, ribonucleic acid interference (RNAi), has been introduced in studying the effect of delta opioid receptor in the spinal cord and dorsal root ganglion (Luo et al., 2005). Double-stranded, short-interfering RNAs (siRNAs) of 21-22 nucleotides in length initiate a sequence-specific, post-trancriptional gene silencing in animals and plants known as RNAi. siRNA has been found to selectively silence the delta opioid receptor, but not mu opioid receptors. The antinocicetive effects of the corresponding agonists are dose-dependently and reversibly blocked (Luo et al., 2005). A brief summary of genetic manipulation is listed in Table 2.

In contrast to an increased sensitivity along the somatosensory system to nociceptive signal transmission, a rare opposite condition, congenital insensitivity to pain (usually associated with anhidrosis), has been reported in the literature (see Table 2). As opposed to increased pain sensitivity, it is characterized by recurrent episodic fevers, anhidrosis (inability to sweat), absence of reaction to noxious (or painful) stimuli, self-mutilating behavior and mental retardation. It is explained by several genetic mechanisms:

1. Developmentally, a combined defect in sensory and au- 
Table 2

Brief Summary of Genetic Modulation of Pain

\begin{tabular}{|c|c|c|c|}
\hline Category & Causes & Symptoms and Signs & References \\
\hline \multirow[t]{8}{*}{$\begin{array}{l}\text { Congenital insensitivity } \\
\text { to pain }\end{array}$} & \multirow{4}{*}{$\begin{array}{l}\text { A combined defect in sensory } \\
\text { and autonomic neurons } \\
\text { derived from the neural } \\
\text { crest }\end{array}$} & $\begin{array}{l}\text { A reduced evoked potential } \\
\text { Lack of pain experience following } \\
\text { electrical shock; }\end{array}$ & $\begin{array}{l}\text { Chatrian et al. (1975); Shorey \& Lobo (1990) } \\
\text { Manfredi et al. (1981) }\end{array}$ \\
\hline & & Self-mutilation and fractures & $\begin{array}{l}\text { Itoh et al. (1986); Chatrian et al. (1975); } \\
\text { Matsuo et al. (1981); Sweet (1981); } \\
\text { Derwin et al. (1994); Nolano et al. (2000); } \\
\text { Schulman et al. (2001) }\end{array}$ \\
\hline & & $\begin{array}{l}\text { Lack of flare response to histamine } \\
\text { injection }\end{array}$ & Manfredi et al. (1981); Nolano et al. (2000) \\
\hline & & Lack of temperature regulation & $\begin{array}{l}\text { Itoh et al., (1986); Matsuo et al. (1981); Vital } \\
\quad \text { et al. (1998); Sztriha et al. (2001) }\end{array}$ \\
\hline & $\begin{array}{l}\text { Overexpression of } \\
\text { endogenous opioids }\end{array}$ & & Dehen et al. $(1977,1978)$ \\
\hline & $\begin{array}{l}\text { Reduced number of primary } \\
\text { afferent nociceptors }\end{array}$ & & Larner et al. (1994) \\
\hline & $\begin{array}{l}\text { Loss of neurons in } \\
\text { sympathetic ganglia }\end{array}$ & & $\begin{array}{l}\text { Dyck et al. (1983); Derwin et al. (1994); } \\
\text { Shorer et al. (2001); Sztriha et al. (2001) }\end{array}$ \\
\hline & $\begin{array}{l}\text { Loss of trkA function } \\
\text { (receptor for nerve growth } \\
\text { factor) as the result of } \\
\text { mutations of the trkA } \\
\text { receptor gene }\end{array}$ & & $\begin{array}{l}\text { Indo et al. (1996); Mardy et al. (1999); } \\
\text { Yotsumoto et al. (1999); Shatzky et al. } \\
\text { (2000); Toscano et al. (2000); Greco et al. } \\
\text { (2000); Miura, Hiura, et al. (2000); Miura, } \\
\text { Mardy, et al. (2000); Indo (2001); Toscano } \\
\text { \& Andria (2001); Bodzioch et al. (2001); } \\
\text { Miranda et al. (2002); Barone et al. (2005) }\end{array}$ \\
\hline Rat strain differences & $\begin{array}{l}\text { Carrageenan to induce } \\
\text { inflammatory pain }\end{array}$ & $\begin{array}{l}\text { Inbred Lewis (LEW), Fischer } 344 \\
\text { (FIS), and outbred Sprague- } \\
\text { Dawley (SD) rat strains differ in } \\
\text { their pain sensitivity to } \\
\text { mechanical and thermal stimuli }\end{array}$ & Fecho et al. (2005) \\
\hline \multirow[t]{3}{*}{$\begin{array}{l}\text { Modulation at sensory } \\
\text { receptor }\end{array}$} & \multirow[t]{2}{*}{ Mechanoreceptor } & $\begin{array}{l}\text { BNC1 (a non-voltage-dependent } \\
\text { sodium channel) DRASIC }\end{array}$ & $\begin{array}{l}\text { M. P. Price et al. (1996); Drummond et al. } \\
\text { (2000); M. P. Price et al. (2000); } \\
\text { Drummond et al. (2001); Welsh et al. } \\
\text { (2002) }\end{array}$ \\
\hline & & DRASIC & M. P. Price et al. (2001) \\
\hline & TRPV1-deficient mice & $\begin{array}{l}\text { Essential for selective modalities of } \\
\text { pain sensation and for thermal } \\
\text { hyperalgesia }\end{array}$ & Numazaki \& Tominaga (2004) \\
\hline \multirow[t]{5}{*}{$\begin{array}{l}\text { Modulation at } \\
\text { membrane receptor }\end{array}$} & $\begin{array}{l}\text { Null mutants for nerve } \\
\text { growth factor }\end{array}$ & $\begin{array}{l}\text { Loss of primary afferent and } \\
\text { sympathetic neurons }\end{array}$ & Crowley et al. (1994) \\
\hline & \multirow[t]{2}{*}{$\begin{array}{l}\text { Deletion of neurokinin-1 } \\
\text { receptors }\end{array}$} & $\begin{array}{l}\text { Reduction in response to } \\
\text { intradermal injection of } \\
\text { capsaicin }\end{array}$ & Laird, Roza et al. (2001) \\
\hline & & $\begin{array}{l}\text { Reduction in response to second } \\
\text { phase of formalin test }\end{array}$ & De Felipe et al. (1998) \\
\hline & Deletion of the CGRP gene & $\begin{array}{l}\text { Fail to develop secondary heat } \\
\text { hyperalgesia by kaolin and } \\
\text { carrageenan }\end{array}$ & Zhang et al. (2001) \\
\hline & $\begin{array}{l}\text { Deletion of mu opioid } \\
\text { receptor gene }\end{array}$ & Oprm1 gene & $\begin{array}{l}\text { Matthes et al. (1996); Sora et al. (1997); } \\
\text { Lotsch \& Geisslinger (2005) }\end{array}$ \\
\hline \multirow[t]{3}{*}{$\begin{array}{l}\text { Genetic modulation at } \\
\text { intracellular } \\
\text { molecules }\end{array}$} & $\begin{array}{l}\text { Deletion of the R1 } 1 \beta \text { subunit } \\
\text { of protein kinase A (PKA) }\end{array}$ & $\begin{array}{l}\text { Reduction of allodynia by tissue } \\
\text { damage, a reduction of the } \\
\text { responses to the second phase of } \\
\text { formalin test, and central } \\
\text { sensitization caused by } \\
\text { intrathecal injection of PGE2 }\end{array}$ & Malmberg, Brandon, et al. (1997) \\
\hline & $\begin{array}{l}\text { Deletion of the gamma } \\
\text { isoform of protein kinase } \mathrm{C} \\
(\mathrm{PKCg})\end{array}$ & $\begin{array}{l}\text { Fail to develop neuropathic pain } \\
\text { after partial sciatic nerve injury, } \\
\text { but show normal responses to } \\
\text { acute noxious stimuli }\end{array}$ & Malmberg, Chen, et al. (1997) \\
\hline & $\begin{array}{l}\text { Mitogen-activated protein } \\
\text { kinase (MAPK) }\end{array}$ & Regulation of central sensitization & Ji \& Woolf (2001) \\
\hline $\begin{array}{l}\text { RNA interference } \\
\text { (RNAi) }\end{array}$ & $\begin{array}{l}\text { Short interfering RNAs } \\
\text { (siRNA) of } 21-22 \\
\text { nucleotide }\end{array}$ & $\begin{array}{l}\text { Selectively silence the delta opioid } \\
\text { receptor, but not mu opioid } \\
\text { receptors }\end{array}$ & Luo et al. (2005) \\
\hline
\end{tabular}


tonomic neurons derived from the neural crest. This has been supported by the following findings: (a) a reduced evoked potential and lack of pain experience following electrical shock, (b) self-mutilation and fractures, (c) lack of flare response to histamine injection, and (d) lack of temperature regulation.

2. Overexpression of endogenous opioids leads to suppression of nociceptive transmission either peripherally or centrally.

3. Reduced number of primary afferent nociceptors eliminates the ability to initiate a nociceptive signal in the periphery, whereas loss of neurons in sympathetic ganglia contributes to anhidrosis.

4. Loss of trkA function (receptor tyrosine kinase type A for nerve growth factor $[\mathrm{NGF}]$ ) results from mutations of the trkA receptor gene, which is located on chromosome 1 . It has also been demonstrated that the presence of a trkA mutation in B lymphocytes results in a lymphocyte signaling defect, which could contribute to recurrent episodes of fever.

Other genes involved in various sensory transmissions have been identified. Mechanoreceptor plays a role in transduction of mechanical force by opening ion channels that link to extracellular matrix and the cytoskeleton. Opening of these channels leads to excitation of mechanoreceptors. Subunits of these ion channels have been demonstrated in cutaneous mechanoreceptors, which are known as BNC1 (brain type Na channel), a nonvoltage-dependent sodium channel, and DRASIC (dorsal root acid sensitive ion channel), both belonging to the DEG/ENaC (epithelial $\mathrm{Na}+$ channel/nematode degenerins) family. In DRASIC-knock-out mice, the sensitivity to light touch is increased, but the sensitivity to noxious pinch is reduced.

NGF has been playing critical roles in developing and maintaining the survival of the nerves (especially sympathetic nerves) and contributing to increased nociception. A loss of primary afferent and sympathetic neurons has also been found in null mutants for NGF. These mice also show depletion of immunoreactivity for trkA receptors and calcitonin gene-related peptide (CGRP) and substance P (SP). Both CGRP and SP are important neuropeptides found in A-delta and $\mathrm{C}$ fibers, the ones responsible for transmission of nociceptive and thermal signals. Most of the animals die within a week. Those who survive show almost no response to noxious mechanical and thermal stimuli. On the other hand, there is an increased sympathetic innervation of dorsal root ganglion cells in mice with an overexpressed NGF. They show exaggerated responses to noxious mechanical and thermal stimuli. In addition, deletion of neurokinin-1 receptors (receptors for SP) in mice shows normal response to brief noxious mechanical stimuli, but a reduction in response to intradermal injection of capsaicin and the second phase of a formalin test. Mice with deletion of the CGRP gene have normal responses to noxious stimuli but fail to develop secondary heat hyperalgesia by kaolin and carrageenan. When carrageenan is used to induce inflammatory pain, inbred and outbred rat strains differ in their pain sensitivity, as tested by mechanical stimulation (the von Frey monofilament test) and noxious heat pain (the Hargreaves radiant heat test), also suggesting a genetic basis for differential sensitivity to pain.

A specific block of the morphine effect in mice with deletion of the mu-opioid receptor gene has also been found. Recent studies with inbred and knockout mice have revealed that the mu-opioid peptide receptor encoded by the Oprm1 gene has a crucial role in the analgesic and addictive properties of opiate drugs. Differences in Oprm1 gene sequences affect the amount of Oprm1 messenger RNA and sensitivity to opiates, and more than 100 polymorphisms have been identified in the human OPRM1 gene, some of which are related to vulnerability to drug dependence in some populations.

Genetic modulation of intracellular signal transduction molecules has played a significant role in pain transmission. Deletion of the $\mathrm{R} 1 \beta$ subunit of protein kinase $\mathrm{A}$ in mice shows a reduction of allodynia by tissue damage, a reduction of the responses to the second phase of formalin test, and central sensitization caused by intrathecal injection of PGE2. In contrast, mice with deletion of the gamma isoform of protein kinase $\mathrm{C}$ show normal responses to acute noxious stimuli but fail to develop neuropathic pain after partial sciatic nerve injury. Tissue injury-induced inflammatory and nerve injury-induced neuropathic pain (expressed as neuronal plasticity) is generated by injury and intense noxious stimuli to trigger an increased excitability of nociceptive neurons in the spinal cord. This central sensitization is an activity-dependent functional plasticity that results from activation of different intracellular kinase cascades, leading to the phosphorylation of key membrane receptors and channels and increasing synaptic efficacy. Several different intracellular signal transduction cascades converge on mitogen-activated protein kinase (MAPK). The activation of MAPK appears to be a master switch or gate for the regulation of central sensitization. In addition to posttranslational regulation, the MAPK pathway may also regulate long-term pain hypersensitivity via transcriptional regulation of key gene products. Furthermore, activated microglia is a key cellular intermediate step in the pathogenesis of nerve injury-induced pain hypersensitivity. This is supported by the observation that p38 MAPK, together with $\mathrm{P}_{2} \mathrm{X}_{4}$ purinoceptors, are present in activated microglia and are required molecular mediators.

Similar to other neural transmission, transmission of pain signals requires a variety of molecules, including neurotransmitters, neuromodulators, neurotransmitter receptors, signal transduction molecules, and enzymes involved in protein synthesis. To ensure a normal synaptic transmission, it is crucial to have a normal process of protein synthesis (transcription and translation from the genetic code), neurotransmitter transportation, storage, release, receptor binding, and breakdown or reuptake. To accomplish these complicated processes, various proteins or peptides are playing either vital or supporting roles. Any malfunction of each individual step will cause either elevated or reduced transmission of pain signals. Some important molecules for pain processing include substances that act on (a) neurotransmitters and neuromodulators (e.g., bradykinin, capsaicin, CGRP, glutamate, histamine, serotonin, norepinephrine, neuropeptide $\mathrm{Y}$, prostaglanding $\mathrm{E}_{2}$, and $\mathrm{SP}$ ); (b) membrane receptors $(\mathrm{mu}$ and delta opiate receptors, purinergic receptor $\mathrm{P} 2 \mathrm{X} 3$, tyrosine kinase receptor $\mathrm{A}$, and vanilloid receptor 1); (c) ion channels (e.g., $\mathrm{Na}^{+}, \mathrm{K}^{+}$, and $\mathrm{Ca}^{++}$channels, tetrodotoxin-resistance $\mathrm{Na}^{+}$channels); (d) intracellular signal transduction molecules (e.g., R1 $\beta$ subunit of protein kinase A and 
gamma isoform of protein kinase C); and (e) enzymes (e.g., fluoride-resistant acid phosphatase).

In summary, with all this aforementioned evidence of how gene expression can modulate the sensitivity of pain, with individual variation, a new direction for screening individual patients for genetic susceptibility will provide a potential targeted treatment of pain in the future. Indeed, three genetic haplotypes of the gene encoding catecholamine- $O$-methyltransferase is significantly associated with variation in sensitivity to experimental pain and is also correlated to the risk of developing temporomandibular joint disorder (Diatchenko et al., 2005). The serotonin transporter gene is also a promising candidate locus for the genetic susceptibility of migraine (Szilagyi et al., 2006). Eventually it may become possible to "turn on" or "turn off" a single gene or batch of gene expression to relieve patient suffering from various types of pain.

\section{Electrophysiology}

Since the perception of pain is mainly dependent on the neuronal activities along the axis of the somatosensory system through signal reception, transduction, action potential generation, and action potential propagation, it makes electrophysiological recording the most direct measurement to study pain nociceptive processing. It provides the most accurate temporal responses of the nervous system in response to external stimuli (mechanical, thermal, chemical, and electrical). In general, there are five electrophysiological approaches to study the peripheral and central neuronal activities involved in pain processing at various levels: (1) extracellular recording in vivo from axon tracts, individual axons, or cell body of neurons; (2) intracellular recording in vivo; (3) intracellular recording from neurons in intact ganglia or tissue slices in vitro; (4) intracellular recording from dissociated neurons in vitro; and (5) patch clamp recording in vitro and in vivo. A simple illustration is presented in Figure 4.

Extracellular recording in vivo. Extracellular recording in vivo has been widely used in the primary afferent neurons, spinal cord dorsal horn neurons, brainstem, thalamus, and the cortex. The advantages of extracellular recording include (a) a complete characterization of receptive fields, response properties, and conduction velocity by primary afferent recording in vivo; (b) minimizing the amount of tissue injury to gain the access to the afferents; (c) the ability to study changes in peripheral terminals of sensory neurons; and (d) the ability to activate brain regions to study the central descending modulation of the primary afferent inputs.

Population responses can be recorded by cord dorsum potential and intraspinal field potentials extracellularly, which are the distributions of activity that are evoked in large populations of spinal cord neurons by stimulation of primary afferent fibers. The potentials reflect, in large part, the depolarization of interneurons or of primary afferent fibers in the dorsal horn. The cord dorsum potentials can be recorded from the dorsal surface of the spinal cord in response to electrical stimulation of myelinated cutaneous afferent fibers in a peripheral nerve, which include an afferent volley, one or more negative $(\mathrm{N})$ waves, and a positive wave (Beall, Applebaum, Foreman, \& Willis, 1977; Gasser \& Graham, 1933; Hughes \& Gasser, 1934a, 1934b; Lindblom \& Ottosson, 1953a, 1953b; Willis, Weir, Skinner, \& Bryan, 1973). The negative potentials can be subsequently named N1 (evoked by A $\alpha \beta$ fibers), N2 (evoked by $A \alpha \beta$ and A $\delta$ fibers), and N3 (evoked by
A $\delta$ fibers). The maximal response of these negative potentials can be recorded within the spinal cord (Beall et al., 1977). The negative potential recorded in the extracellular space is due to the moving of positively charged ions into dorsal horn neurons that occurs during excitatory postsynaptic potentials and action potentials. The positive wave that follows the $\mathrm{N}$ waves, evoked by stimulation of cutaneous nerve, reflects a long-lasting depolarization of primary afferent fibers. This part of the cord dorsum potential corresponds to the negative dorsal root potential, which can be recorded from a disconnected filament of dorsal root (Barron \& Matthews, 1938; Eccles \& Krnjevic, 1959; Eccles, Magni, \& Willis, 1963; Eccles, Schmidt, \& Willis, 1963; Lloyd, 1952; Lloyd \& McIntyre, 1949). Primary afferent fibers are considered to be one of the mechanisms responsible for the inhibitory process known as presynaptic inhibition (Eccles, 1964; Rudomin \& Schmidt, 1999; R. F. Schmidt, 1971; Willis, 1999).

In the spinal cord, ascending tract neurons or motor neurons can be distinguished from interneurons by antidromic activation following stimulation of their axons near projection targets in the brain or of motor axons in a ventral root or peripheral nerve. Criteria for antidromic activation include (a) the action potential follows the stimulus at a constant latency, (b) collision between orthodromic and antidromic action potentials, and (c) the antidromic action potential can follow high frequencies of stimulation (Trevino, Coulter, \& Willis, 1973).

Some of the most important discoveries about the nature of pain and nociception were determined with extracellular recordings. The finding of the superficial laminae of the spinal cord for nociception demonstrated that these neurons responded to mechanical and thermal nociceptive inputs in lamina I (B. N. Christensen $\&$ Perl, 1970) and II (Kumazawa \& Perl, 1978). Another important finding was that the plasticity of neuronal responses is located deeper in the dorsal horn. An enhanced response ("windup") was demonstrated when peripheral nerves were stimulated at C-fiber intensities (Mendell \& Wall, 1965; Woolf, 1996). Clinically, windup has been reported in fibromyalgia patients compared to normal controls, suggesting that central sensitization contributes to processes underlying hyperalgesia and persistant pain states (Price et al., 2002; Staud, Price, Robinson, Mauderli, \& Vierck, 2004).

One type of extracellular recordings is the compound action potential recording from nerves and fiber tracts, which is a record of the various peaks related to the conduction velocity of various axon population in the peripheral nerve (Clark, Hughes, \& Gasser, 1935; Gasser, 1941). Recording of compound action potentials in humans is crucial to determine the impulse conduction in the slowest fibers, which is correlated to the sensation of pain (Collins, Nulsen, \& Randt, 1960; Heinbecker, Bishop, \& O'Leary, 1933). Field potential in the CNS tracts is also a valuable approach in determining the rostrocaudal distribution of nociceptive primary afferent axons and their terminal arborizations (Traub \& Mendell, 1988; Traub, Sedivec, \& Mendell, 1986).

Microneurography (Hagbarth \& Vallbo, 1967) in humans is another extracellular recording technique, which led to many human studies that clearly defined the involvement of unmyelinated C-fibers in pain sensation and some pathological conditions (Hagbarth, 1979; Hallin \& Wu, 1998; Ochoa \& Torebjörk, 1980; Ochoa, Torebjörk, Culp, \& Schady, 1982; Torebjörk \& Hallin, 1970; Torebjörk, Ochoa, \& McCann, 1979; Vallbo, Hagbarth, Torebjörk, \& Wallin, 1979; Van Hees \& Gybels, 1972). The 


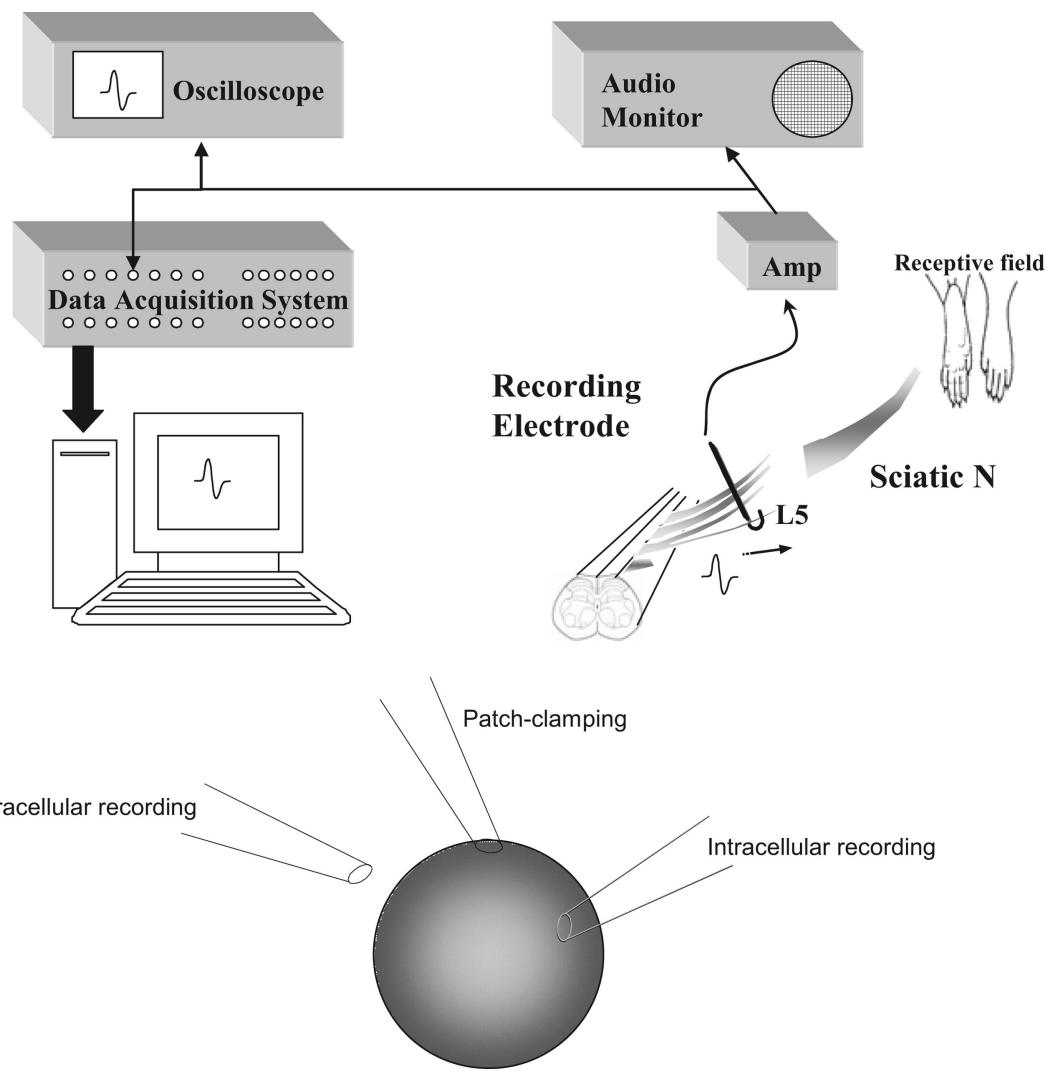

Figure 4. An illustration of an electrophysiological setup for extracellular, intracellular, and patch-clamp recording in either in vivo or in vitro preparations.

advantage of microneurography is that recorded axons can be stimulated relatively selectively following isolation of a single unit (Simone, Marchettini, Caputi, \& Ochoa, 1994; Torebjörk, Vallbo, \& Ochoa, 1987), while allowing the human subject to describe accurately the quality and intensity of pain (Marchettini, Simone, Caputi, \& Ochoa, 1996; Ochoa \& Torebjörk, 1989; Torebjörk et al., 1987) as well as of an itch (Schmelz et al., 2003; Schmelz, Schmidt, Bickel, Handwerker, \& Torebjörk, 1997).

Single unit recording from axon fibers of the peripheral nerve has also been tested on their own peripheral nerves by some neuroscientists (Hensel \& Boman, 1960) and later were mostly used in animals studies (LaMotte \& Campbell, 1978). It is a relatively simple technique, but it is crucial for determining the spontaneous discharge in sensory fibers after peripheral nerve injury, especially when ectopic spikes are generated from the ganglion (Kajander, Wakisaka, \& Bennett, 1992; Xie, Zhang, Petersen, \& LaMotte, 1995).

Intracellular recording. Intracellular recording can directly measure the membrane potential change, and one can inject a dye into the recording neuron for labeling purposes. Technically, it is more difficult than extracellular recording and may not be accessible to small diameter fibers. In addition, it may cause damage of the neuron because of the nature of the technique (puncture of the cell membrane by a sharp electrode). By directly monitoring the membrane potential, intracellular recording in vivo contributes important information of the classification of sensory neurons in response to peripheral receptive properties (Djouhri, Bleazard, \& Lawson, 1998; Giesler, Gerhart, Yezierski, Wilcox, \& Willis, 1981; Koerber, Druzinsky, \& Mendell, 1988; Lawson, Crepps, \& Perl, 1997; Ritter \& Mendell, 1992; Willis, Trevino, Coulter, \& Maunz, 1974), such as inflammation or nerve injury (Czeh, Kudo, \& Kuno, 1977; Djouhri \& Lawson, 1999). Intracellular recording of substantia gelatinosa neurons has demonstrated direct modulation of their activity through stimulation of brainstem structures (NRM and PAG; Bennett, Hayashi, Abdelmoumene, \& Dubner, 1979; Light, Casale, \& Menetrey, 1986; Steedman, Molony, \& Iggo, 1985).

When neurons in a part of the nervous system are isolated and set in a recording chamber, intracellular recording from a tissue slice in vitro has several advantages over in vivo. It has the following properties: better control of the extracellular milieu (e.g., absence of blood-brain barrier), some degree of electrical control of the soma membrane, possible identification of primary afferents and their receptive field properties, a possible observation of injury-induced increase in excitability, and a condition without enzymatic or mechanical treatment prior to recording. However, intracellular recording in vitro also suffers from several disadvantages. For example, it may not be able to determine the change in response properties due to a direct change in the neuron or an indirect change caused by surrounding cells. In an isolated environment, there is an absence or a low level of the proteins necessary for the transduction of stimuli. 
Intracellular recording from dissociated neurons in vitro has several advantages as compared with slice preparation. It allows for complete control of the extracellular milieu, as well as the intracellular milieu, when used with patch-clamp techniques. Redistribution of proteins to the plasma membrane that are normally presenting afferent terminals has been observed. For example, a proton receptor/ion channel complex that is usually present in terminals has been demonstrated in the isolated cell body (Bevan \& Yeats, 1991; Steen, Issberner, \& Reeh, 1995). However, this approach suffers from several disadvantages. It is impossible to identify the primary afferents with respect to conduction velocity or receptive field properties. There is a potential for damage of the membrane properties due to enzymatic treatment. There is also the potential for alteration of neuron properties because of a lack of unknown important factors. The results cannot be applied directly to the conditions in the behaving animals because of lack of supporting cells and other neurons.

Patch-clamp recording in vitro. First described by Neher and Sakmann (1976), patch-clamp recording in vitro is now a powerful method for studying electrophysiological properties and chemosensitivity of neurons involved in the transduction and transmission of nociceptive stimuli. It is widely used to study the primary afferent terminals (Brock, McLachlan, \& Belmonte, 1998; Reid, Scholz, Bostock, \& Vogel, 1999; Scholz, Reid, Vogel, \& Bostock, 1993), soma of the sensory ganglion (Huang \& Neher, 1996; L. Liu \& Simon, 1996; L. Liu, Wang, \& Simon, 1996; Todorovic \& Anderson, 1990), dissociated central neurons (Reichling, Kyrozis, Wang, \& MacDermott, 1994; Rusin, Jiang, Cerne, \& Randic, 1993), slice preparations (Baba et al., 1998; Bao, Li, \& Perl, 1998; Pan, 1998; Pan \& Fields, 1996; Pan, Tershner, \& Fields, 1997; Schneider, Eckert, \& Light, 1998; Yoshimura \& Nishi, 1993), and in vivo (Light \& Willcockson, 1999). Even though cell-attached recording of an afferent terminal of corneal afferents was reported (Brock et al., 1998), this approach has been used to record ion channel activity from C-fiber axons, as well as the afferent cell body (Reid et al., 1999; Scholz et al., 1993). One of the advantages of this technique is that it can generate the most detailed information of the biophysical properties of the ion channel. It is also possible to record from specific sites on a neuron to obtain information of the relative distribution of ion channels. However, the disadvantage is that it is the most technically difficult and labor intensive electrophysiological approach.

A relative easier target is the cell body of the primary afferent neuron. It has been suggested that the cell body of acutely isolated sensory neurons in vitro is a valid model for the afferent terminal in vivo. Receptors and ion channels in the peripheral or central terminals of sensory neurons are present and are functional in the plasma membrane of the cell body in vitro (Huang \& Neher, 1996; L. Liu \& Simon, 1996; L. Liu et al., 1996; Todorovic \& Anderson, 1990). Pharmacologically, these receptors on the cell body show properties similar to those near the peripheral and central terminals (Carlton \& Coggeshall, 1997; Carlton, Zhou, \& Coggeshall, 1999; X. Chen, Belmonte, \& Rang, 1997; X. Chen, Gallar, \& Belmonte, 1997; Coggeshall \& Carlton, 1998; H. Liu, Wang, Sheng, Jan, \& Basbaum, 1994). It is also possible to induce a similar change in the excitability of the cell body in vitro with the same manipulations that induce changes in the peripheral terminals in vivo. For example, PGE2 can induce sensitization of the cell body in vitro (Baccaglini \& Hogan, 1983; Fowler, Wonderlin, \& Weinreich,
1985; Gold, Dastmalchi, \& Levine, 1996; Nicol \& Cui, 1994; Vasko, Campbell, \& Waite, 1994; Weinreich \& Wonderlin, 1987). Furthermore, the sensory neuron cell body in vitro can be induced to release neurotransmitters $(\mathrm{Gu}$, Albuquerque, Lee, \& MacDermott, 1996; Gu \& MacDermott, 1997; Lee, Engelman, \& MacDermott, 1999; MacDermott, Role, \& Siegelbaum, 1999), which is a $\mathrm{Ca}^{2+}$-dependent process (Huang \& Neher, 1996).

Patch-clamp recording in vivo. Following the successful application of patch-clamp recording in vivo in other systems (Covey, Kauer, \& Casseday, 1996; C. I. Moore \& Nelson, 1998), use of whole-cell recording techniques in the nociceptive systems of the spinal cord of the rat in vivo was reported (Furue, Narikawa, Kumamoto, \& Yoshimura, 1999; Graham, Brichta, \& Callister, 2004; Light \& Willcockson, 1999; Weng \& Dougherty, 2002; Yoshimura, Doi, Mizuno, Furue, \& Katafuchi, 2005). The obvious advantages of this technique include better control over the electrical properties of the neuron, a more robust technique than sharp electrode intracellular recording, the ability to observe single channel activity in the native milieu, and easier control of both intracellular and extracellular medium for drug application. However, this technique suffers from difficulties in stabilization of animals and obtaining adequate seals due to movement and covering glial cells. It is not the best choice for obtaining large samples in a study.

\section{Imaging}

A variety of imaging techniques have been developed and used to study pain and nociception. Functional imaging techniques have played a crucial role because of the advantage of correlating the brain activity with human perception.

Positron emission tomography (PET). Since its development in the 1970s, PET has been used for imaging human brain function. A PET image is created by the detection of positrons emitted from an intravenously injected radionuclide (i.e., the tracer). Through blood circulation, the tracer is distributed to the brain. As the tracer decays, it emits a positron which travels a few millimeters, collides with an electron, and releases two photons (gamma rays) in opposite directions. A series of PET detectors over the head detects the signals, which are used to create a tomographic image. PET images can be overlapped with a subject's own fMRI to fit onto a standardized atlas to be visualized. Depending on the half-life, different radionuclides can be used for different purposes. For example, ${ }^{15} \mathrm{O}$ is used to measure cerebral blood flow in activation studies because of its half-life $(2 \mathrm{~min}) ;{ }^{18} \mathrm{~F}$ with a half-life of $110 \mathrm{~min}$ can be used to measure cerebral glucose metabolism; ${ }^{11} \mathrm{C}$ with a half-life of $20 \mathrm{~min}$ can be used to study receptor binding of dopamine, benzodiazepine, and opiates (Kegeles \& Mann, 1997; Phelps \& Mazziotta, 1985; Slifstein \& Laruelle, 2001; Tai \& Piccini, 2004). PET can be used in three major ways. The receptor density and binding properties of ligands in the brain can be identified by injecting a radioactive receptor antagonist or agonist (Sadzot et al., 1991). It can also be used to measure regional cerebral blood flow ( $\mathrm{rCBF}$ ) in the resting state to detect neurological abnormalities in disease or injury (Hsieh, Belfrage, Stone-Elander, Hansson, \& Ingvar, 1995; Iadarola et al., 1995; Peyron et al., 1998). Finally, in activation studies, $\left[{ }^{15} \mathrm{O}\right] \mathrm{H}_{2} \mathrm{O}$ is injected to identify task-related changes in blood flow. The advantages of PET include a relatively open, noise-free environment that 
can accommodate most experimental or internal devices. The disadvantages include that it is relatively expensive, injection of radioactive tracer is invasive, the time frame is relatively restricted because of the half-life of the tracer, and it has a moderate to poor spatial resolution and poor temporal resolution.

The PET scan was first applied to study acute pain (Talbot et al., 1991), which identified four cortical regions of activation by noxious heat stimuli: primary and secondary somatosensory cortex, anterior insula, and anterior cingulated cortex (ACC). Subsequent studies have confirmed and extended cortical areas in thermal, mechanical, and laser-evoked pain, such as prefrontal cortex, supplemental motor cortex, basal ganglia, cerebellum, and the hypothalamus and periaqueductal gray (Aziz, 1997; Casey, 1999; Casey et al., 1994; Casey, Minoshima, Morrow, \& Koeppe, 1996; Coghill et al., 1994; Derbyshire et al., 1997; Hsieh et al., 1996; Jones, Brown, Friston, Qi, \& Frackowiak, 1991; Svensson, Minoshima, Beydoun, Morrow, \& Casey, 1997; Xu et al., 1997). An example is provided in Figure 5. The widespread cortical activations identified in pain studies have been implicated in affective, cognitive, and reflexive responses to a painful stimulus, which demonstrate that there is a distributed network of many brain areas that are recruited by a painful stimulus that contribute to the multidimensional experience (Coghill et al., 1994; Coghill, Sang, Maisog, \& Iadarola, 1999). In a study that used hypnosis to manipulate pain unpleasantness independent of pain intensity, a relationship between unpleasantness and ACC activation was identified (P. Rainville, Duncan, Price, Carrier, \& Bushnell, 1997). The ACC was uniquely activated both in real pain and during an illusion of pain evoked by simultaneous warm and cool stimuli (Craig, Reiman, Evans, \& Bushnell, 1996). PET scans obtained during motor cortex stimulation for chronic pain revealed activation of the thalamus, ACC, anterior insula, and frontal cortex (Garcia-Larrea et al., 1999; Peyron et al., 1995). Thalamic stimulation also activates the ACC (Davis et al., 2000) and the anterior insula, which is accompanied by thermal sensations (Duncan et al., 1998).

Single-photon emission computerized tomography (SPECT). Similar to PET, the SPECT scanner has a gamma camera that detects emissions from decaying isotopes, which have long halflives (often in the order of hours). Cerebral blood flow can be measured with the inhalation of Xenon-133 or technetium $99 \mathrm{mTc}$ HM-PAO (99m-hexamethylpropyleneamineoxime; Canavero et al., 1993; Di Piero, Pantano, Ricci, \& Lenzi, 1993). The long retention of SPECT tracers allows for flexibility in the timing of data acquisition, after injection, of the overall effect of an injury, disease, stimulus, treatment, or other manipulation (Prichard \& Brass, 1992). However, the SPECT scanner is more expensive and suffers from poor spatial and temporal resolution.

Through use of SPECT, different types of pain have been examined. A decrease in cortical $\mathrm{rCBF}$ in the SI region associated

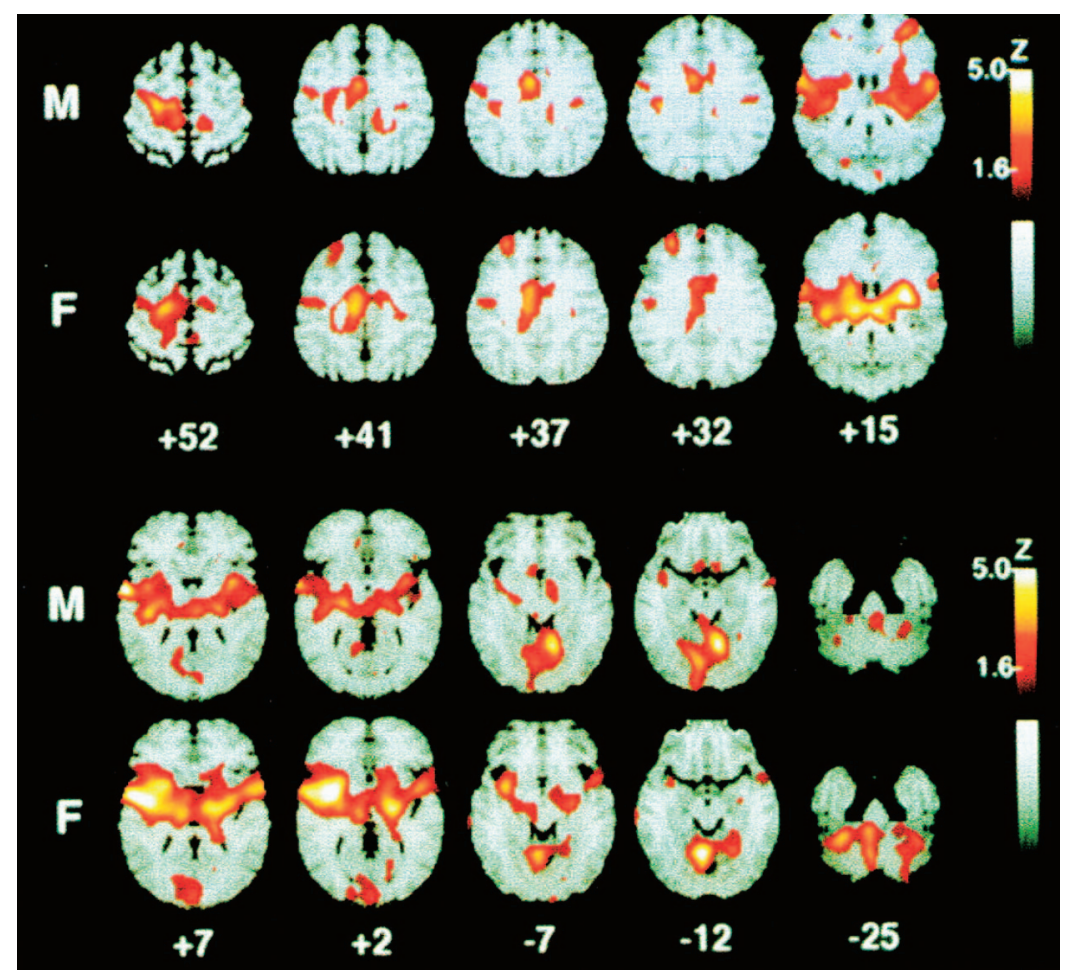

Figure 5. A positron emission tomography scan image of rCBF responses of 10 males $(\mathrm{M})$ and 10 females $(\mathrm{F})$ to repetitive noxious heat stimulation $\left(50^{\circ} \mathrm{C}\right)$ of the left volar forearm. Significant activation of the contralateral anterior cingulate cortex, premotor, insular cortex, ipsilateral insula, and bilateral cerebellar vermis has been identified. From "Gender Differences in Pain Perception and Patterns of Cerebral Activation During Noxious Heat Stimulation in Humans," by P. E. Paulson, S. Minoshima, T. J. Morrow, and K. L. Casey, Pain, 76, 1998, p. 227. Copyright 1998 by the International Association for the Study of Pain. Reprinted with permission. 
with a long ( $3 \mathrm{~min}$ ) sustained contralateral heat pain stimulus was found (Apkarian et al., 1992), whereas an increased rCBF in SI contralateral to a tonic cold-pain stimulus was also reported in a cold pressor test (Di Piero et al., 1994) and among cluster headache patients (Di Piero, Fiacco, Tombari, \& Pantano, 1997). In a chronic pain state, such as painful restless legs syndrome and spinal cord injury, there is an increase in blood flow in the contralateral SI, ACC, and thalamus (see Figure 6; Ness et al., 1998; San Pedro et al., 1998). However, hypoperfusion was also found in the caudate of a patient with spinal cord injury pain (Ness et al., 1998), in the frontoparietal region (Ogawa, Lee, Nayak, \& Glynn, 1990), and in the thalamus of patients with central pain (Pagni \& Canavero, 1995; Tanaka et al., 1997).

Functional magnetic resonance imaging (fMRI). fMRI is now widely used in the medical field to obtain normal or pathological anatomical changes. It was first used to study brain function by intravenous injection of gadolinium as a contrast agent to enhance the magnetic resonance signals in the visual cortex evoked by flashing light (Belliveau et al., 1991). It was soon realized that visualization of these signals did not require injection of a contrast agent because the body has its own natural contrast agent, deoxygenated hemoglobin (Ogawa et al., 1992; Ogawa, Lee, Kay, \& Tank, 1990; Ogawa, Lee, Nayak, \& Glynn, 1990). Most fMRIs now rely on the blood oxygenation level dependent effect, which is based on the increased neuronal firing in response to a stimulus that will induce hemodynamic changes and ultimately modify the magnetic field to increase the fMRI signals (Porro, Lui, Facchin, Maieron, \& Baraldi, 2004). It is thought that an increased metabolic demand, due to increased neuronal activity, results in an increase in blood flow beyond metabolic needs, such that the final ration of deoxyHb/oxyHb actually is reduced. It is the reduction in deoxyHb that alters the magnetic field properties and produces the increased fMRI signal (DeYoe, Bandettini, Neitz, Miller, \& Winans, 1994). The advantages of fMRI include its noninvasiveness, good spatial (down to 1-2 $\mathrm{mm}$ ), and temporal (hundreds of

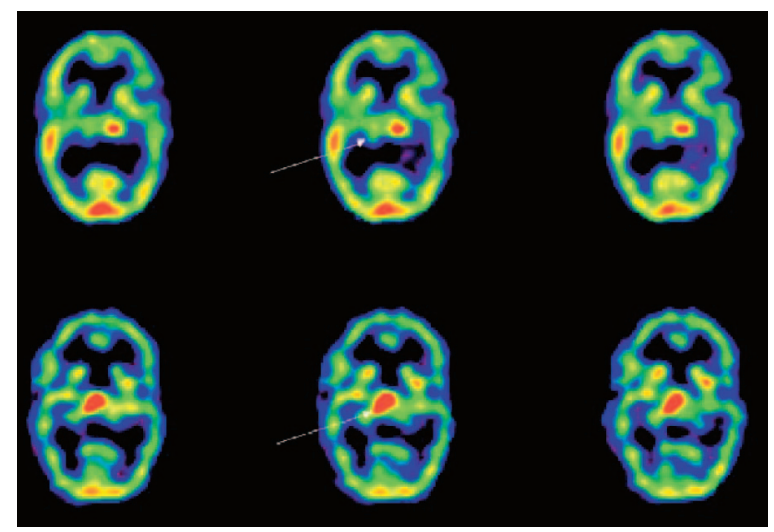

Figure 6. A single-photon emission computerized tomography image showing baseline scan (top row) and postacupuncture scan (bottom row) of the thalamic activity. From "Cerebral Blood Flow Effects of Pain and Acupuncture: A Preliminary Single-Photon Emission Computed Tomography Imaging Study," by A. B. Newberg, P. J. LaRiccia, B. Y. Lee, J. T. Farrar, L. Lee, A. Alavi, 2005, Journal of Neuroimaging, 15, p. 45. Copyright 2005 by the American Society of Neuroimaging. Reprinted with permission. $\mathrm{ms}$ is possible) resolution. The disadvantages include its expense, limited availability due to time-sharing on a clinical scanner, restriction to metallic devices, and loud noise.

A large body of literature, nevertheless, has been conducted investigating brain mechanisms underlying both chronic and acute pain (see one example in Figure 7). fMRI has been used to study stimulus-related responses, such as noxious electrical stimulation of the skin or peripheral nerve (Davis, Taylor, Crawley, Wood, \& Mikulis, 1997; Davis, Wood, Crawley, \& Mikulis, 1995; Oshiro et al., 1998); noxious heat or cold (Apkarian, Darbar, Krauss, Gelnar, \& Szeverenyi, 1999; Becerra et al., 1999; Davis, Kwan, Crawley, \& Mikulis, 1998; Gelnar, Krauss, Sheehe, Szeverenyi, \& Apkarian, 1999; Ploghaus et al., 1999; Raij, Forss, Stancak, \& Hari, 2005); and mechanical (Disbrow, Buonocore, Antognini, Carstens, \& Rowley, 1998), chemical (Maihöfner \& Handwerker, 2005; Porro, Cettolo, Francescato, \& Baraldi, 1998), or visceral stimuli (Binkofski et al., 1998). Brain areas that can be activated include the primary somatosensory cortex (SI), secondary somatosensory cortex (SII), anterior insula, ACC, thalamus, and cerebellum. With the combination of psychophysical assessment and fMRI, painrelated activations have been obtained in parallel psychophysical sessions (Apkarian et al., 1999) or during the imaging sessions (Davis et al., 1997; Porro et al., 1998; Raij et al., 2005) in order to separate those activations that are due to the mere presence of a stimulus (i.e., due to attention) from those that are related to the subjects' actual sensory experiences. On the other hand, the relationship and interaction of pain, attention, and anticipation has been demonstrated to activate slightly different areas of the brain (Davis et al., 1997; Ploghaus et al., 1999). For example, anticipation of pain activated the anterior ACC, whereas the pain itself activated the posterior ACC. Further dissection on this line demonstrated that the posterior insula/secondary somatosensory cortex, the sensorimotor cortex, and the caudal ACC were specific to receiving pain, whereas the anterior insula and rostral ACC activation correlated with individual empathy scores when the subjects watched their loved ones receiving pain stimuli (Singer et al., 2004). The underlying modulatory effect of expectation on pain transmission might involve activation of descending modulatory systems (Keltner et al., 2006).

Recently, a caution has been raised about fMRI (Nair, 2005; Savoy, 2005), especially when it is used in dissecting the cognitive and emotional mechanisms, because cognitive function is a moving target. It is difficult to design a good fMRI study and to analyze and interpret the data. The notion of whether fMRI is a modern phrenology is under debate (D. I. Donaldson, 2004; Terrazas \& McNaughton, 2000; Uttal, 2001). Regardless, fMRI has been used to image allodynia in complex regional pain syndrome (Maihöfner, Handwerker, \& Birklein, 2006) and patients suffering from neuropathic pain (Schweinhardt et al., 2006).

Magnetoencephalography (MEG). MEG is a technique that detects weak magnetic fields within the human brain. MEG is the most sensitive for cortical neuronal activity because electrical currents generated by neurons induce a perpendicularly oriented magnetic field, which can be detected directly outside the head by MEG detectors (Hari \& Forss, 1999; Naatanen, Ilmoniemi, \& Alho, 1994). The major advantage of MEG is that it is noninvasive and has excellent temporal resolution (down to milliseconds) to directly measure neuronal activity. It can also be superimposed onto a high-resolution fMRI to provide good spatial localization. 


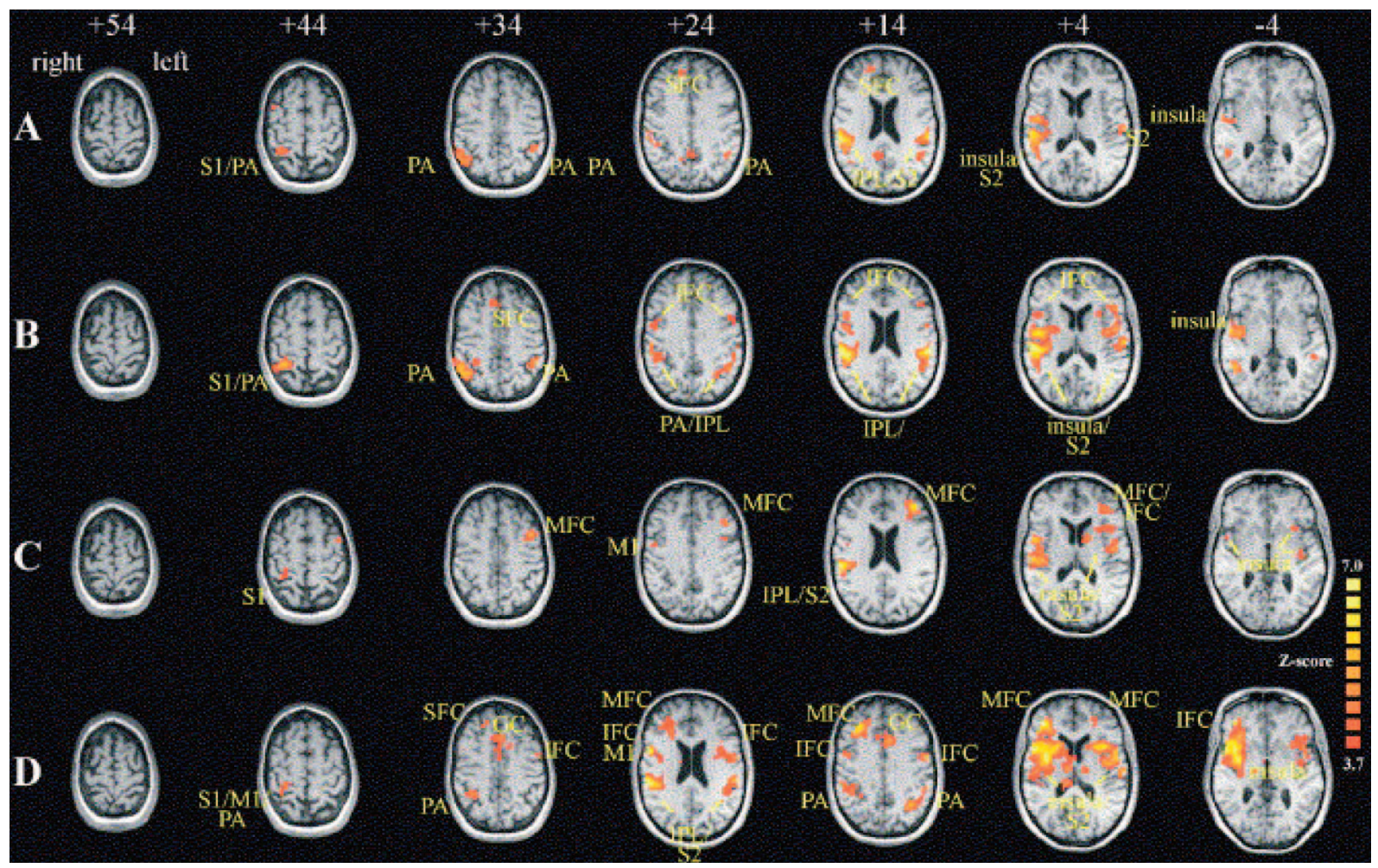

Figure 7. An image from functional magnetic resonance imaging showing key areas of activations in primary somatosensory cortex (S1), primary motor cortex (M1), secondary somatosensory cortex (S2), parietal association cortex (PA), inferior parietal lobule (IPL), superior frontal cortex (SFC), middle frontal cortex (MFC), inferior frontal cortex (IFC), and cingulate cortex (GC) when pin-prick (A, B) or thermal (C, D) stimuli were applied before (A, C) or after (B, D) capsaicin injection. From "Differential Coding of Hyperalgesia in the Human Brain: A Functional MRI Study,” by C. Maihöfner and H. O. Handwerker, 2005, NeuroImage, p. 1000. Copyright 2005 by Elsevier. Reprinted with permission.

The current major disadvantage is the high cost of the device and the necessity for a magnetically shielded space.

In Figure 8, a sample MEG image indicates activation of the primary motor cortex while stimulation is applied at A-delta and C-fiber intensities (Raij et al., 2005). Use of MEG in the study of pain demonstrated responses to electrical stimulation of the digit at short latencies in the contralateral SI (at 40-60 ms), followed by longer latencies in the ipsilateral and bilateral SII and insula (100-250 ms) (Howland, Wakai, Mjaanes, Balog, \& Cleeland, 1995) as well as the ACC (Kitamura et al., 1995, 1997). A study of painful laser-evoked responses reported that both the contralateral SI and SII dipoles occurred at around $130 \mathrm{~ms}$, suggesting a parallel processing of thalamocortical inputs to these two cortical regions (Ploner, Schmitz, Freund, \& Schnitzler, 1999). MEG has also been used to follow the extent of cortical plasticity in phantom limb pain in traumatic or congenital amputees (Flor et al., 1995, 1998). It has also been found that focally applied brief painful stimulus generates a global suppression of spontaneous oscillations in somatosensory, motor, and visual areas, indicating that pain induces a widespread change in cortical function and excitability (Ploner, Gross, Timmermann, Pollok, \& Schnitzler, 2005; Raij et al., 2005).

Intrinsic optical signals (IOS) and intrinsic optical imaging (IOI). Changes in optical signals of transmitted or reflected light through brain tissue can indicate regional differences in brain activity. The transmitted or reflected light through brain tissue can be detected or imaged without using dyes or florescent markers. Use of IOS and IOI to monitor and understand neural activities and physiological changes in vitro and in vivo becomes more recognized (Asai, Kusudo, Ikeda, \& Murase, 2002; Ikeda, Terakawa, Murota, Morita, \& Hirakawa, 1996; Johnson, Hanley, \& Thakor, 2000; Kristal \& Dubinsky, 1997; Lemasters, Nieminen, Qian, Trost, \& Herman, 1997; Miller, Petrozzino, Mahanty, \& Connor, 1993; Scarfone, McComas, Pape, \& Newberry, 1999; Uchino, Elmer, Uchino, Lindvall, \& Siesjo, 1995). It is now popularly utilized in the field of neuroscience (Aitken, Fayuk, Somjen, \& Turner, 1999; Andrew, Jarvis, \& Obeidat, 1999; Haller, Mironov, \& Richter, 2001; Nomura, Fujii, Sato, Nemoto, \& Tamura, 2000). Subcellular organelles, such as nuclei (Ikeda et al., 1996), and mitochondria (Kristal \& Dubinsky, 1997; Lemasters et al., 1997), are known to change size with different levels of tissue activity and injury (Johnson et al., 2000). It is also known that changes of particle size within tissue will result in changes of light scattering. Thus, IOS and IOI of brain tissue have been used to investigate a variety of brain physiology models for more than 25 years (Lipton, 1973), although the causes of changes in light scattering and birefringence (initially studied 30 years ago by L. B. Cohen, Keynes, \& Hille, 1968, in giant axons of squid) are still not completely understood (Johnson et al., 2000; Nomura et al., 2000). 


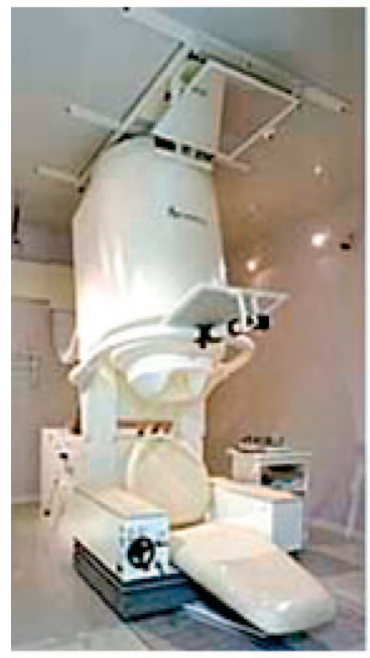

(a)

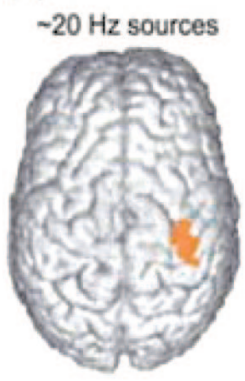

Rhythm level (\% from baseline)

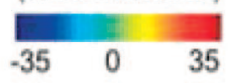

(b)

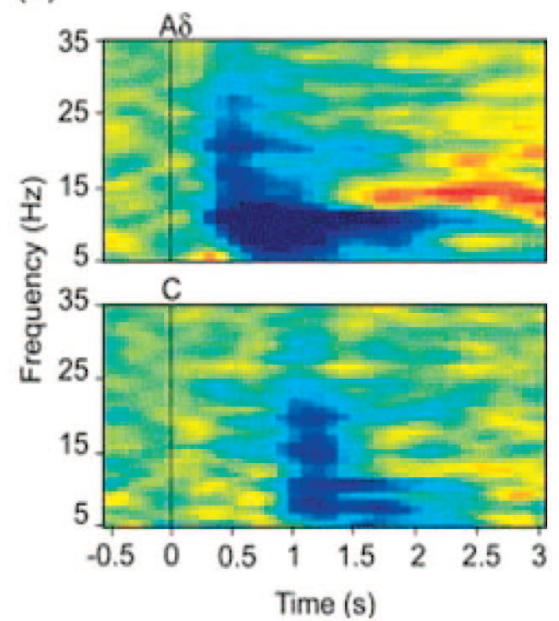

Figure 8. A magnetoencephalography image in the contralateral primary motor cortex (a) while A $\delta$ - and C-fiber stimuli were applied (b). From "Modulation of Motor-Cortex Oscillatory Activity by Painful A $\delta$ - and C-fiber Stimuli," by T. T. Raij, N. Forss, A. Stancak, and R. Hari, 2004, NeuroImage, p. 571. Copyright 2004 by Elsevier. Reprinted with permission.

However, both IOS and IOI are highly affected by light scattering and absorption of the measured neural tissue of the brain, mainly as a result of morphological structures and hemodynamic (such as blood concentrations, blood oxygenation levels, and blood flow) aspects of the brain, respectively. So far, it is difficult to separate light scattering and absorption effects within the measured data of IOS and IOI. One common practice in neuroscience research using optical brain imaging is to define a practical index, such as an intensity index, to associate either the IOS or IOI with the neural activity, without being able to decouple the effects from morphological and hemodynamic aspects of the brain. To date, there is no direct evidence using this technique to address pain problems. However, optical imaging has been used in studying the somatosensory systems (Berwick et al., 2005; Sasaki et al., 2002; Tommerdahl, Simons, Chiu, Favorov, \& Whitsel, 2005; see example in Figure 9) and the visual cortex (Blasdel, 1989, 1992). When a sinusoidal mechanical stimulation is applied to the contralateral or bilateral skin in the cat, there is an increase in absorption in the primary and secondary somatosensory cortices (Tommerdahl et al., 2005), whereas ipsilateral stimulation only elicits an increase of absorption in the secondary somatosensory cortex.

Nanotechnology: Quantum dots. Although histological localization has been used extensively through a variety of staining techniques that can be examined under light or an electron microscope, a recent development in nanotechnology, the use of quantum dots, has advanced the field further. In brief, quantum dots are fluorescent semiconductor nanocrystals (i.e., cadmium selenide) that can be conjugated with antibodies of interested targets (i.e., any proteins and peptides), such as variety of ion channels, neurotransmitters and their receptors, enzymes involved in neurotransmitter synthesis and metabolism, and molecules involved in intracellular cascade. The sizes of the quantum dots can be different (2-9.5 nm), which causes emission of different colors (emission wavelength from 400 to $1,350 \mathrm{~nm}$ ) under microscope. It enables one to label multiple targets in the same tissue to examine cellular or subcellular structures (see Figure 10; Giepmans, Deerinck, Smarr, Jones, \& Ellisman, 2005; Michalet et al., 2005). The major advantages of quantum dots over currently widely used fluorophores include their brightness, distinguishable emission spectra, and resistance to photobleach, which make quantum dots especially valuable for imaging anatomical structure and track physiological events in in vivo (Jaiswal, Mattoussi, Mauro, \& Simon, 2003; Voura, Jaiswal, Mattoussi, \& Simon, 2004) or in vitro (Goldman et al., 2004) preparations (Alivisatos, Gu, \& Larabell, 2005; Jaiswal \& Simon, 2004) without detectable toxicity for weeks to months (Jaiswal et al., 2003) in noninvasive imaging (Ballou, Lagerholm, Ernst, Bruchez, \& Waggoner, 2004). Potential applications of quantum dots include bioanalytical assays, fixed cell imaging, biosensors, in vivo animal targeting, and ex vivo live cell imaging (Michalet et al., 2005). Although there is no report of using quantum dots in the study of pain mechanisms, its use is expected to explode in the near future.

\section{Summary of Neuroscience Research}

The overwhelming experimental data generated by basic neuroscience studies will continue to lead to a better understanding of chronic pain. These techniques or tools include molecular biology, anatomy, physiology, behavior, and imaging at cellular, organic, and systemic levels. Although not yet fully developed, the current data have the following implications for dealing with chronic pain.

1. Genetic factors may play a crucial role in the susceptibility, initiation, maintenance, and aggravation of chronic pain.

2. Imbalance of a variety of neurotransmitters, neuromodulators, and their various types and subtypes of receptors, may contribute to the chronic pain state. An overproduction and release of an excitatory neurotransmitter, for example, may increase the membrane excitability, thus leading to an increased sensitivity of neurons that are part of the pain transmission system. On the other 

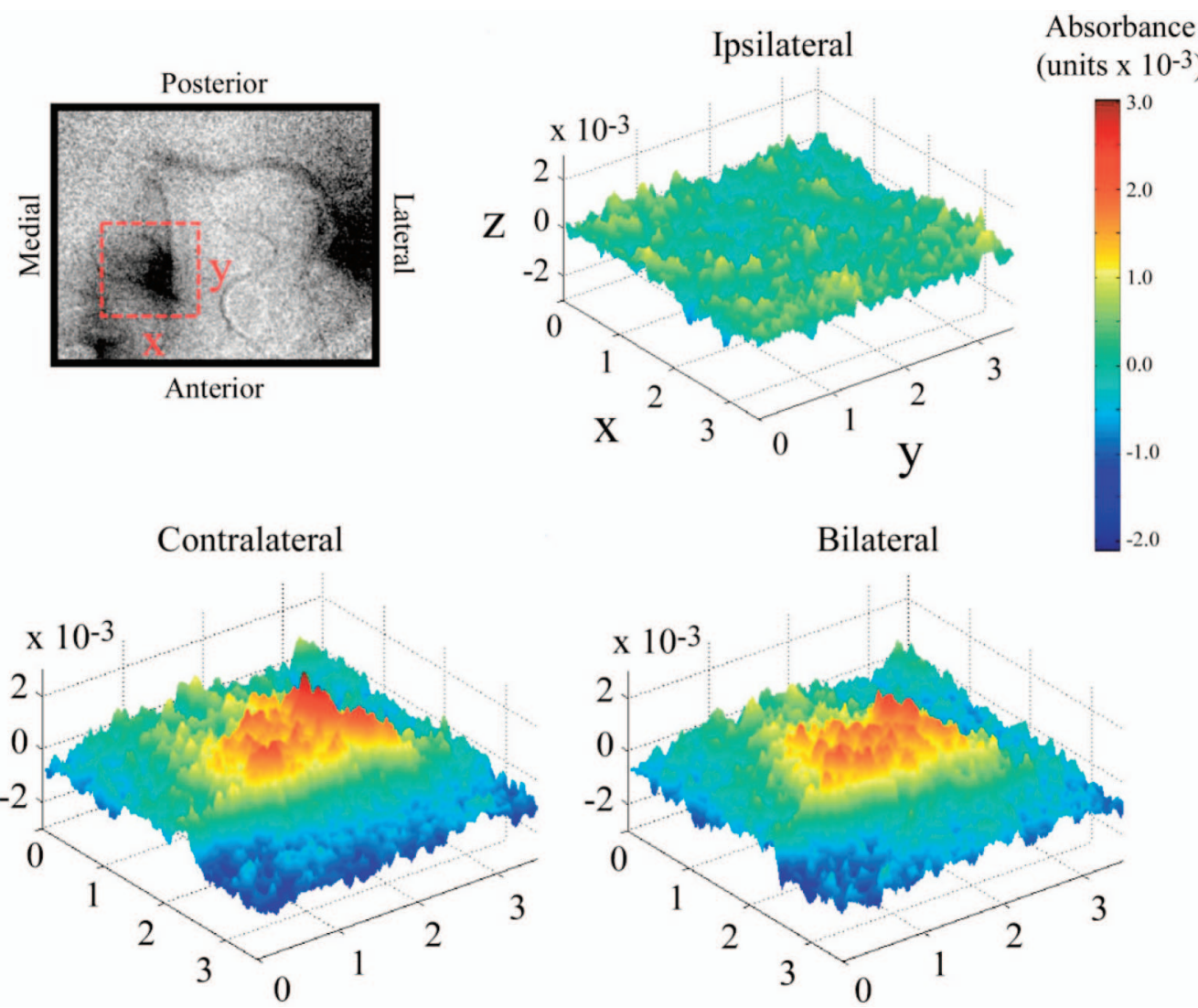

Figure 9. An example of the surface plots of absorbance evoked in somatosensory cortex by contralateral, ipsilateral, and bilateral flutter stimulation in the cat. From "Response of SI Cortex to Ipsilateral, Contralateral and Bilateral Flutter Stimulation in the Cat," by M. Tommerdahl, S. B. Simons, J. S. Chiu, O. Favorov, and B. Whitsel, 2005, BMC Neuroscience, 6, p. 32.

hand, lowered production of an inhibitory neurotransmitter will play a similar function.

3. Neurons in the somatosensory system are "wired" in certain patterns. They are dynamic and subject to constant modification depending on incoming signals from various connections. Although different neurotransmitters may act on their specific receptors, they may share a similar intracellular cascade pathway or interact with different intracellular pathway. Some of these intracellular events are critical to modifying genetic expression that may have a long-term effect, like in chronic pain.

4. Chronic pain is also phasic depending on the psychosocial status of the patient; it may change within hours, days, or weeks, possibly related to various hormones and their concentrations in the system.

5. Noninvasive imaging tools (CT, fMRI) have greatly advanced our knowledge of the anatomical and pathological conditions of the nervous system. PET, SPECT, and MEG techniques have added a further step in understanding the dynamic changes of the brain in response to certain stimuli or tasks. However, interpretation of results from these relatively new technologies should be made with some caution, especially in dealing with chronic pain. A newly developed, much less expensive tool-optical imaging - is another new potential technique, but it may suffer from less resolution in terms of noninvasiveness. A critical component of future research is to examine tonic neuronal activity, since some chronic pain conditions may possibly be associated with abnormalities in tonic levels of activity, in noxious evoked brain activation, or both.

6. Recent developments in nanotechnology could also contribute to the understanding of basic mechanisms (by using quantum dots labeling) and may provide a potential therapeutical mean (by targeted drug delivery).

\section{Pain and Emotion}

Historically, pain has been viewed as a symptom secondary to the presence of tissue pathology and, thus, as being of secondary importance. From this perspective, the amount of pain experienced and reported should be directly proportional to the amount of tissue pathology. Once the physical pathology has resolved, the pain should subside. Emphasis then should be on treating the cause of pain. Conversely, as noted previously, pain has also been viewed as being outside the senses and among the emotions (e.g., Aristotle). A new era in thinking about pain was ushered in by the conceptual model underlying the gate control theory by Melzack and Casey (1968) who, as we reviewed earlier in this article, suggested that the end experience of pain was a composite of 
(a)

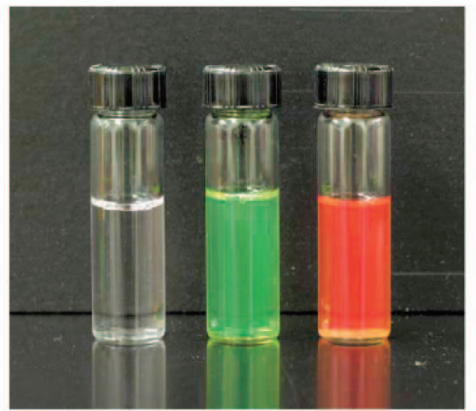

(c)

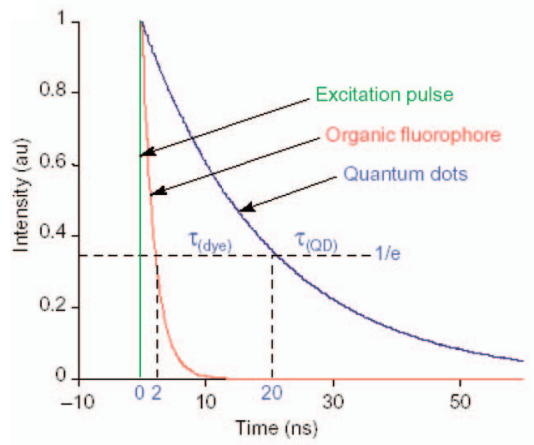

(b)

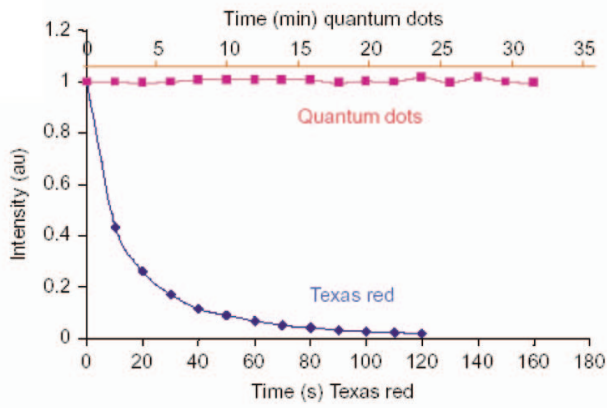

(d)

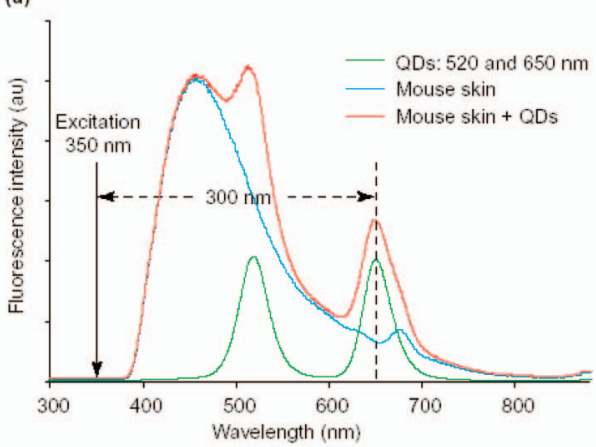

(f)
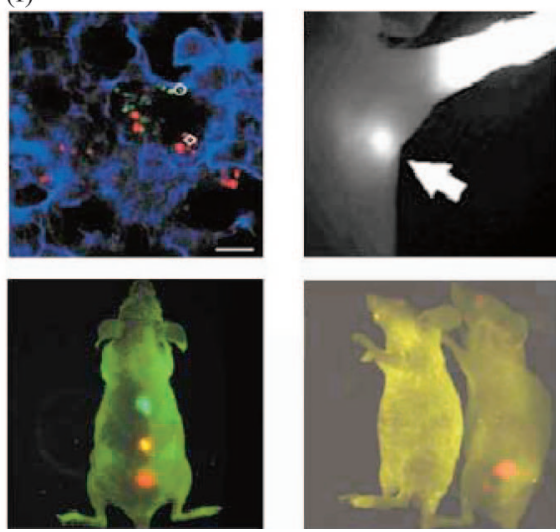

Figure 10. The optical properties of quantum dots (a-d) and potential applications in imaging cellular structures (e) and lymph nodes or prostate tumor in live animal (f). From "In vivo Molecular and Cellular Imaging With Quantum Dots,” by X. Gao, L. Yang, J. A. Petros, F. F. Marshall, J. W. Simons, and S. Nie, 2005, Current Opinion in Biotechnology, 16,p. 67. Copyright 2005 by Elsevier. Reprinted with permission.

sensory-discriminative, cognitive-evaluative, and motivational features. In this view, although the three components may be disentangled and assessed separately, they are interdependent. As noted, the integrative model postulated by Melzack and Wall (1965), and expanded by Melzack and Casey, has become the dominant paradigm in the specialized field of pain and pain management; however, there continue to be vestiges of mind-body, dualistic views in research on pain and clinical pain management.

Pain is ultimately a subjective, private experience, but it is invariably described in terms of sensory and affective properties. As defined by the International Association for the Study of Pain, "[pain] is unquestionably a sensation in a part or parts of the body but it is also always unpleasant and therefore also an emotional experience [emphasis added]" (Merskey, 1986, p. 1 ). The central and interactive roles of sensory information and affective state are supported by an overwhelming amount of evidence (Fernandez, 2002; Robinson \& Riley, 1999; Smeets, Vlaeyen, Kester \& Knottnerus, 2006; Keogh \& Asmundson, 2004; Turk \& Monarch, 2002). The affective component of pain incorporates many different emotions, but they are primarily negative. Depression and anxiety have received the greatest amount of attention in chronic pain patients; however, anger has 
recently received considerable interest as a significant emotion in chronic pain patients.

In addition to affect being one of the three interconnected components of pain, pain and emotions interact in a number of ways. Emotional distress may predispose people to experience pain, be a precipitant of symptoms, be a modulating factor amplifying or inhibiting the severity of pain, be a consequence of persistent pain, or be a perpetuating factor. Moreover, these potential roles are not mutually exclusive, and any number of them may be involved in a particular circumstance interacting with cognitive appraisals. For example, the literature is replete with studies demonstrating that current mood state modulates reports of pain as well as tolerance for acute pain (e.g., Fernandez \& Turk, 1992; Turk \& Monarch, 2002). Levels of anxiety have been shown to influence not only pain severity but also complications following surgery and number of days of hospitalization (e.g., DeGroot et al., 1997; Pavlin, Rapp, \& Pollisar, 1998). Individual difference variables, such as anxiety sensitivity (discussed later in this article), have also been shown to play an important predisposing and augmenting role in the experience of pain (Asmundson, 1999; Asmundson, Wright, \& Hadjistavropoulos, 2000). Level of depression has been observed to be closely tied to chronic pain (Gatchel, 2005) and to play a significant role in premature termination from pain rehabilitation programs (Kerns \& Haythornthwaite, 1988).

Emotional distress is commonly observed in people with chronic pain. People with chronic and recurrent (episodic) acute pain often feel rejected by the medical system, believing that they are blamed or labeled as symptom magnifiers and complainers by their physicians, family members, friends, and employers when their pain condition does not respond to treatment. They may see multiple physicians and undergo numerous laboratory tests and imaging procedures in an effort to have their pain diagnosed and successfully treated. As treatments expected to alleviate pain are proven ineffective, pain sufferers may lose faith and become frustrated and irritated with the medical system. As their pain persists, they may be unable to work or have financial difficulties, difficulty performing everyday activities, sleep disturbance, or treatment-related complications. They may be fearful and have inadequate or maladaptive support systems and other coping resources available to them. They may feel hostility toward the health care system in its inability to eliminate their pain. They may also feel resentment toward their significant others who they may perceive as providing inadequate support. And, they may even be angry with themselves for allowing their pain to take over their lives. These consequences of chronic pain can result in depression, anger, anxiety, self-preoccupation, and isolation - an overall sense of demoralization. Because chronic pain persists for long periods of time, affective state will continue to play a role as the impact of pain comes to influence all aspects of the pain sufferers' lives.

Although we provide an overview of research on the predominant emotions-anxiety, depression, and anger-associated with pain individually, it is important to acknowledge that these emotions are not as distinct when it comes to the experience of pain. They interact and augment each other over time.

\section{Anxiety}

It is common for patients with symptoms of pain to be anxious and worried. This is especially true when the symptoms are unex- plained, as is often the case for chronic pain syndromes. For example, in a large-scale, multicentered study of fibromyalgia syndrome patients, between $44 \%$ and $51 \%$ of patients acknowledged that they were anxious (Wolfe et al., 1990). People with persistent pain may be anxious about the meaning of their symptoms and for their futures-will their pain increase, will their physical capacity diminish, will their symptoms result in progressive disability where they ultimately end in a wheelchair or bedridden? In addition to these sources of fear, pain sufferers may be worried that, on the one hand, people will not believe that they are suffering and, on the other, they may be told that they are beyond help and will just have to learn to live with it. Fear and anxiety also relate to activities that people with pain anticipate will increase their pain or exacerbate whatever physical factors might be contributing to the pain. These fears may contribute to avoidance, motivate inactivity, and ultimately greater disability (Boersma \& Linton, 2006). Continual vigilance and monitoring of noxious stimulation and the belief that it signifies disease progression may render even low-intensity aversive sensations less bearable. In addition, such fears will contribute to increased muscle tension and physiological arousal that may exacerbate and maintain pain (Gatchel, 2005; Robinson \& Riley, 1999).

Threat of intense pain captures attention in such a way that individuals have difficulty disengaging from it. The experience of pain may initiate a set of extremely negative thoughts, as noted previously, and arouse fears-fears of inciting more pain and injury or fear of their future impact (see Vlaeyen \& Linton, 2000). Fear and anticipation of pain are cognitive-perceptual processes that are not driven exclusively by the actual sensory experience of pain and can exert a significant impact on the level of function and pain tolerance (Feuerstein \& Beattie, 1995; Vlaeyen et al., 1999; Vlaeyen \& Linton, 2000). People are motivated to avoid and escape from unpleasant consequences; they learn that avoidance of situations and activities in which they have experienced acute episodes of pain will reduce the likelihood of reexperiencing pain or causing further physical damage. They may become hypervigilant to their environment as a way of preventing the occurrence of pain.

Investigators (e.g., Lethem, Slade, Troup, \& Bentley, 1983; Vlaeyen, Kole-Snijders, Rotteveel, et al., 1995) have suggested that fear of pain, driven by the anticipation of pain and not by the sensory experience of pain itself, produce strong negative reinforcement for the persistence of avoidance behavior and the putative functional disability in pain patients. Avoidance behavior is reinforced in the short term through the reduction of suffering associated with noxious stimulation (McCracken, Gross, Sorg, \& Edmands, 1993). Avoidance, however, can be a maladaptive response if it persists and leads to increased fear, limited activity, and other physical and psychological consequences that contribute to disability and persistence of pain.

Studies have demonstrated that fear of movement and fear of (re)injury are better predictors of functional limitations than biomedical parameters or even pain severity and duration (e.g., Crombez, Vlaeyen, \& Heuts, 1999; Turk, Robinson, \& Burwinkle, 2004; Vlaeyen, Kole-Snijders, Rotteveel, et al., 1995). For example, Crombez et al. (1999) showed that pain-related fear was the best predictor of behavioral performance in trunk-extension, flexion, and weight-lifting tasks, even after the effects of pain intensity are partialled out. Moreover, Vlaeyen, Kole-Snijders, Rotteveel, Rue- 
sink, and Heuts (1995) found that fear of movement and (re)injury was the best predictor of self-reported disability among chronic back-pain patients and that physiological sensory perception of pain and biomedical findings did not add any predictive value. The importance of fear of activity appears to generalize to daily activities as well as the clinical experimental context. Approximately two thirds of chronic nonspecific low back-pain sufferers avoid back straining activities because of fear of (re)injury (Crombez et al., 1999). For example, fear-avoidance beliefs about physical demands of a job are strongly related to disability and work lost during the previous year, even more so than pain severity or other pain variables (Asmundson, Norton, \& Norton, 1999; Vlaeyen \& Crombez, 1999; Vlaeyen, Kole-Snijders, Boeren, \& van Eek, 1995; Vlaeyen, Kole-Snijders, Rotteveel, et al., 1995). Interestingly, reduction in pain-related anxiety predicts improvement in functioning, affective distress, pain, and pain-related interference with activity (McCracken \& Gross, 1998). Clearly, fear, painrelated anxiety, and concerns about harm-avoidance all play important roles in chronic pain and need to be assessed and addressed in treatment.

Pain-related fear and concerns about harm avoidance all appear to exacerbate symptoms (Vlaeyen, Kole-Snijders, Boeren, \& van Eek, 1995). Anxiety is an affective state that is greatly influenced by appraisal processes; to cite the stoic philosopher Epictetus, "There is nothing either bad or good but thinking makes it so." Thus, there is a reciprocal relationship between affective state and cognitive-interpretive processes. Thinking affects mood, and mood influences appraisals and, ultimately, the experience of pain (Boersma \& Linton, 2006; Gatchel, 2005).

\section{Depression}

Research suggests that $40 \%-50 \%$ of chronic pain patients suffer from depressive disorders (Banks \& Kerns, 1996; Dersh, Gatchel, Mayer, Polatin, \& Temple, 2006; Romano \& Turner, 1985). Epidemiologic studies provide solid evidence for a strong association between chronic pain and depression but do not address whether chronic pain causes depression or depression causes chronic pain. Prospective studies of patients with chronic musculoskeletal pain have suggested that chronic pain can cause depression (Atkinson, Slater, Patterson, Gant, \& Garfin, 1991), that depression can cause chronic pain (Magni, Moreschi, Rigatti Luchini, \& Merskey, 1994), and that they exist in a mutually reinforcing relationship (Rudy, Kerns, \& Turk, 1988).

One fact often raised to support the idea that pain causes depression is that the current depressive episode often began after the onset of the pain problem. The majority of studies appear to support this contention (Brown, 1990). However, several studies have documented that many patients with chronic pain (especially those disabled patients seen in pain clinics) have often had prior episodes of depression that predated their pain problem by years (Katon, Egan, \& Miller, 1985). A small longitudinal study (Dworkin et al., 1992) followed patients with herpes zoster for 1 year. They observed that those who developed more severe pain (i.e., post-herpetic neuralgia) 3 months after the initial diagnosis scored higher on baseline levels of depressed mood. However, these results were not confirmed in a recent larger study conducted by this group (Katz et al., 2005). One important prospective study (Jarvik et al., 2005) demonstrated that levels of depression pre- dicted the development of low back pain 3 years following the initial assessment. Patients with depression were 2.3 times more likely to report back pain compared to those who did not report depression. Depression was a much stronger predictor of incident back pain than any clinical or anatomic risk factors. This has led some investigators to propose that there may exist a common trait of susceptibility to dysphoric physical symptoms (including pain) and to negative psychological symptoms (including anxiety as well as depression). They concluded that "pain and psychological illness should be viewed as having reciprocal psychological and behavioral effects involving both processes of illness expression and adaptation" (Von Korff \& Simon, 1996, p. 107).

Given the scenario of chronic pain above, it is hardly surprising that chronic pain patients are depressed. It is interesting, however, to ponder the flip side of the coin — why are not all chronic pain patients depressed? Turk and colleagues (Rudy et al., 1988; Turk, Okifuji, \& Scharff, 1995) examined this question and determined that two factors appear to mediate the pain-depression relationship: patients' appraisals of the effects of the pain on their lives and appraisals of their ability to exert any control over their pain and lives. That is, those patients who believed that they could continue to function, and that they could maintain some control despite their pain, were less likely to become depressed. Here we see the interdependence of cognition and affect.

As noted previously, in the majority of cases, depression appears to be reactive, although some have suggested that chronic pain is a form of "masked depression," whereby patients use pain to express their depressed mood because they feel it is more acceptable to complain of pain than to acknowledge that one is depressed. Once a person has a chronic pain diagnosis, it no longer matters which is the cause and which is the consequence-pain or depression. Both need to be treated.

\section{Anger}

Anger has been widely observed in people with chronic pain (Schwartz, Slater, Birchler, \& Atkinson, 1991). Even though chronic pain patients might present an image of themselves as even tempered, Corbishley, Hendrickson, Beutler, and Engle (1990) found that $88 \%$ acknowledged their feelings of anger when these were explicitly sought. Approximately $98 \%$ of the patients referred to a multidisciplinary pain rehabilitation center reported that they were feeling some degree of anger at the time of the assessment (Okifuji, Turk, \& Curran, 1999). We must be cautious in interpreting data from patients recruited at pain centers, however, as there may be a referral bias such that the most distressed patients are sent to these facilities, and they do not represent the large number of people with persistent pain who are never evaluated in treatment facilities that specialize in pain management.

Since anger is frequently considered as socially undesirable, some patients in the studies cited previously may have found it difficult to admit that they were angry to the health care professionals. Thus, it is possible that the anger rates may actually be an underestimate. The high prevalence of anger observed is perhaps not surprising, given the frustrations related to persistence of symptoms, limited information on etiology, and repeated treatment failures, along with anger toward others (employers, insurance companies, the health care system, family members) and anger 
toward themselves, perhaps, for their inability to alleviate their symptoms and to move on with their lives (Okifuji et al., 1999).

Several empirical studies provide preliminary support for the association between anger and pain intensity (Gaskin, Greene, Robinson, \& Geisser, 1992; Summers, Rapoff, Varghese, Porter, \& Palmer, 1991), unpleasantness of pain (Wade, Price, Hamer, Schwartz, \& Hart, 1990), affective component of pain (Fernandez \& Milburn, 1994), and emotional distress in chronic pain patients (Duckro, Chibnall, \& Tomazic, 1995; Kinder, Curtiss, \& Kalichman, 1992) as well as families of chronic pain patients (Schwartz et al., 1991).

Anger in chronic pain has been considered by some to be attributable to enduring personality dispositions associated with unconscious conflicts (Fromm-Reichman, 1937), whereas others have suggested that anger may be a reaction to the presence of recalcitrant symptoms that have been unsubstantiated by objective medical findings and unrelieved by medical treatments (Fernandez \& Turk, 1995). There is some evidence supporting the latter hypothesis. For example, a laboratory study (Berkowitz \& Thomas, 1987) demonstrated that the mere anticipation of pain was sufficient to provoke angry behavioral responses in healthy individuals. Using the cross-lagged design with a clinical sample, Arena, Blanchard, and Andrasik (1984) found that an increase in pain tends to precede anger, directly contradicting the angersomatization association.

The relatively fruitless debate over the cause-effect relationship between anger and pain is reminiscent of the arguments on the associations between pain and depression (see Romano \& Turner, 1985). In order to refine researchers' understanding of the association between anger and pain beyond this debate, several investigators have begun to examine individual differences in how anger is expressed. In an early study, Pilowsky and Spence (1976) found that chronic pain patients are less willing to express anger compared to outpatient medical patients. Similarly, individuals with chronic pain problems appear to inhibit their anger compared to pain-free, healthy persons (Franz, Paul, Bautz, Choroba, \& Hildebrandt, 1986; Hatch et al., 1991). Furthermore, inhibition of anger seems to contribute to aversiveness of the chronic pain experience. Inhibition of anger has been found to be related to pain severity and overt pain behaviors (Kerns, Rosenberg, \& Jacob, 1994) as well as to increased emotional distress (Duckro et al., 1995; Tschannen, Duckro, Margolis, \& Tomazic, 1992).

Denial of anger also appears to be common among chronic pain patients. However, awareness of anger should not be confused with anger expression. For example, Corbishley et al. (1990) observed that chronic pain patients tend to show strong reservations about expressing socially undesirable emotions that could create interpersonal conflict. For these individuals, it seems that expression of the emotion is under conscious control. They are aware of their anger but choose not to express it. On the other hand, some chronic pain patients may lack awareness of their angry feelings and have increased difficulties in recognizing and reporting these feelings (Braha \& Catchlove, 1985).

Fernandez and Turk (1995) proposed that the specificity of targets toward which patients experience angry feelings may be important in understanding the relationship between pain and anger. When a pain sufferer is angry, there are a range of possible targets (e.g., employer, insurance company, health care providers). The presence or intensity of anger toward different targets may be differentially related to chronic pain experience. That is, there may be some targets of anger that are more relevant to the chronic pain experience than others. As is discussed below, Okifuji et al. (1999) found that anger directed toward oneself was particularly common among chronic pain patients evaluated at a pain rehabilitation facility.

Another important issue regarding anger concerns gender differences. There is a growing literature suggesting the presence of important differences in the ways that males and females respond to pain (Unruh, 1996). Moreover, in the Western cultures, there appear to be social conventions regarding the expression of anger. In general, it seems acceptable for men to display angry feelings, whereas women are socialized to avoid overt expression of anger. However, research investigating gender differences in anger expression has revealed equivocal results. Some studies reported that women indicate significantly higher levels of generalized anger than men (e.g., Hashida \& Mosche, 1988), some report the opposite results (Fischer, Smith, Leonard, \& Fuqua, 1993; Kinder et al., 1992; Sternbach, Wolfe, Murphy, \& Akeson, 1973), and still others reported no gender differences in anger expression (Averill, 1983; Stoner \& Spencer, 1987). In the chronic pain population, some studies noted that male patients seem to acknowledge angry feelings more readily than do female patients (Kinder et al., 1992; Sternbach et al., 1973). In contrast, other investigators (Burns, Johnson, Devine, Mahoney, \& Pawl, 1998; Curtiss, Kinder, Kalichman, \& Spana, 1988; Okifuji et al., 1999) suggested that there may be substantial variability within groups of men and women. There seems to be a subgroup of female patients who do outwardly express anger, whereas some male patients may suppress their anger.

Although the effects of anger and frustration on exacerbation of pain and treatment acceptance has not received as much attention as anxiety and depression, Kerns et al. (1994) found that the suppressed feelings of anger accounted for a significant portion of the variance in pain intensity, perceived interference, and frequency of pain behaviors. Furthermore, Summers et al. (1991) found that anger and hostility were powerful predictors of pain severity in people with spinal cord injuries. It is thus reasonable to expect that the presence of anger may serve as a complicating factor, increasing autonomic arousal and blocking motivation and acceptance of treatments oriented toward rehabilitation and disability management rather than cure, which are often the only treatments available for chronic pain (Fernandez \& Turk, 1995).

Frustrations related to persistence of symptoms, unknown etiology, and repeated treatment failures, along with anger toward employers, insurers, the health care system, family, and themselves, all contribute to the general dysphoric mood of patients (Okifuji et al. 1999). Okifuji et al. (1999) reported that $60 \%$ of patients expressed anger toward health care providers, 39\% toward significant others, $30 \%$ toward insurance companies, $26 \%$ toward employers, and 20\% toward attorneys. The target of anger most commonly acknowledged, however, was oneself (endorsed by approximately $70 \%$ of the sample). Internalization of angry feelings is strongly related to measures of pain intensity, perceived interference, and frequency of pain behaviors (Kerns et al., 1994). Overall, correlations between anger and pain severity have been shown to be statistically significant, ranging from .17 to .35 (Burns, Wiegner, Derleth, Kiselica, \& Pawl, 1996; Kerns et al., 1994). Okifuji et al., (1999) reported that anger was significantly 
correlated with pain intensity $(r=.30-.35)$. Okifuji et al. also reported that anger was significantly correlated with disability $(r=$ .26) and was highly associated with depression $(r=.52)$.

The precise mechanisms by which anger and frustration exacerbate pain are not known. One reasonable possibility is that anger exacerbates pain by increasing physiological arousal (Burns, 1997; Cacioppo, Bernston, Klein, \& Poehlmann, 1997). For example, Burns et al. (1996) reported the results of a study that demonstrated anger-induced stress produced increased muscle tension, which in turn predicted a greater level of pain severity in chronic back-pain patients. It was found that this effect was specific to anger; a measure of depression that was significantly correlated with pain was not associated with increased muscle reactivity.

Anger may also interact with depression to modulate perceived severity of pain. In addition, anger may block motivation for, and acceptance of, treatments oriented toward rehabilitation and disability management rather than cure. Yet, rehabilitation and disability management are often the only treatments available for these patients.

\section{Negative Affect: A Summary}

In summary, it is important to be aware of the significant role of negative mood in chronic pain patients, because it is likely to influence treatment motivation and compliance with treatment recommendations. For example, patients who are anxious may fear engaging in what they perceive as demanding activities, patients who are depressed and who feel helpless may have little initiative to comply, and patients who are angry with the health care system are not likely to be motivated to respond to recommendations from yet another health care professional. Finally, as noted by Robinson and Riley (1999),

Inhibition of negative emotion has also been suggested in the etiology of chronic pain through increased autonomic and central nervous system activity, which in turn weakens the cognitive processes that promote health, resulting in sleep disturbance, elevation of cortisol levels, and increased health care utilization. (p. 78)

Thus, clinicians who are treating people with persistent pain must focus on their mood states as well as on physical pathology and somatic factors. Pain cannot be treated successfully without attending to the patient's emotional state. This is true for acute pain, such as pain associated with surgery, and persistent pain states.

\section{Pain and Cognitive Factors}

As pointed out in the last section, pain and emotions interact in a number of ways that, in turn, may interact with cognitive appraisals of the pain state. A review of these cognitive factors is provided next.

\section{Appraisal and Beliefs}

Pain appraisal refers to the meaning ascribed to pain by an individual (Sharp, 2001). In accordance with the transactional stress model (Lazarus \& Folkman, 1984), a distinction can be made between primary appraisal (evaluation of the significance of pain in terms of it being threatening, benign, or irrelevant) and secondary appraisal (evaluation of the controllability of pain and one's coping resources). Beliefs refers to assumptions about reality that shape how one interprets events and can thus be considered as determinants of appraisal. Pain beliefs develop during the lifetime as a result of an individual's learning history and cover all aspects of the pain experience (e.g., the causes of pain, its prognosis, suitable treatments).

Appraisal and beliefs about pain can have a strong impact on an individual's affective and behavioral response to pain. If a pain signal is interpreted as harmful (threat appraisal) and is believed to be associated with actual or potential tissue damage, it may be perceived as more intense and unpleasant and may evoke more escape or avoidance behavior. For instance, pain associated with cancer is rated as more unpleasant than labor pain, even when the intensity is rated as equivalent (Price, Harkins, \& Baker, 1987). Similarly, Smith, Gracely, and Safer (1998) demonstrated that cancer patients, who attributed pain sensations after physiotherapy directly to cancer, reported more intense pain than patients who attributed this pain to other causes. Perception of danger of an experimental pain stimulus (cold-presser test) may also lead to avoidance of this stimulus (Cipher \& Fernandez, 1997). Arntz and Claassens (2004) experimentally manipulated the appraisal of a mildly painful stimulus (a very cold metal bar placed against the neck) by suggesting that it was either very hot or very cold. It was assumed that heat would be more strongly associated with tissue damage than cold. As expected, participants rated the stimulus as more painful in the condition where they were informed that it was hot. In addition, the effect appeared to be mediated by the belief that the stimulus would be harmful. These studies demonstrate the important role of people's interpretations regarding the meaning of pain.

Pain appraisal and pain beliefs are also prominent determinants of adjustment to chronic pain (Jensen, Romano, Turner, Good, \& Wald, 1999; Turner, Jensen, \& Romano, 2000). The following pain beliefs have been identified as particularly maladaptive in dealing with pain: Pain is a signal of damage, activity should be avoided when one has pain, pain leads to disability, pain is uncontrollable, and pain is a permanent condition (Jensen, Turner, Romano, \& Lawler, 1994; Turner et al., 2000). The belief that pain is a signal of damage and the belief that activity should be avoided in order to recover from pain appear to be widespread (Balderson, Lin, \& Von Korff, 2004; Ihlebaek \& Eriksen, 2003). Two months after seeking treatment, a large majority of back-pain patients believed that a wrong movement could have serious negative consequences for their back. Moreover, this belief was associated with reduced activity levels and increased disability (Balderson et al., 2004).

\section{Catastrophizing and Fear-Avoidance Beliefs}

In the last decade, chronic pain researchers have emphasized the role of a specific set of negative appraisal and beliefs (i.e., pain catastrophizing and fear-avoidance beliefs). Pain catastrophizing can be defined as an exaggerated negative orientation toward actual or anticipated pain experiences. There has been much debate about the specific nature of catastrophizing as a psychological construct (Sullivan et al., 2001; Turner \& Aaron, 2001). However, current conceptualizations most often describe it in terms of appraisal or as a set of maladaptive beliefs (Severeijns, Vlaeyen, \& van den Hout, 2004; Thorn, Rich, \& Boothby, 1999). The evidence 
for the role of pain catastrophizing in chronic pain adjustment is overwhelming and has been summarized in several review articles and studies (e.g. Keefe, Rumble, Scipio, Giordano, \& Perri, 2004; Smeets et al., 2006; Sullivan et al., 2001). Cross-sectional studies have demonstrated that catastrophizing is associated with increased pain, increased illness behavior, and physical and psychological dysfunction across numerous clinical and nonclinical populations. Prospective studies indicated that catastrophizing might be predictive of the inception of chronic musculoskeletal pain in the general population (Picavet, Vlaeyen, \& Schouten, 2002; Severeijns, Vlaeyen, van den Hout, \& Picavet, 2005) and of more intense pain and slower recovery after surgical intervention (Granot \& Ferber, 2005; Kendell, Saxby, Farrow, \& Naisby, 2001; Pavlin, Sullivan, Freund, \& Roesen, 2005).

The role of catastrophizing and the belief that pain means harm and activity should be avoided has been most articulated in fearavoidance models of chronic pain (Asmundson, Norton, \& Vlaeyen, 2004; Vlaeyen \& Linton, 2000). Although fearavoidance models are multifaceted and include affective (fear) and behavioral (avoidance) components, cognitions are identified as the core determinants of entering into a negative pain cycle. Philips (1987) was the first to stress the importance of beliefs in shaping avoidance behavior in response to pain. She identified memory of past pain experiences, the belief that activity will lead to a pain increase, and self-efficacy beliefs as the major determinants of avoidance behavior. The tenets of contemporary fear-avoidance models can be summarized as follows: When pain is perceived following injury, an individual's idiosyncratic beliefs will determine the extent to which pain is catastrophically interpreted. A catastrophic interpretation of pain gives rise to physiological (arousal), behavioral (avoidance), and cognitive fear responses. The cognitive shift that takes place during fear enhances threat perception (e.g., by narrowing of attention) and further feeds the catastrophic appraisal of pain (Asmundson et al., 2004).

The evidence that fear and avoidance are associated with increased pain and disability in chronic pain patients has been reviewed above in the section on pain and emotion. In addition, prospective studies have shown that fear-avoidance beliefs in patients seeking care for acute pain may be predictive of pain persistence, disability, and long-term sick leave (e.g., Boersma \& Linton, 2005; Fritz, George, \& Delitto, 2001). Fear-avoidance beliefs are also related to the future inception of (back) pain in the general population (Linton, Buer, Vlaeyen, \& Hellsing, 2000; Picavet et al., 2002).

Health care providers are often not able to adequately address the fear-avoidance beliefs of patients (Balderson et al., 2004). In fact, some practitioners hold beliefs themselves that may encourage fear-avoidance in their patients (Houben et al., 2005; Linton, Vlaeyen, \& Ostelo, 2002). Fear-avoidance beliefs of health care providers were found to be related to their treatment behavior and their recommendation for engaging in physical activities (Houben et al. 2004; J. Rainville, Carlson, Polatin, Gatchel, \& Indahl, 2000). The beliefs of patients and health care providers may further interact with each other in a mutually reinforcing way, because a patient's beliefs may guide the choice of which health care provider is visited (Werner, Ihlebaek, Skouen, \& Laerum, 2005).

Since catastrophizing and fear-avoidance beliefs appear to play such a prominent role in maladaptive responses to pain and in pain perpetuation, it is of vital importance that these negative and maladaptive beliefs are corrected. Several investigators have demonstrated the therapeutic efficacy of doing so (Ehde \& Jensen, 2004; Smeets et al., 2006; Thorn, 2004). Moreover, educational interventions in a primary care setting addressing fear-avoidance beliefs and encouragement to stay active have been found to reduce disability in back-pain patients (Burton, Waddell, Tillotson, \& Summerton, 1999; J. E. Moore, Von Korff, Cherkin, Saunders, \& Lorig, 2000). Also a population-based media campaign was shown to be effective in changing beliefs about back pain and reducing disability and worker's compensation costs related to back pain (Buchbinder, Jolley, \& Wyatt, 2001). The improvement in population beliefs about back pain were sustained until 3 years after cessation of the campaign (Buchbinder \& Jolley, 2005).

However, education alone may not be sufficient for reducing fear-avoidance beliefs in those patients with very high levels of catastrophizing and fear-avoidance beliefs (de Jong, Vlaeyen, Onghena, Goossens, et al., 2005). These patients may require a more tailored treatment approach, such as graded exposure to disconfirm their fear-avoidance beliefs (Vlaeyen, de Jong, Onghena, et al., 2002). In graded exposure therapy, first a hierarchy of fearful activities is established. Patients are encouraged to engage in a moderately feared activity until disconfirmation of harm beliefs for this particular activity has occurred. Then, patients proceed to the next item in the hierarchy until he or she is able to perform even the most feared activities. During the performance of activities, behavioral experiments are used to challenge the catastrophic interpretations of the consequences of the activity. Graded exposure appears to be a very effective treatment for altering fear-avoidance beliefs and catastrophizing and for reducing pain and disability in chronic pain patient who are characterized by high levels of fear-avoidance (Boersma et al., 2004; de Jong, Vlaeyen, Onghena, Cuypers, et al., 2005; Vlaeyen, de Jong, Geilen, Heuts, \& van Breukelen, 2002).

Although graded exposure is the most specific treatment for reducing fear-avoidance beliefs, most cognitive behavioral treatment (CBT) packages for chronic pain patients contain at least some components (e.g., education, physical exercise, challenging negative cognitions) that are likely to be effective at reducing fear-avoidance beliefs (Williams \& McCracken, 2004). Several studies have indeed demonstrated that CBT can lead to a reduction in fear-avoidance beliefs and that treatment success may be mediated by changes in fear-avoidance beliefs (e.g., Jensen, Turner, \& Romano, 2001; McCracken, Gross, \& Eccleston, 2002). CBT approaches are further reviewed later in this article.

\section{Perceived Control and Self-Efficacy}

Perceived control over pain refers to the belief that one can exert influence on the duration, frequency, intensity or unpleasantness of pain. Perceived controllability of a pain stimulus may modify the meaning of this stimulus and directly affect threat appraisal (Arntz \& Schmidt, 1989; Bandura, O'Leary, Taylor, Gauthier \& Gossard, 1987). As a consequence, pain may be rated as less intense or less unpleasant, and pain tolerance may increase. However, studies in which the control over pain stimuli was experimentally manipulated yielded mixed results as to whether perceived controllability affects pain intensity or pain tolerance (Janssen, Spinhoven, \& Arntz, 2004; Salomons, Johnstone, Back- 
onja, \& Davidson, 2004; Thompson, 1981). However, a recent study by Samwel, Evers, Crul, and Kraaimaat (2006) found that, in a group of 169 chronic pain patients treated at an interdisciplinary pain center, perceived helplessness appeared to be the strongest contributor to disability and pain level. Moreover, in another study, fMRI showed that manipulation of the controllability of a pain stimulus attenuated the neural response to pain (Salomons et al., 2004). Offering control in an experimental pain situation may interact with individual characteristics, such as self-efficacy and feeling of helplessness, in determining whether it is effective in reducing pain (Müller \& Netter, 2000).

Outside of the laboratory, the relevance of perceived control over pain has also been examined. The belief that one has control over pain has a strong influence on disability in patients with chronic pain complaints (Jensen \& Karoly, 1991; Turner et al., 2000), and an increase in this belief after multidisciplinary pain treatment may predict pain reduction and decreases in disability (Jensen et al., 2001; Spinhoven et al., 2004). However, there may be a downside to trying to gain control over pain. When repeated attempts to gain control over pain fail, this may lead to frustration and preoccupation with pain and, finally, to exacerbations of disability and distress (McCracken, Carson, Eccleston, \& Keefe, 2004). Instead of trying to gain control over pain itself, it may be more effective to control the effect of pain on one's life. Of course, there is a fine line between controlling one's pain and controlling the impact of pain in one's life. These are not mutually exclusive. For example, relaxation may control both one's pain and the impact of pain on one's life. Regardless, though, as Tan et al. (2002) demonstrated, perceived control over the effects of pain was more strongly related to better adjustment and less disability than perceived control over pain itself. McCracken et al. (2004) proposed that the ineffective struggle to gain control over pain that is essentially uncontrollable should be abandoned, and that acceptance of pain may foster the sense of general life control. Indeed, a consistent relationship between pain acceptance and better adjustment has been found (e.g., McCracken \& Eccleston, 2003; Viane et al., 2003), and preliminary evidence has been obtained for the efficacy of acceptance-based treatment for chronic pain patients (McCracken, Vowles, \& Eccleston, 2005). On the other hand, however, there are growing data from imaging studies showing the positive physiological effects of cognitive coping (e.g., deCharms et al., 2005; Salomons et al., 2004). Thus, this issue still needs to be resolved. Afterall, on a pure clinical basis, to simply give up or give in would appear to be a certain route to depression.

Related to perceived control is the construct of self-efficacy. Self-efficacy is the conviction that one can successfully perform a certain task or produce a desirable outcome (Bandura, 1977). A major determinant of self-efficacy is prior mastery experience. In laboratory experiments, self-efficacy beliefs predict pain tolerance (e.g., Dolce et al., 1986; Keefe, Lefebvre, Maixner, Salley, \& Caldwell, 1997). In chronic pain patients, self-efficacy positively affects physical and psychological functioning (Asghari \& Nicholas, 2001; Rudy, Lieber, Boston, Gourley, \& Baysal, 2003; Woby, Watson, Roach, \& Urmston, 2005), and improvements in self-efficacy after self-management and cognitive-behavioral interventions are associated with improvements in pain, functional status, and psychological adjustment (Keefe et al., 2004; Marks, 2001). Recent reviews of psychological factors in chronic pain have concluded that the evidence for the role of self-efficacy across a broad range of pain populations is impressive (Geisser, Robinson, Miller, \& Bade, 2003; Keefe et al., 2004). Moreover, self-efficacy also influences the prognosis after acute physical interventions like surgery. Prospective studies in patients who underwent orthopedic surgery demonstrated that high self-efficacy before the start of rehabilitation and larger increases over the course of a rehabilitation speed recovery and predict better longterm outcome (Dohnke, Knauper, \& Muller Fahrnow, 2005; Orbell, Johnston, Rowley, Davey, \& Espley, 2001; Waldrop, Lightsey, Ethington, Woemmel, \& Coke, 2001). A preoperative intervention (an instruction video demonstrating movement and breathing skills) in hysterectomy patients was able to enhance preoperative self-efficacy and decrease pain associated with postoperative activities and promote earlier mobilization (Heye, Foster, Bartlett, \& Adkins, 2002).

Why is a high level of self-efficacy beneficial when people are confronted with an acute or chronic pain experience? For one thing, high self-efficacious people may be more motivated to engage in health promoting behaviors and adhere better to treatment recommendations because they have higher performance success expectancies. Also, they are less likely to give up an activity when facing barriers (e.g., pain), and this may prevent them from becoming trapped in the negative spiral of activity avoidance, physical deconditioning, loss of social reinforcers and depression. In addition, perceived self-efficacy can affect the body's opioid and immune systems (Weisenberg, 1998).

\section{Vulnerability and Resilience}

As discussed above, specific pain cognitions (appraisal and beliefs) are largely shaped by an individual's learning history, either through direct experience, modeling, or information from others. These learning experiences may interact with an individual trait characteristic and the global outlook on the world that an individual holds. That is, temperamental or personality factors may predispose some people to make certain kinds of maladaptive appraisals and to be more susceptible to some beliefs than to others. Temperament is supposed to be (at least partly) heritable and show continuity throughout life; personality in adulthood reflects the molding of underlying temperament by life experiences. Temperament and personality can be a vulnerability factor that predisposes toward catastrophic misinterpretation of pain sensations and maladaptive pain beliefs, or they can be a resilience factor protecting against maladaptive cognitions and promoting self-efficacy beliefs. Some potential vulnerability and resilience factors for chronic pain adaptation are reviewed here.

Trait characteristics that have received most attention as potential vulnerability factors leading to maladaptive cognitions are negative affectivity, anxiety sensitivity and, more recently, illness/ injury sensitivity (Keogh \& Asmundson, 2004). In the earlier section on Pain and Emotion, we discussed some of the basic emotional states associated with chronic pain. These negative emotions may be particularly prominent in patients with a high level of negative affectivity. Negative affectivity is considered a heritable, stable, and general tendency to view the world as threatening and distressing, and a high level of negative affectivity may evoke experiencing a broad range of negative emotions (Watson, Clark, \& Harkness, 1994). Negative affectivity has been associated with heightened vigilance to bodily sensations and interpretational 
biases toward ambiguous internal signals (Stegen, Van Diest, Van de Woestijne, \& Van den Bergh, 2000; Watson \& Pennebaker, 1989). Studies in nonclinical populations found negative affectivity to predict lower pain tolerance (Fillingim et al., 2005). However, studies in chronic pain populations have so far not provided consistent evidence for a role of trait negative affectivity. Negative affectivity does not seem to account for heightened pain vigilance in patients with various chronic pain syndromes (Crombez, Eccleston, Van den Broeck, Van Houdenhove, \& Goubert, 2002; Peters, Vlaeyen, \& van Drunen, 2000). There are also a few prospective studies on the prognostic role of negative affectivity in recovery after whiplash trauma. Again, the role of negative affectivity was not substantiated (Radanov, di Stefano, Schnidrig, \& Ballinari, 1991; Scholten-Peeters et al., 2003). In conclusion, although negative affectivity has often been implicated as a vulnerability factor in chronic pain, convincing evidence is still waiting.

More convincing has been the research on another potential vulnerability factor: anxiety sensitivity. Anxiety sensitivity is defined as the fear of anxiety-related sensations and is conceived as a partly heritable personality trait (Reiss, Peterson, Gursky, \& McNally, 1986; Stein, Jang, \& Livesley, 1999). Individuals with high anxiety sensitivity interpret unpleasant physical sensations (like rapid heart beating, feeling faint) more often as a sign of danger than do individuals with low anxiety sensitivity. Elevated levels of anxiety sensitivity have been found in several emotional disorders but especially in panic disorder (Taylor, 1995). There is growing evidence that anxiety sensitivity may also be a risk factor for the maintenance and exacerbation of chronic pain and disability (Asmundson et al., 2000). Anxiety sensitivity correlates with measures of fear avoidance and is associated with distress, analgesic use, and physical and social functioning in patients across a wide range of different pain-related condtions (for reviews see Asmundson et al., 2000; Keogh \& Asmundson, 2004). Moreover, path analyses and mediation models suggest that anxiety sensitivity exacerbates fear-avoidance beliefs and the negative interpretation of bodily sensations, which in turn leads to enhanced pain experience and pain avoidance (Asmundson \& Taylor, 1996; Keogh, Hamid, Hamid, \& Ellery, 2004). It should be noted, though, that because anxiety sensitivity is quite highly correlated with a more general factor of neuroticism (Taylor, 1993), future research is required to determine whether it contributes any unique variance in explaining outcomes.

To determine whether anxiety sensitivity is really a vulnerability factor that is causally associated with maladaptive pain cognitions and poor behavioral and psychological adjustment to pain, and not merely a correlate of the chronic pain experience, researchers have examined the predictive value of anxiety sensitivity in relation to cognitive and behavioral reactions to experimentally induced pain in nonclinical samples. In agreement with its supposed role as a vulnerability factor, anxiety sensitivity predicted pain threshold and reported pain intensity after cold-pressor pain induction (Keogh \& Birkby, 1999; Keogh \& Mansoor, 2001; N. B. Schmidt \& Cook, 1999). Moreover, individuals high in anxiety sensitivity show attentional and interpretational biases for physical threatrelated material (Asmundson, Carleton, \& Ekong, 2005; Keogh \& Cochrane, 2002), and the negative interpretational bias regarding bodily sensations mediated the effect of anxiety sensitivity on affective pain responses (Keogh \& Cochrane, 2002). Thus, anxiety sensitivity may indeed be causally implicated in maladaptive cognitive and behavioral pain responses.

Recently, researchers have begun to consider yet another vulnerability factor: illness/injury sensitivity (Carleton, Asmundson, \& Taylor, 2005; Vancleef, Peters, Roelofs, \& Asmundson, 2006). According to Reiss (1991), illness/injury sensitivity is one of the three fundamental fears besides anxiety sensitivity and fear of negative evaluation. It may be proposed that illness/injury sensitivity, not anxiety sensitivity, is the fundamental fear that qualifies most as a specific vulnerability factor for chronic pain and disability. Illness/injury sensitivity is conceptually more strongly related to the content of fear-avoidance beliefs of chronic pain patients than anxiety sensitivity. This can be illustrated by the items of the inventories that are used to measure anxiety sensitivity and illness or injury sensitivity-the Anxiety Sensitivity Index (Peterson \& Heilbronner, 1987) and the Injury/Illness Sensitivity Index (Taylor, 1993), respectively. The Anxiety Sensitivity Index contains items that very specifically apply to panic symptoms (e.g., fear of heart beating fast), whereas the Injury/Illness Sensitivity Index contains items that reflect worries about one's future physical condition (e.g., worrying about getting injured). In his analyses of the relationship between fundamental fears and common fears, Taylor (1993) showed that anxiety sensitivity was most predictive of agoraphobia, and illness/injury sensitivity was most predictive of medical fears. Fear-avoidance beliefs and catastrophizing were not included in this analysis.

Recent studies in healthy volunteers demonstrated that, indeed, illness/injury sensitivity may be a more specific vulnerability factor for maladaptive pain responses than anxiety sensitivity (Vancleef et al., 2006). In a cross-sectional study, illness/injury sensitivity, anxiety sensitivity, fear of negative evaluation, and trait anxiety were tested for their independent contribution to pain catastrophizing and fear-avoidance beliefs. Illness/injury sensitivity appeared to be the single best predictor of pain catastrophizing, fear of pain and pain avoidance. Moreover, when healthy volunteers were subjected to three different pain induction procedures (ischemic pain, electrical pain, and heat pain), only illness/injury sensitivity predicted anticipatory fear for the pain stimulus and not anxiety sensitivity (Vancleef et al., 2006). Another study examined whether illness/injury sensitivity is also predictive of behavior in physically threatening situations. Vignettes were used that described situations that could potentially signal damage to the body (e.g., having pain in the wrist after a fall) and the likelihood of performing safety behaviors was assessed (e.g., going to the general practitioner). As hypothesized, illness/injury sensitivity was the best predictor of safety behavior regarding physical health, superior to anxiety sensitivity and general trait anxiety (Vancleef, Peters, \& de Jong, in press). In short, research has begun to demonstrate that the fundamental fear illness/injury sensitivity may be a vulnerability factor for negative pain appraisal and beliefs and avoidant pain behaviour in nonclinical populations. More research is needed to substantiate it role in chronic pain adjustment.

In contrast to a rather extensive search after negative predisposing factors, there has been relatively little research on protective factors for chronic pain and disability. Three potential resilience factors will be discussed here: optimism, hope, and benefit finding. Review of the literature suggests that optimism may be one of the most important personality traits in relation to adjustment to 
chronic pain. Dispositional optimism is defined as "the tendency to believe that one will generally experience good vs. bad outcomes in life" (Scheier \& Carver, 1985, p. 219) and is distinguishable from neuroticism and trait anxiety (Scheier, Carver, \& Bridges, 1994). In cross-sectional and prospective studies, optimism was found to be associated with better general health, adaptation to chronic disease and recovery after various surgical procedures (Scheier \& Carver, 1992). Also, optimism predicted ischemic pain tolerance and unpleasantness in patients with temporomandibular disorder (Costello et al., 2002).

Trait hope is a personality construct that is closely related to optimism (Snyder, Rand, \& Sigmond, 2005), and recently, at least, some research has begun to address its association with adjustment to pain. Using the cold-pressor test to induce experimental pain, Snyder, Berg, et al. (2005) found that high hope people experienced less pain and tolerated the pain stimulus longer than low hope people.

Only a few studies have been looking at the role of dispositional optimism or hope in adaptation to chronic pain. Novy, Nelson, Hetzel, Squitieri, and Kennington (1998) found that optimism was related to less catastrophizing and more use of active coping strategies in chronic pain patients. Affleck, Tennen, and Apter (2001) reported that dispositional optimism predicts pleasant daily mood in fibromyalgia but that it is not related to daily pain. Finally, in studying rheumatoid arthritis patients, Treharne, Kitas, Lyons, and Booth (2005) found that optimism was associated with less depression and higher life satisfaction and to less pain for patients in the early and intermediate stages of disease.

The main mechanism of the beneficial effect of optimism may be differences in coping behaviour between optimistic and pessimistic people (Garofalo, 2000). In general, pessimists turn to avoidant coping strategies and denial more often, whereas optimists use more problem-focused coping strategies. When problem-focused coping is not possible, they turn to coping strategies such as acceptance, use of humor and positive reframing of the situation (Garofalo, 2000; Scheier et al., 1994). Thus, it may not be the use of specific coping strategies but rather flexibility of coping that protects against disability and distress (Carver \& Scheier, 2005). Snyder, Rand, and Sigmond (2005) have described a similar pathway for hope, with people with low hope showing a tendency to catastrophize, whereas people with high hope seek means to encounter future challenges and show flexibility in finding alternative life goals when their original goals are blocked.

Although not a personality trait, another resilience factor in dealing with the problem of chronic pain receiving attention in recent years is benefit finding (Tennen \& Affleck, 2005). Some people are able to identify positive aspects of adverse life circumstances (e.g., that it made them more aware of their purpose in life). Benefit finding has been found to lead to less distress and superior psychological adjustment in a range of medical conditions and less activity limitations in rheumatoid arthritis (Tennen \& Affleck, 2005). A diary study in fibromyalgia patients indicated that benefit finding influenced mood but not pain intensity (Affleck \& Tennen, 1996). Clearly, more research on the role of these and other potential resilience factors for chronic pain (e.g., humor, sense of coherence) is needed.

\section{CBT and Chronic Pain}

As discussed earlier, the findings that cognitive factors play an important role in chronic pain has led to the development of CBT methods as a means of more effectively managing it. These CBT techniques proceed from the view that an individual's interpretation, evaluation, and beliefs about his or her health condition and coping repertoire, with respect to pain and disability, will affect the degree of emotional and physical disability associated with the pain condition (Sullivan, Feuerstein, Gatchel, Linton, \& Pransky, 2005). In a very influential early study, Morley, Eccleston, and Williams (1999) reported the results of their systematic review and meta-analysis of the existing randomized trials of CBT for chronic pain. Their findings concluded that such treatment is effective for a variety of chronic pain conditions. Again, the major goals of such treatment are to replace maladaptive patient cognitions and behaviors with more adaptive ones. Most recently, Linton and Nordin (2006) reported a 5-year follow-up of a randomized controlled trial of early CBT intervention for back pain. Results demonstrated that this intervention resulted in significantly less pain, produced more active and better quality of life, and resulted in better general health, relative to the comparison group. There were also significantly greater economic benefits associated with the CBT intervention group.

A recent study by Brox et al. (2003) was an exceptional randomized controlled trial that compared the relative efficacy of lumbar spinal fusion versus CBT for back-pain patients who had documented underlying pathophysiology. A total of 64 patients were randomized into one of these two treatments. At the 1-year follow-up, the "difference between the groups given lumbar instrumental fusion and cognitive intervention and exercise was neither clinically important nor significant" (p. 1920). Both groups displayed significant clinical improvement on a wide range of measures. These findings were similar to those of the Fairbank et al. (2005) research study, which reported outcomes at 2 years. Even more recently, Brox et al. (2006) conducted randomized clinical trial demonstrating the effectiveness of CBT with lumbar instrumental fusion patients who had chronic low back pain and who also had a previous surgery for disc herniation. Again, no differences in treatment efficacy were found. Finally, the following are a number of other studies documenting the efficacy of CBT: Astin, Beckner, Soeken, Hochberg, and Berman (2002); Keefe and Caldwell (1997); Bradley (2003); Burns, Kubilis, Bruehl, Harden, and Lofland (2003); E. Chen, Cole, and Kato (2004); Cutler et al. (1994); Spinhoven et al. (2004); Weydert, Ball, and Davis (2003); and Turner, Mancl, and Aaron (2006).

It should also be noted that the usage of the term cognitive behavioral therapy varies widely and may include self-instructions (e.g., distraction, imagery, motivational self-talk), relaxation or biofeedback, development of coping strategies (e.g., increasing assertiveness, minimizing of negative self-defeating thoughts), changing maladaptive beliefs about pain, and goal setting. A patient referred for CBT may be exposed to varying selections of these strategies. Finally, it should also be pointed out that these CBT techniques are embedded in more comprehensive pain management programs that also include functional restoration, pharmacotherapy, and general medical management. Evidence-based scientific data documenting the treatment- and cost-effectiveness 
of such comprehensive pain management programs for chronic nonmalignant pain patients has been recently well documented (Gatchel \& Okifuji, 2006).

\section{Summary and Conclusions}

The biopsychosocial approach is now widely accepted as the most heuristic perspective to the understanding and treatment of chronic pain disorders (Gatchel, 2004a, 2004b). The biopsychosocial model views physical illnesses such as pain as the result of the dynamic interaction among physiologic, psychological, and social factors, which perpetuates and may even worsen the clinical presentations. Each individual experiences pain uniquely, and a range of psychological and socioeconomic factors can interact with physical pathology to modulate a patient's report of symptoms and subsequent disability. As we pointed out, such a comprehensive conceptual model of the biopsychosocial interactive processes involved in pain can be quite complex. The goal of the present article was to provide a review of the major breakthroughs in recent years concerning the basic neuroscience processes of pain (the bio part of biopsychosocial), as well as the psychosocial factors.

A number of investigators have provided excellent overviews of biopsychosocial interactions and how social and behavioral factors can act on the brain to influence health, illness, and even death ( $\mathrm{S}$. Cohen \& Rodriguez, 1995; Gatchel, 2004a, 2004b; Ray, 2004). In the present article, we have discussed research that is starting to delineate the pathways involved in the complex interaction processes. For example, Melzack's neuromatrix model of pain (Melzack, 2001, 2005) emphasizes the importance of the HPA axis and stress system in pain. Chronic pain is a stressor that will tax the stress system. Prolonged activation of the stress regulation system will ultimately generate breakdowns of muscle, bone, and neural tissue that, in turn, will cause major pain and produce a vicious cycle of pain-stress-reactivity (Gatchel, 2004). One important measure of this pain-stress cycle is cortisol. Indeed, cortisol is the main hormonal product of the HPA axis in humans. Although increased cortisol secretions are considered an adaptive response of the organism when stressed (for purposes of energy mobilization), prolonged secretion can lead to negative effects such as muscle atrophy, impairment of growth and tissue repair, immune system suppression, and so forth. Melzack (2005) has suggested that cortisol can serve as a good marker of the degree of stress that should closely parallel the development of chronic pain. Gatchel, Garofalo, and Robinson (in press) have recently confirmed this relationship.

We also discussed the development of new technologies, such as brain imaging, that have provided novel insights into brain-pain mechanisms. This is also leading to potentially new effective methods for better managing pain. For example, a recent study by deCharms et al. (2005) addressed the following question: If a person is able to learn to directly control activation of localized regions within the brain associated with pain (e.g., the rostral anterior cingulate cortex, which is a region involved in pain perception and regulation), would that change the person's perception of pain? To test this, these investigators provided real-time fMRI to participants in order to guide their training. It was found that when subjects learned to control this activation, they were also able to control the perception of pain. When they voluntarily increased activation, there was a corresponding increase in the perception of pain in response to an applied noxious thermal stimulus; when they decreased activation, there was a corresponding decrease in pain. Such results clearly demonstrated that subjects can gain voluntary control over activation in a specific brain region (when provided appropriate training), indicating that direct control over the neurophysiological mechanisms that mediate pain may provide an important new route for treating illness and pain behavior.

Neuroscience research has also made major inroads into better understanding basic neural and biochemical mechanisms involved in pain processing. These mechanisms, in turn, have led to important clinical applications, such as the development of analgesic agents for managing chronic pain. This is further evidenced by the potentially common pathogenic mechanisms involved in chronic pain and the comorbid psychiatric disorders such as depression (Polatin, 1991). For example, both nociceptive and affective pathways coincide automatically. Furthermore, norepinephrine and serotonin-the two neurotransmitters most implicated in the pathophysiology of mood disorders-are also involved in the pain process.

Finally, the emergence of the biopsychosocial model of chronic pain has led to the development of the most heuristic approach to the management of chronic pain - the interdisciplinary pain management approach. As noted earlier, patients with chronic pain are at increased risk for emotional disorders (such as anxiety, depression, and anger), maladaptive cognitions (such as catastrophizing and poor coping skills), functional deficits and physical deconditioning (due to decreased physical activity and fear of reinjury), as well as basic nociceptive dysregulation. All of these aforementioned variables, in turn, are often interdependent so that one cannot simply treat one to the exclusion of the others. Interdisciplinary pain management embraces the fact that the comprehensive assessment-treatment of all these dimensions is needed in order to be effective. Such an approach has been demonstrated to be the most therapeutic and cost-effective means of managing the often recalcitrant chronic pain syndromes. There is usually not a documentable isomorphic relationship between a specific nociceptive event and pain. Instead, as we have reviewed, multiple other dimensions, involving emotion, cognition, and behavioral and brain processing (i.e., total biopsychosocial functioning) must be carefully considered in order to maximize the probability of treatment success. Future breakthroughs in the understanding of such biopsychosocial mechanisms will hopefully lead to even greater understandings in the areas of etiology, assessment, treatment, and prevention of chronic pain. The role of the genetic factors is also an especially promising new area of research that should provide even greater insights into etiological mechanisms of pain that may account for important individual differences in the pain experience and one's response to it.

\section{References}

Abbott, F. V., Franklin, K. B. J., \& Westbrook, R. F. (1995). The formalin test: Scoring properties of the first and second phases of the pain response in rats. Pain, 60, 91-102.

Abelli, L., Conte, B., Somma, V., Maggi, C. A., Giuliani, S., Geppetti, P., et al. (1988). The contribution of capsaicin-sensitive sensory nerves to xylene-induced visceral pain in conscious, freely moving rats. Naunyn Schmiedeberg's Archives of Pharmacology, 37, 545-551. 
Abelli, L., Conte, B., Somma, V., Maggi, C. A., Giuliani, S., \& Meli, A. (1989). A method for studying pain arising from the urinary bladder in conscious, freely-moving rats. Journal of Urology, 141, 148-151.

Affleck, G., \& Tennen, H. (1996). Construing benefits from adversity: Adaptational significance and dispositional underpinnings. Journal of Personality, 64, 899-922.

Affleck, g., Tennen, H., \& Apter, A. (2001). Optimism, pessimism, and daily life with chronic illness. In E. C. Chang (Ed.), Optimism \& pessimism: Implications for theory, research, and practice (pp. 147168). Washington, DC: American Psychological Association.

Aitken, P. G., Fayuk, D., Somjen, G. G., \& Turner, D. A. (1999). Use of intrinsic optical signals to monitor physiological changes in brain tissue slices. Methods, 18, 91-103.

Al-Chaer, E. D., Lawand, N. B., Westlund, K. N., \& Willis, W. D. (1996). Visceral nociceptive input into the ventral posterolateral nucleus of the thalamus: A new function for the dorsal column pathway. Journal of Neurophysiology, 76, 2661-2674.

Aley, K. O., Reichling, D. B., \& Levine, J. D. (1996). Vincristine hyperalgesia in the rat: A model of painful vincristine neuropathy in humans. Neuroscience, 73, 259-265.

Ali, Z., Ringkamp, M., Hartke, T. V., Chien, H. F., Flavahan, N. A., Campbell, J. N., et al. (1999). Uninjured C-fiber nociceptors develop spontaneous activity and alpha- adrenergic sensitivity following L6 spinal nerve ligation in monkey. Journal of Neurophysiology, 81, 455466.

Alivisatos, A. P., Gu, W., \& Larabell, C. (2005). Quantum dots as cellular probes. Annual Review Biomedical Engineering, 7, 55-76.

American Academy of Pain Management. (2003, May). Proceedings of the 2003 Annual Meeting of the American Chronic Pain Association, Denver, $\mathrm{CO}$.

Andrew, R. D., Jarvis, C. R., \& Obeidat, A. S. (1999). Potential sources of intrinsic optical signals imaged in live brain slices. Methods, 18, 185196.

Apfel, S. C., Lipton, R. B., Arezzo, J. C., \& Kessler, J. A. (1991). Nerve growth factor prevents toxic neuropathy in mice. Annals of Neurology, 29, 87-90.

Apkarian, A. V., Darbar, A., Krauss, B. R., Gelnar, P. A., \& Szeverenyi, N. M. (1999). Differentiating cortical areas related to pain perception from stimulus identification: Temporal analysis of fMRI activity. Journal of Neurophysiology, 81, 2956-2963.

Apkarian, A. V., Stea, R. A., Manglos, S. H., Szeverenyi, N. M., King, R. B., \& Thomas, F. D. (1992). Persistent pain inhibits contralateral somatosensory cortical activity in humans. Neuroscience Letters, 140, 141-147.

Arena, J., Blanchard, E., \& Andrasik, F. (1984). The role of affect in the etiology of chronic headache. Journal of Psychosomatic Research, 28, $79-86$.

Aristotle. (1941). Ethica nicomachea (W. D. Ross, Trans.). In R. McKeon (Ed.), The basic works of Aristotle (pp. 128-146). New York: Random House.

Arntz, A., \& Claassens, L. (2004). The meaning of pain influences its experienced intensity. Pain, 109, 20-25.

Arntz, A., \& Schmidt, A. J. M. (1989). Perceived control and the experience of pain. In A. Steptoe \& A. Appels (Eds.), Stress, personal control and health (pp. 131-162). Oxford, England: Wiley.

Asai, T., Kusudo, K., Ikeda, H., \& Murase, K. (2002). Intrinsic optical signals in the dorsal horn of rat spinal cord slices elicited by brief repetitive stimulation. European Journal of Neuroscience, 15, 17371746.

Asghari, A., \& Nicholas, M. K. (2001). Pain self-efficacy beliefs and pain behaviour. A prospective study. Pain, 94, 85-100.

Asmundson, G. J. G. (1999). Anxiety sensitivity and chronic pain: Empirical findings, clinical implications, and future directions. In S. Taylor
(Ed.), Anxiety sensitivity: Theory, research, and treatment of the fear of anxiety (pp. 269-286). Mahwah, NJ: Erlbaum.

Asmundson, G. J., Carleton, R. N., \& Ekong, J. (2005). Dot-probe evaluation of selective attentional processing of pain cues in patients with chronic headaches. Pain, 114, 250-256.

Asmundson, G. J. G., Norton, P. J., \& Norton, G. R. (1999). Beyond pain: The role of fear and avoidance in chronicity. Clinical Psychology Review, 19, 97-119.

Asmundson, G. J., Norton, P. J., \& Vlaeyen, J. W. S. (2004). Fearavoidance models of chronic pain: An overview. In G. J. Asmundson, J. W. S. Vlaeyen, \& G. Crombez (Eds.), Understanding and treating fear of pain (pp. 3-24). Oxford, England: Oxford University Press.

Asmundson, G. J., \& Taylor, S. (1996). Role of anxiety sensitivity in pain-related fear and avoidance. Journal of Behavioral Medicine, 19, 577-586.

Asmundson, G. J. G., Wright, K. D., \& Hadjistavropoulos, H. D. (2000). Anxiety sensitivity and disabling chronic health conditions: State of the art and future directions. Scandinavian Journal of Behaviour Therapy, $22,100-117$

Astin, J. A., Beckner, W., Soeken, K., Hochberg, M. C., \& Berman, B. (2002). Psychological interventions for rheumatoid arthritis: A metaanalysis of randomized controlled trials. Arthritis and Rheumatology, 47, 291-302.

Atkinson, J. H., Slater, M. A., Patterson, T. L., Gant, I., \& Garfin, S. R. (1991). Prevalence, onset, and risk of psychiatric disorders in men with chronic low back pain: A controlled study. Pain, 45, 111-121.

Authier, N., Gillet, J. P., Fialip, J., Eschalier, A., \& Coudore, F. (2000). Description of a short-term Taxol-induced nociceptive neuropathy in rats. Brain Research, 887, 239-249.

Averill, J. (1983). Studies on anger and aggression: Implications for theories of emotion. American Psychologist, 38, 1145-1160.

Aziz, Q. (1997). Identification of human brain loci processing esophageal sensation using positron emission tomography. Gastroenterology, 113, $50-59$.

Baba, H., Kohno, T., Okamoto, M., Goldstein, P. A., Shimoji, K., \& Yoshimura, M. (1998). Muscarinic facilitation of GABA release in substantia gelatinosa of the rat spinal dorsal horn. Journal of Physiology (London), 508, 83-93.

Baccaglini, P. I., \& Hogan, P. G. (1983). Some rat sensory neurons in culture express characteristics of differentiated pain sensory cells. Proceedings of the National Academy of Sciences, USA, 80, 594-598.

Balderson, B. H. K., Lin, E. H. B., \& Von Korff, M. (2004). The management of pain-related fear in primary care. In G. J. Asmundson, J. W. S. Vlaeyen, \& G. Crombez (Eds.), Understanding and treating fear of pain (pp. 267-292). Oxford, England: Oxford University Press.

Ballou, B., Lagerholm, B. C., Ernst, L. A., Bruchez, M. P., \& Waggoner, A. S. (2004). Noninvasive imaging of quantum dots in mice. Bioconjugate Chemistry, 15, 79-86.

Bandura, A. (1977). Self-efficacy: Toward a unifying theory of behavioral change. Psychological Review, 84, 191-215.

Bandura, A., O'Leary, A., Taylor, C. B., Gauthier, J., \& Gossard, D. (1987). Perceived self-efficacy and pain control: Opioid and nonopioid mechanisms. Journal of Personality and Social Psychology, 53, 563571.

Banks, S. M., \& Kerns, R. D. (1996). Explaining high rates of depression in chronic pain: A diathesis-stress framework. Psychological Bulletin, $119,95-110$.

Bao, J., Li, J. J., \& Perl, E. R. (1998). Differences in Ca2+ channels governing generation of miniature and evoked excitatory synaptic currents in spinal laminae I and II. Journal of Neuroscience, 18, 87408750.

Barone, R., Lempereur, L., Anastasi, M., Parano, E., \& Pavone, P. (2005). Congenital insensitivity to pain with Anhidrosis (NTRK1 mutation) and 
early onset renal disease: Clinical report on three sibs with a 25 -year follow-up in one of them. Neuropediatrics, 36, 270-273.

Barron, D. H., \& Matthews, B. H. C. (1938). The interpretation of potential changes in the spinal cord. Journal of Physiology, 92, 276-321.

Basbaum, A. I., \& Wall, P. D. (1976). Chronic changes in the response of cells in adult cat dorsal horn following partial deafferentation: The appearance of responding cells in a previously non-responsive region. Brain Research, 116, 181-204.

Basso, D. M., Beattie, M. S., \& Bresnahan, J. C. (1995). A sensitive and reliable locomotor rating scale for open field testing in rats. Journal of Neurotrauma, 12, 1-21.

Beall, J. E., Applebaum, A. E., Foreman, R. D., \& Willis, W. D. (1977). Spinal cord potentials evoked by cutaneous afferents in the monkey. Journal of Neurophysiology, 40, 199-211.

Becerra, L. R., Breiter, H. C., Stojanovic, M., Fishman, S., Edwards, A., Comite, A. R., et al. (1999). Human brain activation under controlled thermal stimulation and habituation to noxious heat: An fMRI study. Magnetic Resonance Medicine, 41, 1044-1057.

Beecher, H. K. (1959). Measurement of subjective responses: Quantitative effects of drugs. New York: Oxford University Press.

Belliveau, J. W., Kennedy, D. N., Jr., McKinstry, R. C., Buchbinder, B. R., Weisskoff, R. M., Cohen, M. S., et al. (1991, November 1). Functional mapping of the human visual cortex by magnetic resonance imaging. Science, 254, 716-719.

Bennett, G. J., Hayashi, H., Abdelmoumene, M., \& Dubner, R. (1979). Physiological properties of stalked cells of the substantia gelatinosa intracellularly stained with horseradish peroxidase. Brain Research, 23, 285-289.

Bennett, G. J., \& Xie, Y. K. (1988). A peripheral mononeuropathy in rat that produces disorders of pain sensation like those seen in man. Pain, 33, 87-107.

Berkley, K. J., Cason, A., Jacobs, H., Bradshaw, H., \& Wood, E. (2001). Vaginal hyperalgesia in a rat model of endometriosis. Neuroscience Letters, 306, 185-188.

Berkowitz, L., \& Thomas, P. (1987). Pain expectation, negative affect, and angry aggression. Motivation and Emotion, 11, 183-193.

Berwick, J., Johnston, D., Jones, M., Martindale, J., Redgrave, P., McLoughlin, N., et al. (2005). Neurovascular coupling investigated with two-dimensional optical imaging spectroscopy in rat whisker barrel cortex. European Journal of Neuroscience, 22, 1655-1666.

Bevan, S., \& Yeats, J. (1991). Protons activate a cation conductance in a sub-population of rat dorsal root ganglion neurones. Journal of Physiology (London), 433, 145-161.

Binkofski, F., Schnitzler, A., Enck, P., Frieling, T., Posse, S., Seitz, R. J., et al. (1998). Somatic and limbic cortex activation in esophageal distention: A functional magnetic resonance imaging study. Annals of Neurology, 44, 811-815.

Blasdel, G. G. (1989). Visualization of neuronal activity in monkey striate cortex. Annual Review of Physiology, 51, 561-581.

Blasdel, G. G. (1992). Orientation selectivity, preference, and continuity in monkey striate cortex. Journal of Neuroscience, 12, 3139-3161.

Blyth, F. M., March, L. M., Brnabic, A. J., Jorm, L. R., Williamson, M., \& Cousins, M. J. (2001). Chronic pain in Australia: A prevalence study. Pain, 89, 127-134.

Bodnar, R. J., Simone, D. A., Kordower, J. H., Kirchgessner, A. L., \& Nilaver, G. (1983). Capsaicin treatment and stress-induced analgesia. Pharmacology, Biochemistry, \& Behavior, 18, 65-71.

Bodzioch, M., Lapicka, K., Aslanidis, C., Kacinski, M., \& Schmitz, G. (2001). Two novel mutant alleles of the gene encoding neurotrophic tyrosine kinase receptor type 1 (NTRK1) in a patient with congenital insensitivity to pain with anhidrosis: A splice junction mutation in intron 5 and cluster of four mutations in exon 15. Human Mutation, 17, 72.

Boersma, K., \& Linton, S. J. (2005). Screening to identify patients at risk:
Profiles of psychological risk factors for early intervention. Clinical Journal of Pain, 21, 38-43.

Boersma, K., \& Linton, S. J. (2006). Psychological processes underlying the development of a chronic pain problem: A prospective study of the relationship between profiles of psychological variables in the fearavoidance model in disability. Clinical Journal of Pain, 22, 160-166.

Boersma, K., Linton, S., Overmeer, T., Jansson, M., Vlaeyen, J., \& de Jong, J. (2004). Lowering fear-avoidance and enhancing function through exposure in vivo: A multiple baseline study across six patients with back pain. Pain, 108, 8-16.

Boivie, J. (1990). Central pain. In P. D. Wall \& R. Melzack (Eds.), Textbook of pain (4th ed., pp. 879-914). New York: Churchill Livingstone.

Boivie, J., Leijon, G., \& Johansson, I. (1989). Central post-stroke pain: A study of the mechanisms through analyses of the sensory abnormalities. Pain, 37, 173-185.

Boyle, F. M., Wheeler, H. R., \& Shenfield, G. M. (1999). Amelioration of experimental cisplatin and paclitaxel neuropathy with glutamate. Journal of Neurooncology, 41, 107-116.

Bradley, L. A. (2003). Cognitive-behavioral therapy interventions for pain associated with chronic illness. Seminars in Pain Medicine, 1, 44-54.

Braha, R., \& Catchlove, R. (1985). Pain and anger: Inadequate expression in chronic pain patients. Pain Clinic, 1, 125-129.

Brinkhus, H. B., \& Zimmerman, M. (1983). Characteristics of spinal dorsal horn neurons after partial chronic deafferentation by dorsal root transection. Pain, 15, 221-236.

Brock, J. A., McLachlan, E. M., \& Belmonte, C. (1998). Tetrodotoxinresistant impulses in single nociceptor nerve terminals in guinea-pig cornea. Journal of Physiology, 512(Pt. 1), 211-217.

Brown, G. K. (1990). A causal analysis of chronic pain and depression. Journal of Abnormal Psychology, 99, 127-137.

Brox, J. I., Reikeras, O., Nygaard, O., Sorenson, R., Indahl, A., Holm, I., et al. (2006). Lumbar instrumented fusion compared with chronic intervention and exercises in patients with chronic back pain after previous surgery for disc herniation: A prospective randomized controlled trial. Pain, 122, 145-155.

Brox, J. I., Sorenson, R., Friis, P. T., Nyegaard, O., Indahl, A., Keller, A., et al. (2003). A randomized clinical trial of lumbar instrumented fusion and cognitive intervention in exercises in patients with chronic low back pain and disc degeneration. Spine, 28, 1913-1921.

Buchbinder, R., \& Jolley, D. (2005). Effects of a media campaign on back beliefs is sustained 3 years after its cessation. Spine, 30, 1323-1330.

Buchbinder, R., Jolley, D., \& Wyatt, M. (2001). Population based intervention to change back pain beliefs and disability: Three part evaluation. British Medical Journal, 322, 1516-1520.

Burns, J. W. (1997). Anger management style and hostility: Predicting symptom-specific physiological reactivity among chronic low back pain patients. Journal of Behavioral Medicine, 20, 505-522.

Burns, J. W., Johnson, B. J., Devine, J., Mahoney, N., \& Pawl, R. (1998). Anger management style and the prediction of treatment outcome among male and female chronic pain patients. Behaviour Research and Therapy, 36, 1055-1062.

Burns, J. W., Kubilus, A., Bruehl, S., Harden, R. N., \& Lofland, K. (2003). Do changes in cognitive factors influence outcome following multidisciplinary treatment for chronic pain? A cross-lagged panel analysis. Journal of Consulting and Clinical Psychology, 71, 81-91.

Burns, J. W., Wiegner, S., Derleth, M., Kiselica, K., \& Pawl, R. (1996). Linking symptom-specific physiological reactivity to pain severity in chronic low back pain patients: A test of mediation and moderation models. Health Psychology, 16, 319-326.

Burton, A. K., Waddell, G., Tillotson, K. M., \& Summerton, N. (1999). Information and advice to patients with back pain can have a positive effect. A randomized controlled trial of a novel educational booklet in primary care. Spine, 24, 2484-2491. 
Butler, S. H., Godefroy, F., Besson, J.-M., \& Weil-Fugazza, J. (1992). A limited arthritic model for chronic pain studies in the rat. Pain, 48, 73-81.

Cacioppo, J. T., Bernston, G. G., Klein, D. J., \& Poehlmann, K. M. (1997). The psychophysiology of emotion across the lifespan. Annual Review of Gerontology and Geriatrics, 17, 27-74.

Canavero, S., Pagni, C. A., Castellano, G., Bonicalzi, V., Bello, M., Duca, S., et al. (1993). The role of cortex in central pain syndromes: Preliminary results of a long-term technetium-99 hexamethylpropyleneamineoxime single photon emission computed tomography study. Neurosurgery, 32, 185-189.

Carleton, R. N., Asmundson, G. J. G., \& Taylor, S. (2005). Fear of physical harm: Factor structure and psychometric properties of the illness/injury sensitivity index. Journal of Psychopathology and Behavioral Assessment, 27, 235-241.

Carlton, S. M., \& Coggeshall, R. E. (1997). Immunohistochemical localization of 5-HT2A receptors in peripheral sensory axons in rat glabrous skin. Brain Research, 763, 271-275.

Carlton, S. M., Lekan, H. A., Kim, S. H., \& Chung, J. M. (1994). Behavioral manifestations of an experimental model for peripheral neuropathy produced by spinal nerve ligation in the primate. Pain, 56, 155-166

Carlton, S. M., Zhou, S., \& Coggeshall, R. E. (1999). Peripheral GABA(A) receptors: Evidence for peripheral primary afferent depolarization. Neuroscience, 93, 713-722.

Carver, C. S., \& Scheier, M. F. (2005). Optimism. In C. R. Snyder \& S. J. Lopez (Eds.), Handbook of positive psychology (pp. 231-243). Oxford, England: Oxford University Press.

Casey, K. L. (1999). Forebrain mechanisms of nociception and pain: Analysis through imaging. Proceedings of the National Academy of Sciences, USA, 96, 7668-7674.

Casey, K. L., Minoshima, S., Berger, K. L., Koeppe, R. A., Morrow, T. J., \& Frey, K. A. (1994). Positron emission tomographic analysis of cerebral structures activated specifically by repetitive noxious heat stimuli. Journal of Neurophysiology, 71, 802-807.

Casey, K. L., Minoshima, S., Morrow, T. J., \& Koeppe, R. A. (1996). Comparison of human cerebral activation pattern during cutaneous warmth, heat pain, and deep cold pain. Journal of Neurophysiology, 76, 571-581.

Cavaletti, G., Tredici, G., Braga, M., \& Tazzari, S. (1995). Experimental peripheral neuropathy induced in adult rats by repeated intraperitoneal administration of taxol. Experimental Neurology, 133, 64-72.

Chacur, M., Milligan, E. D., Gazda, L. S., Armstrong, C., Wang, H., Tracey, K. J., et al. (2001). A new model of sciatic inflammatory neuritis (SIN): Induction of unilateral and bilateral mechanical allodynia following acute unilateral peri-sciatic immune activation in rats. Pain, 94, 231-244

Chatrian, G. E., Farrell, D. F., Canfield, R. C., \& Lettich, E. (1975). Congenital insensitivity to noxious stimuli. Archives of Neurology, 32, 141-145.

Chen, E., Cole, S. W., \& Kato, P. M. (2004). A review of empirically supported psychosocial interventions for pain and adherence outcomes in sickle cell disease. Journal of Pediatric Psychology, 29, 197-209.

Chen, J., Li, H., Luo, C., Li, Z., \& Zheng, J. (1999). Involvement of peripheral NMDA and non-NMDA receptors in development of persistent firing of spinal wide-dynamic-range neurons induced by subcutaneous bee venom injection in the cat. Brain Research, 844, 98-105.

Chen, J., Luo, C., \& Li, H. L. (1998). The contribution of spinal neuronal changes to development of prolonged, tonic nociceptive responses of the cat induced by subcutaneous bee venom injection. European Journal of Pain, 2, 359-376.

Chen, X., Belmonte, C., \& Rang, H. P. (1997). Capsaicin and carbon dioxide act by distinct mechanisms on sensory nerve terminals in the cat cornea. Pain, 70, 23-29.
Chen, X., Gallar, J., \& Belmonte, C. (1997). Reduction by antiinflammatory drugs of the response of corneal sensory nerve fibers to chemical irritation. Investigational Ophthalmology \& Visual Science, 38, 1944 1953.

Christensen, B. N., \& Perl, E. R. (1970). Spinal neurons specifically excited by noxious or thermal stimuli: Marginal zone of the dorsal horn. Journal of Neurophysiology, 33, 293-307.

Christensen, M. D., Everhart, A. W., Pickelman, J. T., \& Hulsebosch, C. E. (1996). Mechanical and thermal allodynia in chronic central pain following spinal cord injury. Pain, 68, 97-107.

Christensen, M. D., \& Hulsebosch, C. E. (1997a). Chronic central pain after spinal cord injury. Journal of Neurotrauma, 14, 517-537.

Christensen, M. D., \& Hulsebosch, C. E. (1997b). Spinal cord injury and anti-NGF treatment results in changes in CGRP density and distribution in the dorsal horn in the rat. Expean Neurology, 147, 463-475.

Chrousos, G. P., \& Gold, P. W. (1992). The concepts of stress system disorders: Overview of behavioral and physical homeostasis. Journal of the American Medical Association, 267, 1244-1252.

Cipher, D. J., \& Fernandez, E. (1997). Expectancy variables predicting tolerance and avoidance of pain in chronic pain patients. Behaviour Research and Therapy, 35, 437-444.

Clark, D., Hughes, J., \& Gasser, H. S. (1935). Afferent function in the group of nerve fibres of slowest conduction velocity. American Journal of Physiology, 114, 69-76.

Cliffer, K. D., Siuciak, J. A., Carson, S. R., Radley, H. E., Park, J. S., Lewis, D. R., et al. (1998). Physiological characterization of Taxolinduced large-fiber sensory neuropathy in the rat. Annals of Neurology, $43,46-55$.

Coderre, T. J., Fundytus, M. E., McKenna, J. E., Dalal, S., \& Melzack, R. (1993). The formalin test: A validation of the weighted-scores method of behavioural pain rating. Pain, 54, 43-50.

Coderre, T. J., \& Melzack, R. (1992a). The contribution of excitatory amino acids to central sensitization and persistent nociception after formalin-induced tissue injury. Journal of Neuroscience, 12, 3665-3670.

Coderre, T. J., \& Melzack, R. (1992b). The role of NMDA receptoroperated calcium channels in persistent nociception after formalininduced tissue injury. Journal of Neuroscience, 12, 3671-3675.

Coderre, T. J., Vaccarino, A. L., \& Melzack, R. (1990). Central nervous system plasticity in the tonic pain response to subcutaneous formalin injection. Brain Research, 535, 155-158.

Coggeshall, R. E. \& Carlton, S. M. (1998). Ultrastructural analysis of NMDA, AMPA, and kainate receptors on unmyelinated and myelinated axons in the periphery. Journal of Comparative Neurology, 391, 78-86.

Coghill, R. C., Sang, C. N., Maisog, J. M., \& Iadarola, M. J. (1999). Pain intensity processing within the human brain: A bilateral, distributed mechanism. Journal of Neurophysiology, 82, 1934-1943.

Coghill, R. C., Talbot, J. D., Evans, A. C., Meyer, E., Gjedde, A., Bushnell, M. C., et al. (1994). Distributed processing of pain and vibration by the human brain. Journal of Neuroscience, 14, 4095-4108.

Cohen, L. B., Keynes, R. D., \& Hille, B. (1968, May 4). Light scattering and birefringence changes during nerve activity. Nature, 218, 438-441.

Cohen, S., \& Rodriguez, M. S. (1995). Pathways linking affective disturbances and physical disorders. Health Psychology, 14, 371-393.

Collins, W. F., Nulsen, F. E., \& Randt, C. T. (1960). Relation of peripheral nerve fiber size and sensation in man. Archives of Neurology, 3, 381385 .

Corbishley, M., Hendrickson, R., Beutler, L., \& Engle, D. (1990). Behavior, affect, and cognition among psychogenic pain patients in group expressive psychotherapy. Journal of Pain and Symptom Management, $5,241-248$.

Costello, N. L., Bragdon, E. E., Light, K. C., Sigurdsson, A., Bunting, S., Grewen, K., et al. (2002). Temporomandibular disorder and optimism: Relationships to ischemic pain sensitivity and interleukin-6. Pain, 100, 99-110. 
Courteix, C., Bardin, M., Chantelauze, C., Lavarenne, J., \& Eschalier, A. (1994). Study of the sensitivity of the diabetes-induced pain model in rats to a range of analgesics. Pain, 57, 153-160.

Courteix, C., Eschalier, A., \& Lavarenne, J. (1993). Streptozocin-induced diabetic rats: Behavioural evidence for a model of chronic pain. Pain, $53,81-88$

Covey, E., Kauer, J. A., \& Casseday, J. H. (1996). Whole-cell patch-clamp recording reveals subthreshold sound-evoked postsynaptic currents in the inferior colliculus of awake bats. Journal of Neuroscience, 16, 3009-3018.

Craig, A. D., Reiman, E. M., Evans, A., \& Bushnell, M. C. (1996, November 21). Functional imaging of an illusion of pain. Nature, 384, $258-260$.

Crombez, G., Eccleston, C., Van den Broeck, A., Van Houdenhove, B., \& Goubert, L. (2002). The effects of catastrophic thinking about pain on attentional interference by pain: No mediation of negative affectivity in healthy volunteers and in patients with low back pain. Pain Research and Management, 7, 31-39.

Crombez, G., Vlaeyen, J. W., \& Heuts, P. H. (1999). Pain-related fear is more disabling than pain itself: Evidence on the role of pain-related fear in chronic back pain disability. Pain, 80, 329-339.

Crowley, C., Spencer, S. D., Nishimura, M. C., Chen, K. S., Pitts-Meek, S., Armanini, M. P. et al. (1994). Mice lacking nerve growth factor display perinatal loss of sensory and sympathetic neurons yet develop basal forebrain cholinergic neurons. Cell, 76, 1001-1011.

Curtiss, G., Kinder, B., Kalichman, S., \& Spana, R. (1988). Affective differences among subgroups of chronic pain patients. Anxiety Research, $1,65-73$.

Cutler, R. B., Fishbain, D. A., Rosomoff, H. L., Abdel-Moty, E., Khalil, T. M., Rosomoff, R. S. (1994). Does nonsurgical pain center treatment of chronic pain return patients to work? A review and meta-analysis of the literature. Spine, 19, 643-652.

Czeh, G., Kudo, N., \& Kuno, M. (1977). Membrane properties and conduction velocity in sensory neurones following central or peripheral axotomy. Journal of Physiology (London), 270, 165-180.

Davis, K. D., Kwan, C. L., Crawley, A. P., \& Mikulis, D. J. (1998). Functional MRI study of thalamic and cortical activations evoked by cutaneous heat, cold, and tactile stimuli. Journal of Neurophysiology, 80, 1533-1546.

Davis, K. D., Taub, E., Duffner, F., Lozano, A. M., Tasker, R. R., Houle, S. et al. (2000). Activation of the anterior cingulate cortex by thalamic stimulation in patients with chronic pain: A positron emission tomography study. Journal of Neurosurgery, 92, 64-69.

Davis, K. D., Taylor, S. J., Crawley, A. P., Wood, M. L., \& Mikulis, D. J. (1997). Functional MRI of pain- and attention-related activations in the human cingulate cortex. Journal of Neurophysiology, 77, 3370-3380.

Davis, K. D., Wood, M. L., Crawley, A. P., \& Mikulis, D. J. (1995). fMRI of human somatosensory and cingulate cortex during painful electrical nerve stimulation. NeuroReport, 7, 321-325.

deCharms, R. C., Maeda, F., Glover, G. H., Ludlow, D., Pauly, J. M., Soneji, D., et al. (2005). Control over brain activation and pain learned by using real-time functional MRI. Neuroscience, 102, 18626-18631.

De Felipe, C., Herrero, J. F., O'Brien, J. A., Palmer, J. A., Doyle, C. A., Smith, A. J. et al. (1998, March 26). Altered nociception, analgesia and aggression in mice lacking the receptor for substance P. Nature, 392, 394-397.

DeGroot, K. I., Boeke, S., van den Berge, H. J., Duivenvoorden, H. J., Bonke, B., \& Passchier, J. (1997). Assessing short- and long-term recovery from lumbar surgery with pre-operative biographical, medical and psychological variables. British Journal of Health Psychology, 2, 229-243.

Dehen, H., Willer, J. C., Boureau, F., \& Cambier, J. (1977, August 6). Congenital insensitivity to pain, and endogenous morphine-like substances. Lancet, 2, 293-294.
Dehen, H., Willer, J. C., Prier, S., Boureau, F., \& Cambier, J. (1978). Congenital insensitivity to pain and the morphine-like analgesic system. Pain, 5, 351-358.

de Jong, J. R., Vlaeyen, J. W. S., Onghena, P., Cuypers, C., den Hollander, M., \& Ruijgrok, J. (2005). Reduction of pain-related fear in complex regional pain syndrome type I: The application of graded exposure in vivo. Pain, 116, 264-275.

de Jong, J. R., Vlaeyen, J. W. S., Onghena, P., Goossens, M. E., Geilen, M., \& Mulder, H. (2005). Fear of movement/(re)injury in chronic low back pain: Education or exposure in vivo as mediator to fear reduction? Clinical Journal of Pain, 21, 9-17.

de Koning, P., Neijt, J. P., Jennekens, F. G., \& Gispen, W. H. (1987a). Evaluation of cis-diamminedichloroplatinum (II) (cisplatin) neurotoxicity in rats. Toxicology \& Applied Pharmacology, 89, 81-87.

de Koning, P., Neijt, J. P., Jennekens, F. G., \& Gispen, W. H. (1987b). Org. 2766 protects from cisplatin-induced neurotoxicity in rats. Experimental Neurology, 97, 746-750.

DeLeo, J. A., Coombs, D. W., Willenbring, S., Colburn, R. W., Fromm, C., Wagner, R., et al. (1994). Characterization of a neuropathic pain model: Sciatic cryoneurolysis in the rat. Pain, 56, 9-16.

Derbyshire, S. W., Jones, A. K., Gyulai, F., Clark, S., Townsend, D., \& Firestone, L. L. (1997). Pain processing during three levels of noxious stimulation produces differential patterns of central activity. Pain, 73, 431-445.

Dersh, J., Gatchel, R. J., Mayer, T. G., Polatin, P. B., \& Temple, O. W. (2006). Prevalence of psychiatric disorders in patients with chronic disabling occupational spinal disorders. Spine, 31, 1156-1162.

Derwin, K. A., Glover, R. A., \& Wojtys, E. M. (1994). Nociceptive role of substance-P in the knee joint of a patient with congenital insensitivity to pain. Journal of Pediatric Orthopedics, 14, 258-262.

Devor, M., \& Wall, P. D. (1981a). Effect of peripheral nerve injury on receptive fields of cells in the cat spinal cord. Journal of Comparative Neurology, 199, 277-291.

Devor, M., \& Wall, P. D. (1981b). Plasticity in the spinal cord sensory map following peripheral nerve injury in rats. Journal of Neuroscience, 1 , 679-684.

DeYoe, E. A., Bandettini, P., Neitz, J., Miller, D., \& Winans, P. (1994). Functional magnetic resonance imaging (FMRI) of the human brain. Journal of Neuroscience Methods, 54, 171-187.

Diatchenko, L., Slade, G. D., Nackley, A. G., Bhalang, K., Sigurdsson, A., Belfer, I., et al. (2005). Genetic basis for individual variations in pain perception and the development of a chronic pain condition. Human Molecular Genetics, 14, 135-143.

Dickenson, A. H., \& Sullivan, A. F. (1987). Subcutaneous formalininduced activity of dorsal horn neurons in the rat: Differential response to an intrathecal opiate administered pre- and post-formalin. Pain, 30, $349-360$.

Dina, O. A., Chen, X., Reichling, D., \& Levine, J. D. (2001). Role of protein kinase Cepsilon and protein kinase: A in a model of paclitaxelinduced painful peripheral neuropathy in the rat. Neuroscience, 108, 507-515.

Di Piero, V., Ferracuti, S., Sabatini, U., Pantano, P., Cruccu, G., \& Lenzi, G. L. (1994). A cerebral blood flow study on tonic pain activation in man. Pain, 56, 167-173.

Di Piero, V., Fiacco, F., Tombari, D., \& Pantano, P. (1997). Tonic pain: A SPET study in normal subjects and cluster headache patients. Pain, 70, 185-191.

Di Piero, V., Pantano, P., Ricci, M., \& Lenzi, G. L. (1993). Motor activation by single-photon emission computed tomography. A comparison of xenon-133 and technetium-99m HM-PAO "split-dose" methods. Journal of Neuroimaging, 3, 103-108.

Disbrow, E., Buonocore, M., Antognini, J., Carstens, E., \& Rowley, H. A. (1998). Somatosensory cortex: A comparison of the response to noxious 
thermal, mechanical, and electrical stimuli using functional magnetic resonance imaging. Human Brain Mapping, 6, 150-159.

Djouhri, L., Bleazard, L., \& Lawson, S. N. (1998). Association of somatic action potential shape with sensory receptive properties in guinea-pig dorsal root ganglion neurones. Journal of Physiology (London), 513, 857-872.

Djouhri, L., \& Lawson, S. N. (1999). Changes in somatic action potential shape in guinea-pig nociceptive primary afferent neurones during inflammation in vivo. Journal of Physiology (London), 520, 565-576.

Dohnke, B., Knauper, B., \& Muller Fahrnow, W. (2005). Perceived selfefficacy gained from, and health effects of, a rehabilitation program after hip joint replacement. Arthritis and Rheumatism, 53, 585-592.

Dolce, J. J., Doleys, D. M., Raczynski, J. M., Lossie, J., Poole, L., \& Smith, M. (1986). The role of self-efficacy expectancies in the prediction of pain tolerance. Pain, 27, 261-272.

Donaldson, D. I. (2004). Parsing brain activity with fMRI and mixed designs: What kind of a state is neuroimaging in? Trends in Neuroscience, 27, 442-444.

Donaldson, L. F., Seckl, J. R., \& McQueen, D. S. (1993). A discrete adjuvant-induced monoarthritis in the rat: Effects of adjuvant dose. Journal of Neuroscience Methods, 49, 5-10.

Drummond, H. A., Abboud, F. M., \& Welsh, M. J. (2000). Localization of beta and gamma subunits of ENaC in sensory nerve endings in the rat foot pad. Brain Research, 884, 1-12.

Drummond, H. A., Welsh, M. J., \& Abboud, F. M. (2001). ENaC subunits are molecular components of the arterial baroreceptor complex. Annals of the New York Academy of Science, 940, 42-47.

Dubuisson, D., \& Dennis, S. G. (1977). The formalin test: A quantitative study of the analgesic effects of morphine, meperidine, and brain stem stimulation in rats and cats. Pain, 4, 161-174.

Duckro, P. N., Chibnall, J. T., \& Tomazic, T. J. (1995). Anger, depression, and disability: A path analysis of relationships in a sample of chronic posttraumatic headache patients. Headache, 35, 7-9.

Duncan, G. H., Kupers, R. C., Marchand, S., Villemure, J. G., Gybels, J. M., \& Bushnell, M. C. (1998). Stimulation of human thalamus for pain relief: Possible modulatory circuits revealed by positron emission tomography. Journal of Neurophysiology, 80, 3326-3330.

Dworkin, R. H., Hartstein, G., Rosner, H., Walther, R. R., Sweeney, E. W., \& Brand, L. (1992). A high-risk method of studying psychosocial antecedents of chronic pain: The prospective investigation of herpes zoster. Journal of Abnormal Psychology, 101, 200-205.

Dyck, P. J., Mellinger, J. F., Reagan, T. J., Horowitz, S. J., McDonald, J. W., Litchy, W. J. et al. (1983). Not "indifference to pain" but varieties of hereditary sensory and autonomic neuropathy. Brain, 106, 373-390.

Eccles, J. C. (1964). Presynaptic inhibition in the spinal cord. In J. C. Eccles \& J. P. Schade (Eds.), Progress in brain research, physiology of spinal neurones (pp. 65-89). Amsterdam: Elsevier.

Eccles, J. C. \& Krnjevic, K. (1959). Potential changes recorded inside primary afferent fibres within the spinal cord. Journal of Physiology, 149, 250-273.

Eccles, J. C., Magni, F., \& Willis, W. D. (1963). Depolarization of central terminals of group I afferent fibres from muscle. Journal of Physiology, 160, 62-93.

Eccles, J. C., Schmidt, R. F., \& Willis, W. D. (1963). Depolarization of the central terminals of cutaneous afferent fibers. Journal of Neurophysiology, 26, 646-661.

Ehde, D. M., \& Jensen, M. P. (2004). Feasability of a cognitive restructuring intervention for treatment of chronic pain in persons with disabilities. Rehabilitation Psychology, 49, 254-258.

Eliav, E., Herzberg, U., Ruda, M. A., \& Bennett, G. J. (1999). Neuropathic pain from an experimental neuritis of the rat sciatic nerve. Pain, 83, $169-182$.

Engel, G. L. (1977, April 8). The need for a new medical model: A challenge for biomedicine. Science, 196, 129-136.
Fairbank, J., Frost, H., Wilson-McDonald, J., Yu, L. M., Barker, K., \& Collins, R. (2005). Randomized controlled trial to compare surgical stabilisation of the lumbar spine with an intensive rehabilitation programme for patients with chronic low back pain: The MRC Stabilisation Trial. British Medical Journal, 330, 1233.

Fecho, K., Nackley, A. G., Wu, Y., \& Maixner, W. (2005). Basal and carrageenan-induced pain behavior in Sprague-Dawley, Lewis and Fischer rats. Physiology \& Behavior, 85, 177-186.

Fernandez, E. (2002). Anxiety, depression, and anger in pain: Research implications. Dallas, TX: Advanced Psychology Resources.

Fernandez, E., \& Milburn, T. W. (1994). Sensory and affective predictors of overall pain and emotions associated with affective pain. Clinical Journal of Pain, 10, 3-9.

Fernandez, E., \& Turk, D. C. (1992). Sensory and affective components of pain: Separation and synthesis. Psychological Bulletin, 112, 205-217.

Fernandez, E., \& Turk, D. C. (1995). The scope and significance of anger in the experience of chronic pain. Pain, 61, 165-175.

Feuerstein, M., \& Beattie, P. (1995). Biobehavioral factors affecting pain and disability in low back pain: Mechanisms and assessment. Physical Therapy, 75, 267-269.

Fillingim, R. B., Hastie, B. A., Ness, T. J., Glover, T. L., Campbell, C. M., \& Staud, R. (2005). Sex-related psychological predictors of baseline pain perception and analgesic responses to pentazocine. Biological Psychology, 69, 97-112.

Finger, S. (1994). Origins of neuroscience. New York: Oxford University Press.

Fischer, P., Smith, R., Leonard, E., \& Fuqua, D. (1993). Sex differences on affective dimensions: Continuing examination. Journal of Counseling and Development, 71, 440-443.

Fleetwood-Walker, S. M., Quinn, J. P., Wallace, C., Blackburn-Munro, G., Kelly, B. G., Fiskerstrand, C. E., et al. (1999). Behavioural changes in the rat following infection with varicella-zoster virus. Journal of Genetic Virology, 80, 2433-2436.

Flor, H., Elbert, T., Knecht, S., Wienbruch, C., Pantev, C., Birbaumer, N. et al. (1995, June 8). Phantom-limb pain as a perceptual correlate of cortical reorganization following arm amputation. Nature, 375, 482484.

Flor, H., Elbert, T., Muhlnickel, W., Pantev, C., Wienbruch, C., \& Taub, E. (1998). Cortical reorganization and phantom phenomena in congenital and traumatic upper-extremity amputees. Experimental Brain Research, $119,205-212$

Fowler, J. C., Wonderlin, W. F., \& Weinreich, D. (1985). Prostaglandins block a Ca2+-dependent slow spike afterhyperploarization independent of effects on $\mathrm{Ca} 2+$ influx in visceral afferent neurons. Brain Research, 345, 345-349.

Franz, C., Paul, R., Bautz, M., Choroba, B., \& Hildebrandt, J. (1986). Psychosomatic aspects of chronic pain: A new way of description based on MMPI item analysis. Pain, 26, 33-43.

Fritz, J. M., George, S. Z., \& Delitto, A. (2001). The role of fear-avoidance beliefs in acute low back pain: Relationships with current and future disability and work status. Pain, 94, 7-15.

Fromm-Reichman, F. (1937). Contributions to the psychogenesis of migraine. Psychoanalytic Review, 24, 26-35.

Furue, H., Narikawa, K., Kumamoto, E., \& Yoshimura, M. (1999). Responsiveness of rat substantia gelatinosa neurones to mechanical but not thermal stimuli revealed by in vivo patch-clamp recording. Journal of Physiology, 521, 529-535.

Gao, X., Yang, L., Petros, J. A., Marshall, F. F., Simons, J. W., \& Nie, S. (2005). In Vivo molecular and cellular imaging with quantum dots. Current Opinion in Biotechnology, 16, 63-72.

Garcia-Larrea, L., Peyron, R., Mertens, P., Gregoire, M. C., Lavenne, F., Le Bars, D., et al. (1999). Electrical stimulation of motor cortex for pain control: A combined PET-scan and electrophysiological study. Pain, 83, 259-273. 
Garofalo, J. P. (2000). Perceived optimism and chronic pain. In R. J. Gatchel \& J. N. Weisberg (Eds.), Personality characteristics of patients with pain (pp. 203-217), Washington, DC: American Psychological Association.

Gaskin, M. E., Greene, A. F., Robinson, M. E., \& Geisser, M. E. (1992). Negative affect and the experience of chronic pain. Journal of Psychosomatic Research, 36, 707-713.

Gasser, H. S. (1941). The classification of nerve fibers. Ohio Journal of Science, 41, 145-159.

Gasser, H. S. \& Graham, H. T. (1933). Potentials produced in the spinal cord by stimulation of dorsal roots. American Journal of Physiology, 103, 303-320.

Gatchel, R. J. (2004a). Award for Distinguished Professional Contributions to Applied Research. American Psychologist, 59, 794-805.

Gatchel, R. J. (2004b). Comorbidity of chronic pain and mental health: The biopsychosocial perspective. American Psychologist, 59, 792-794.

Gatchel, R. J. (2005). Clinical essentials of pain management. Washington, DC: American Psychological Association.

Gatchel, R. J., \& Baum, A. (1983). An introduction to health psychology. Reading, MA: Addison-Wesley.

Gatchel, R. J., Garofalo, J. P., \& Robinson, R. C. (in press). Decreases in cortisol variability between treated and untreated jaw pain patients. Journal of Applied Behavioral Research.

Gatchel, R. J., \& Okifuji, A. (2006). Evidence-based scientific data documenting the treatment- and cost-effectiveness of comprehensive pain programs for chronic pain management. The Journal of Pain, 7, 779793

Gazda, L. S., Milligan, E. D., Hansen, M. K., Twining, C. M., Poulos, N. M., Chacur, M., et al. (2001). Sciatic inflammatory neuritis (SIN): Behavioral allodynia is paralleled by peri-sciatic proinflammatory cytokine and superoxide production. Journal of the Peripheral Nervous System, 6, 111-129.

Gelnar, P. A., Krauss, B. R., Sheehe, P. R., Szeverenyi, N. M., \& Apkarian, A. V. (1999). A comparative fMRI study of cortical representations for thermal painful, vibrotactile, and motor performance tasks. NeuroImage, 10, 460-482.

Geisser, M. E., Robinson, M. E., Miller, Q. L., \& Bade, S. M. (2003). Psychosocial factors and functional capacity evaluation among persons with chronic pain. Journal of Occupational Rehabilitation, 13, 259-276.

Giamberardino, M. A., Valente, R., de Bigontina, P., \& Vecchiet, L. (1995). Artificial ureteral calculosis in rats: Behavioural characterization of visceral pain episodes and their relationship with referred lumbar muscle hyperalgesia. Pain, 61, 459-469.

Giepmans, B. N., Deerinck, T. J., Smarr, B. L., Jones, Y. Z., \& Ellisman, M. H. (2005). Correlated light and electron microscopic imaging of multiple endogenous proteins using Quantum dots. Natural Methods, 2, 743-749.

Giesler, G. J., Jr., Gerhart, K. D., Yezierski, R. P., Wilcox, T. K., \& Willis, W. D. (1981). Postsynaptic inhibition of primate spinothalamic neurons by stimulation in nucleus raphe magnus. Brain Research, 204, 184-188.

Gold, M. S., Dastmalchi, S., \& Levine, J. D. (1996). Co-expression of nociceptor properties in dorsal root ganglion neurons from the adult rat in vitro. Neuroscience, 71, 265-275.

Goldberger, M. E., \& Murray, M. (1974). Restitution of function and collateral sprouting in the cat spinal cord: The deafferented animal. Journal of Comparative Neurology, 158, 37-53.

Goldman, E. R., Clapp, A. R., Anderson, G. P., Uyeda, H. T., Mauro, J. M., Medintz, I. L., et al. (2004). Multiplexed toxin analysis using four colors of quantum dot fluororeagents. Analytic Chemistry, 76, 684-688.

Graham, B. A., Brichta, A. M., \& Callister, R. J. (2004). An in vivo mouse spinal cord preparation for patch-clamp analysis of nociceptive processing. Neuroscience Methods, 136, 221-228.

Granot, M., \& Ferber, S. G. (2005). The roles of pain catastrophizing and anxiety in the prediction of postoperative pain intensity: A prospective study. Clinical Journal of Pain, 21, 439-445.

Greco, A., Villa, R., Fusetti, L., Orlandi, R., \& Pierotti, M. A. (2000). The Gly571Arg mutation, associated with the autonomic and sensory disorder congenital insensitivity to pain with anhidrosis, causes the inactivation of the NTRK1/nerve growth factor receptor. Journal of Cell Physiology, 182, 127-133.

Grubb, B. D., Stiller, R. U., \& Schaible, H. G. (1993). Dynamic changes in the receptive field properties of spinal cord neurons with ankle input in rats with chronic unilateral inflammation in the ankle region. Experimental Brain Research, 92, 441-452.

Gu, J. G., Albuquerque, C., Lee, C. J., \& MacDermott, A. B. (1996, June 27). Synaptic strengthening through activation of $\mathrm{Ca} 2+$-permeable AMPA receptors. Nature, 381, 793-796.

Gu, J. G., \& MacDermott, A. B. (1997, October 16). Activation of ATP $\mathrm{P} 2 \mathrm{X}$ receptors elicits glutamate release from sensory neuron synapses. Nature, 389, 749-753.

Gureje, O., Von Korff, M., Simon, G. E., \& Gater, R. (1998). Persistent pain and well being: A World Health Organization study in primary care. Journal of the American Medical Association, 280, 145-151.

Hagbarth, K. E. (1979). Exteroceptive, proprioceptive, and sympathetic activity recorded with microelectrodes from human peripheral nerves. Mayo Clinic Proceedings, 54, 353-365.

Hagbarth, K. E., \& Vallbo, A. B. (1967). Mechanoreceptor activity recorded percutaneously with semimicroelectrodes in human peripheral nerves. Acta Physiologica Scandinavica, 69, 121-122.

Haller, M., Mironov, S. L., \& Richter, D. W. (2001). Intrinsic optical signals in respiratory brain stem regions of mice: Neurotransmitters, neuromodulators, and metabolic stress. Journal of Neurophysiology, 86, 412 .

Hallin, R. G., \& Wu, G. (1998). Protocol for microneurography with concentric needle electrodes. Brain Research and Brain Research Protocols, 2, 120-132.

Hao, J.-X., Xu, X.-J., Aldskogius, H., Seiger, A., \& Wiesenfeld-Hallin, Z. (1992). Photochemically induced transient spinal ischemia induces behavioral hypersensitivity to mechanical and cold stimuli, but not to noxious-heat stimuli, in the rat. Experimental Neurology, 118, 187-194.

Hao, J.-X., Xu, X.-J., Aldskogius, H., Seiger, A., \& Wiesenfeld-Hallin, Z. (1991). Allodynia-like effects in rat after ischaemic spinal cord injury photochemically induced by laser irradiation. Pain, 45, 175-185.

Hao, J.-X., Xu, X.-J., Yu, Y.-X., Seiger, Å., \& Wiesenfeld-Hallin, Z. (1991). Hypersensitivity of dorsal horn wide dynamic range neurons to cutaneous mechanical stimuli after transient spinal cord ischemia in the rat. Neuroscience Letters, 128, 105-108.

Hao, J.-X., Xu, X.-J., Yu, Y.-X., Seiger, Å., \& Wiesenfeld-Hallin, Z. (1992). Transient spinal cord ischemia induces temporary hypersensitivity of dorsal horn wide dynamic range neurons to myelinated, but not unmyelinated, fiber input. Journal of Neurophysiology, 68, 384-391.

Hari, R., \& Forss, N. (1999). Magnetoencephalography in the study of human somatosensory cortical processing. Philosophical Transactions of the Royal Society of London, Series B, 354, 1145-1154.

Hashida, B., \& Mosche, Z. (1988). Sex differences in anxiety, curiosity, and anger: A cross cultural study. Sex Roles, 19, 335-347.

Hatch, J. P., Schoenfeld, L. S., Boutros, N. N., Seleshi, E., Moore, P. J., \& Cyr-Provost, M. (1991). Anger and hostility in tension-type headache. Headache, 31, 302-304.

Hebb, D. O. (1949). Organization of behavior: A neuropsychological theory. New York: Wiley.

Heinbecker, P., Bishop, G. H., \& O'Leary, J. (1933). Pain and touch fibres in peripheral nerves. Archives of Neurology and Psychiatry, 29, 771789.

Hendershot, L. C., \& Forsaith, J. (1959). Antagonism of the frequency of phenylquinone-induced writhing in the mouse by weak analgesics and 
nonanalgesics. Journal of Pharmacology \& Experimental Therapeutics, $125,237-240$.

Hensel, H., \& Boman, K. K. A. (1960). Afferent impulses in cutaneous sensory nerves in human subjects. Journal of Neurophysiology, 23, $564-578$.

Heye, M. L., Foster, L., Bartlett, M. K., \& Adkins, S. (2002). A preoperative intervention for pain reduction, improved mobility, and selfefficacy. Applied Nursing Research, 15, 174-183.

Hoeger-Bement, M. K., \& Sluka, K. A. (2003). Phosphorylation of CREB and mechanical hyperalgesia is reversed by blockade of the cAMP pathway in a time-dependent manner after repeated intramuscular acid injections. Journal of Neuroscience, 23, 5437-5445.

Honore, P., Luger, N. M., Sabino, M. A., Schwei, M. J., Rogers, S. D., Mach, D. B., et al. (2000). Osteoprotegerin blocks bone cancer-induced skeletal destruction, skeletal pain and pain-related neurochemical reorganization of the spinal cord. Nature Medicine, 6, 521-528.

Houben, R. M., Ostelo, R. W., Vlaeyen, J. W. S., Wolters, P. M., Peters, M. L., \& Stomp van den Berg, S. G. (2005). Health care providers' orientations towards common low back pain predict perceived harmfulness of physical activities and recommendations regarding return to normal activity. European Journal of Pain, 9, 173-183.

Houben, R. M., Vlaeyen, J. W. S., Peters, M. L., Ostelo, R. W., Wolters, P. M., \& Stomp van den Berg, S. G. (2004). Health care providers' attitudes and beliefs towards common low back pain: Factor structure and psychometric properties of the HC-PAIRS. Clinical Journal of Pain, 20, 37-44.

Howland, E. W., Wakai, R. T., Mjaanes, B. A., Balog, J. P., \& Cleeland, C. S. (1995). Whole head mapping of magnetic fields following painful electric finger shock. Brain Research and Cognitive Brain Research, 2, $165-172$.

Hsieh, J. C., Belfrage, M., Stone-Elander, S., Hansson, P., \& Ingvar, M. (1995). Central representation of chronic ongoing neuropathic pain studied by positron emission tomography. Pain, 63, 225-236.

Hsieh, J. C., Ståhle-Bäckdahl, M., Hägermark, Ö., Stone-Elander, S., Rosenquist, G., \& Ingvar, M. (1996). Traumatic nociceptive pain activates the hypothalamus and the periaqueductal gray: A positron emission tomography study. Pain, 64, 303-314.

Huang, L. Y., \& Neher, E. (1996). Ca(2+)-dependent exocytosis in the somata of dorsal root ganglion neurons. Neuron, 17, 135-145.

Hughes, J., \& Gasser, H. S. (1934a). The response of the spinal cord to two afferent volleys. American Journal of Physiology, 108, 307-321.

Hughes, J. \& Gasser, H. S. (1934b). Some properties of the cord potentials evoked by a single afferent volley. American Journal of Physiology, 108, 295-306.

Hulsebosch, C. E., Xu, G. Y., Perez-Polo, J. R., Westlund, K. N., Taylor, C. P., \& McAdoo, D. J. (2000). Rodent model of chronic central pain after spinal cord contusion injury and effects of gabapentin. Journal of Neurotrauma, 17, 1205-1217.

Hunter, J. P., Katz, J., \& Davis, K. E. (2005). Dissociation of phantom limb phenomena from stump tactile spatial acuity and sensory thresholds. Brain, 128, 308-320.

Hylden, J. L. K., Nahin, R. L., \& Dubner, R. (1987). Altered responses of nociceptive cat lamina I spinal dorsal horn neurons after chronic sciatic neuroma formation. Brain Research, 411, 341-350.

Iadarola, M. J., Max, M. B., Berman, K. F., Byas-Smith, M. G., Coghill, R. C., Gracely, R. H., et al. (1995). Unilateral decrease in thalamic activity observed with positron emission tomography in patients with chronic neuropathic pain. Pain, 63, 55-64.

Ihlebaek, C., \& Eriksen, H. R. (2003). Are the "myths" of low back pain alive in the general Norwegian population? Scandinavian Journal of Public Health, 31, 395-398.

Ikeda, J., Terakawa, S., Murota, S., Morita, I., \& Hirakawa, K. (1996). Nuclear disintegration as a leading step of glutamate excitotoxicity in brain neurons. Journal of Neuroscience Research, 43, 613-622.
Imamura, Y., \& Bennett, G. J. (1995). Felbamate relieves several abnormal pain sensations in rats with an experimental peripheral neuropathy. Journal of Pharmacology and Experimental Therapy, 275, 177-182.

Indo, Y. (2001). Molecular basis of congenital insensitivity to pain with anhidrosis (CIPA): Mutations and polymorphisms in TRKA (NTRK1) gene encoding the receptor tyrosine kinase for nerve growth factor. Human Mutation, 18, 462-471.

Indo, Y., Tsuruta, M., Hayashida, Y., Karim, M. A., Ohta, K., Kawano, T., et al. (1996). Mutations in the TRKA/NGF receptor gene in patients with congenital insensitivity to pain with anhidrosis. Nature Genetics, 13, $485-488$.

Institute of Medicine of the National Academies. (2005). Improving medical education: Enhancing the behavioral and social science content of medical school curricula. Washington, DC: National Academies Press.

Itoh, Y., Nakajima, S., Yagishita, S., Nakano, T., \& Kawada, H. (1986). Congenital insensitivity to pain with anhidrosis: Morphological and morphometrical studies on the skin and peripheral nerves. Neuropediatrics, 17, 103-110.

Jaiswal, J. K., Mattoussi, H., Mauro, J. M., \& Simon, S. M. (2003). Long-term multiple color imaging of live cells using quantum dot bioconjugates. Nature Biotechnology, 21, 47-51.

Jaiswal, J. K., \& Simon, S. M. (2004). Potentials and pitfalls of fluorescent quantum dots for biological imaging. Trends Cell Biology, 14, 497-504.

Janssen, S. A., Spinhoven, P., \& Arntz, A. (2004). The effects of failing to control pain: An experimental investigation. Pain, 107, 227-233.

Jarvik, J. G., Hollingworth, W., Heagerty, P. J., Haynor, D. R., Boyco, E. J., \& Deyo, R. A. (2005). Three-year incidence of low back pain in an initially asymptomatic cohort. Clinical and imaging risk factors. Spine, 30, 1541-1548.

Jasny, B. R., \& Kennedy, D. (2001, February 16). The human genome [Special issue]. Science, 291(5507).

Jensen, M. P., \& Karoly, P. (1991). Control beliefs, coping efforts, and adjustment to chronic pain. Journal of Consulting and Clinical Psychology, 59, 431-438.

Jensen, M. P., Romano, J. M., Turner, J. A., Good, A. B., \& Wald, L. H. (1999). Patient beliefs predict patient functioning: Further support for a cognitive-behavioural model of chronic pain. Pain, 81, 95-104.

Jensen, M. P., Turner, J. A., \& Romano, J. M. (2001). Changes in beliefs, catastrophizing, and coping are associated with improvement in multidisciplinary pain treatment. Journal of Consulting and Clinical Psychology, 69, 655-662.

Jensen, M. P., Turner, J. A., Romano, J. M., \& Lawler, B. K. (1994). Relationship of pain-specific beliefs to chronic pain adjustment. Pain 57, 301-309.

Ji, R. R., \& Woolf, C. J. (2001). Neuronal plasticity and signal transduction in nociceptive neurons: Implications for the initiation and maintenance of pathological pain. Neurobiology of Disease, 8, 1-10.

Johnson, L. J., Hanley, D. F., \& Thakor, N. V. (2000). Optical light scatter imaging of cellular and sub-cellular morphology changes in stressed rat hippocampal slices. Journal of Neuroscience Methods, 98, 21-31.

Jones, A. K., Brown, W. D., Friston, K. J., Qi, L. Y., \& Frackowiak, R. S. (1991). Cortical and subcortical localization of response to pain in man using positron emission tomography. Proceedings: Biological Sciences, 244, 39-44.

Kajander, K. C., Wakisaka, S., \& Bennett, G. J. (1992). Spontaneous discharge originates in the dorsal root ganglion at the onset of a painful peripheral neuropathy in the rat. Neuroscience Letters, 138, 225-228.

Katon, W., Egan, K., \& Miller, D. (1985). Chronic pain: Lifetime psychiatric diagnoses and family history. American Journal of Psychiatry, 142, $1156-1160$.

Katz, J., McDermott, M. P., Cooper, E. M., Walther, R. R., Sweeney, E. W., \& Dworkin, R. H. (2005). Psychosocial risk factors for postherpetic neuralgia: A prospective study of patients with herpes zoster. Journal of Pain, 6, 782-790. 
Katz, J., \& Melzack, R. (1990). Pain "memories" in phantom limbs: Review and clinical observations. Pain, 43, 319-336.

Keefe, F. J., \& Caldwell, D. S. (1997). Cognitive behavioral control of arthritis pain. Medical Clinics of North America, 81, 277-290.

Keefe, F. J., Lefebvre, J. C., Maixner, W., Salley, A. N., Jr., \& Caldwell, D. S. (1997). Self-efficacy for arthritis pain: Relationship to perception of thermal laboratory pain stimuli. Arthritis Care Research, 10, 177184

Keefe, F. J., Rumble, M. E., Scipio, C. D., Giordano, L. A., \& Perri, L. M. (2004). Psychological aspects of persistent pain: Current state of the science. Journal of Pain, 5, 195-211.

Kegeles, L. S., \& Mann, J. J. (1997). In vivo imaging of neurotransmitter systems using radiolabeled receptor ligands. Neuropsychopharmacology, 17, 293-307.

Keltner, J. R., Furst, A., Fan, C., Redfern, R., Inglis, B., Fields, H. L. (2006). Isolating the modulatory effect of expectation on pain transmission: A functional magnetic resonance imaging study. The Journal of Neuroscience, 26, 4437-4443.

Kendell, K., Saxby, B., Farrow, M., \& Naisby, C. (2001). Psychological factors associated with short-term recovery from total knee replacement. British Journal of Health Psychology, 6, 41-52.

Keogh, E., \& Asmundson, G. J. (2004). Negative affectivity, catastrophizing and anxiety sensitivity. In G. J. Asmundson, J. W. S. Vlaeyen, \& G. Crombez (Eds.), Understanding and treating fear of pain (pp. 91115). Oxford, England: Oxford University Press.

Keogh, E., \& Birkby, J. (1999). The effect of anxiety sensitivity and gender on the experience of pain. Cognition and Emotion, 13, 813-829.

Keogh, E., \& Cochrane, M. (2002). Anxiety sensitivity, cognitive biases, and the experience of pain. Journal of Pain, 3, 320-329.

Keogh, E., Hamid, R., Hamid, S., \& Ellery, D. (2004). Investigating the effect of anxiety sensitivity, gender and negative interpretative bias on the perception of chest pain. Pain, 111, 209-217.

Keogh, E., \& Mansoor, L. (2001). Investigating the effects of anxiety sensitivity and coping on the perception of cold pressor pain in healthy women. European Journal of Pain, 5, 11-22.

Kerns, R. D., \& Haythornthwaite, J. A. (1988). Depression among chronic pain patients: Cognitive-behavioral analysis and effect on rehabilitation outcome. Journal of Consulting and Clinical Psychology, 56, 870-876.

Kerns, R. D., Rosenberg, R., \& Jacob, M. (1994). Anger expression and chronic pain. Journal of Behavioral Medicine, 17, 57-67.

Kim, K. J., Yoon, Y. W., \& Chung, J. M. (1997). Comparison of three rodent neuropathic pain models. Experimental Brain Research, 113, 200-206.

Kim, S. H., \& Chung, J. M. (1992). An experimental model for peripheral neuropathy produced by segmental spinal nerve ligation in the rat. Pain, 50, 355-363.

Kinder, B. N., Curtiss, G., \& Kalichman, S. (1992). Affective differences among empirically derived subgroups of headache patients. Journal of Personality Assessment, 58, 516-524.

Kitamura, Y., Kakigi, R., Hoshiyama, M., Koyama, S., Shimojo, M., \& Watanabe, S. (1995). Pain-related somatosensory evoked magnetic fields. Electroencephalogaphy \& Clinical Neurophysiology, 95, 463474.

Kitamura, Y., Kakigi, R., Hoshiyama, M., Koyama, S., Watanabe, S., \& Shimojo, M. (1997). Pain-related somatosensory evoked magnetic fields following lower limb stimulation. Journal of Neurological Science, 145, 187-194.

Koerber, H. R., Druzinsky, R. E., \& Mendell, L. M. (1988). Properties of somata of spinal dorsal root ganglion cells differ according to peripheral receptor innervated. Journal of Neurophysiology, 60, 1584-1596.

Koltzenburg, M., \& Handwerker, H. O. (1994). Differential ability of human cutaneous nociceptors to signal mechanical pain and to produce vasodilation. Journal of Neuroscience, 14, 1756-1765.

Koltzenburg, M., Lundberg, L. E. R., \& Torebjörk, H. E. (1992). Dynamic and static components of mechanical hyperalgesia in human hairy skin. Pain, 51, 207-219.

Korte, S. M., Koolhaas, J. M., Wingfield, J. C., McEwen, B. S. (2005). The Darwinian concept of stress: Benefits of allostasis and costs of allostatic load and the trade-offs in health and disease. Neuroscience and Biobehavioral Reviews, 29, 3-38.

Kristal, B. S., \& Dubinsky, J. M. (1997). Mitochondrial permeability transition in the central nervous system: induction by calcium cyclingdependent and -independent pathways. Journal of Neurochemistry, 69, $524-538$.

Kumazawa, T., \& Perl, E. R. (1978). Excitation of marginal and substantia gelatinosa neurons in the primate spinal cord: Indications of their place in dorsal horn functional organization. Journal of Comparative Neurology, 177, 417-434.

LaBuda, C. J., Cutler, T. D., Dougherty, P. M., \& Fuchs, P. N. (2000). Mechanical and thermal hypersensitivity develops following kainate lesion of the ventral posterior lateral thalamus in rats. Neuroscience Letters, 290, 79-83.

LaGraize, S. C., Borzan, J., Rinker, M. M., Kopp, J. L., \& Fuchs, P. N. (2004). Behavioral evidence for competing motivational drives of nociception and hunger. Neuroscience Letters, 371, 30-34.

Laird, J. M., Martinez-Caro, L., Garcia-Nicas, E., \& Cervero, F. (2001). A new model of visceral pain and referred hyperalgesia in the mouse. Pain, 92, 335-342.

Laird, J. M., Roza, C., De Felipe, C., Hunt, S. P., \& Cervero, F. (2001). Role of central and peripheral tachykinin NK1 receptors in capsaicininduced pain and hyperalgesia in mice. Pain, 90, 97-103.

LaMotte, R. H., \& Campbell, J. N. (1978). Comparison of responses of warm and nociceptive $\mathrm{C}$-fiber afferents in monkey with human judgements of thermal pain. Journal of Neurophysiology, 41, 509-528.

LaMotte, R. H., Lundberg, L. E. R., \& Torebjörk, H. E. (1992). Pain, hyperalgesia and activity in nociceptive $\mathrm{C}$ units in humans after intradermal injection of capsaicin. Journal of Physiology (London), 448, 749-764.

LaMotte, R. H., Shain, C. N., Simone, D. A., \& Tsai, E.-F. P. (1991) Neurogenic hyperalgesia: Psychophysical studies of underlying mechanisms. Journal of Neurophysiology, 66, 190-211.

Lariviere, W. R., \& Melzack, R. (1996). The bee venom test: A new tonic-pain test. Pain, 66, 271-277.

Lariviere, W. R., \& Melzack, R. (2000). The bee venom test: Comparisons with the formalin test with injection of different venoms. Pain, 84, $111-112$.

Larner, A. J., Moss, J., Rossi, M. L., \& Anderson, M. (1994). Congenital insensitivity to pain: A 20 year follow up. Journal of Neurology, Neurosurgery, \& Psychiatry, 57, 973-974.

Lawson, S. N., Crepps, B. A., \& Perl, E. R. (1997). Relationship of substance $\mathrm{P}$ to afferent characteristics of dorsal root ganglion neurones in guinea-pig. Journal of Physiology (London), 505, 177-191.

Lazarus, R. S., \& Folkman, S. (1984). Stress, appraisal, and coping. New York: Springer.

Lee, C. J., Engelman, H. S., \& MacDermott, A. B. (1999). Activation of kainate receptors on rat sensory neurons evokes action potential firing and may modulate transmitter release. Annals of the New York Academy of Science, 868, 546-549.

Leijon, G., Boivie, J., \& Johansson, I. (1989). Central post-stroke pain: Neurological symptoms and pain characteristics. Pain, 36, 13-25.

Lemasters, J. J., Nieminen, A. L., Qian, T., Trost, L. C., \& Herman, B. (1997). The mitochondrial permeability transition in toxic, hypoxic and reperfusion injury. Molecular and Cellular Biochemistry, 174, 159-165.

Lenthem, J., Slade, P. D., Troup, J. D. G., \& Bentley, G. (1983). Outline of a fear-avoidance model of exaggerated pain perception: I. Behavior Research and Therapy, 21, 401-408.

Lenz, F. A., Kwan, H. C., Dostrovsky, J. O., \& Tasker, R. R. (1989). Characteristics of the bursting pattern of action potentials that occur in 
the thalamus of patients with central pain. Brain Research, 496, 357360 .

Lenz, F. A., Tasker, R. R., Dostrovsky, J. O., Kwan, H. C., Gorecki, J., Hirayama, T. et al. (1987). Abnormal single-unit activity recorded in the somatosensory thalamus of a quadriplegic patient with central pain. Pain, 31, 225-236.

Lethem, J., Slade, P. D., Troup, J. D., \& Bentley, G. (1983). Outline of a fear-avoidance model of exaggerated pain perception: I. Behaviour Research and Therapy, 21, 401-408.

Levine, J. D., \& Reichling, D. B. (1999). Peripheral mechanisms of inflammatory pain. In P. D. Wall \& R. Melzack (Eds.), Textbook of pain (4th ed., pp. 59-84). New York: Churchill Livingstone.

Levitt, M., \& Levitt, J. H. (1981). The deafferentation syndrome in monkeys: Dysesthesias of spinal origin. Pain, 10, 129-147.

Light, A. R., Casale, E. J., \& Menetrey, D. M. (1986). The effects of focal stimulation in nucleus raphe magnus and periaqueductal gray on intracellularly recorded neurons in spinal laminae I and II. Journal of Neurophysiology, 56, 555-571.

Light, A. R., \& Willcockson, H. H. (1999). Spinal laminae I-II neurons in rat recorded in vivo in whole cell, tight seal configuration: Properties and opioid responses. Journal of Neurophysiology, 82, 3316-3326.

Lindblom, U. F. \& Ottosson, J. O. (1953a). Effects of spinal sections on the spinal cord potentials elicited by stimulation of low threshold cutaneous fibres. Acta Physiologica Scandinavica, 29, 191-206.

Lindblom, U. F., \& Ottosson, J. O. (1953b). Localization of the structure generating the negative cord dorsum potential evoked by stimulation of low threshold cutaneous fibres. Acta Physiologica Scandinavica, 29, $180-190$.

Linton, S. J., Buer, N., Vlaeyen, J., \& Hellsing, A. L. (2000). Are fearavoidance beliefs related to the inception of an episode of back pain? A prospective study. Psychology and Health, 14, 1051-1059.

Linton, S. J., \& Nordin, E. (2006). A five-year follow-up evaluation of the health and economic consequences of an early cognitive-behavioral intervention for back pain: A randomized, controlled trial. Spine, 31, $853-858$

Linton, S. J., Vlaeyen, J., \& Ostelo, R. (2002). The back pain beliefs of health care providers: Are we fear-avoidant? Journal of Occupational Rehabilitation, 12, 223-232.

Lipton, P. (1973). Effects of membrane depolarization on light scattering by cerebral cortical slices. Journal of Physiology, 231, 365-383.

Liu, C. N., \& Chambers, W. W. (1958). Intraspinal sprouting of dorsal root axons: Development of new collaterals and preterminals following partial denervation of the spinal cord in the cat. Archives of Neurology \& Psychiatry, 79, 46-61.

Liu, H., Wang, H., Sheng, M., Jan, L. Y., \& Basbaum, A. I. (1994). Evidence for presynaptic $N$-methyl-D-aspartate autoreceptors in the spinal cord dorsal horn. Proceedings of the National Academy of Sciences, USA, 91, 8383-8387.

Liu, L., \& Simon, S. A. (1996). Capsaicin and nicotine both activate a subset of rat trigeminal ganglion neurons. American Journal of Physiology, 1807-1814.

Liu, L., Wang, Y., \& Simon, S. A. (1996). Capsaicin activated currents in rat dorsal root ganglion cells. Pain, 64, 191-195.

Livingston, W. K. (1943). Pain mechanisms. New York: Macmillan.

Livingston, W. K. (1998). Pain and suffering. Seattle, WA: International Association for the Study of Pain.

Lloyd, D. P. C. (1952). Electrotonus in dorsal nerve roots. Cold Spring Harbor Symposia on Quantitative Biology, 17, 203-219.

Lloyd, D. P. C., \& McIntyre, A. K. (1949). On the origins of dorsal root potentials. Journal of General Physiology, 32, 409-443.

Loeser, J. D. (1982). Concepts of pain. In J. Stanton-Hicks \& R. Boaz (Eds.), Chronic low back pain (pp. 109-142). New York: Raven Press.

Loeser, J. D., \& Ward, A. A., Jr. (1967). Some effects of deafferentation on neurons of the cat spinal cord. Archives of Neurology, 17, 629-636.
Lotsch, J., \& Geisslinger, G. (2005). Are mu-opioid receptor polymorphisms important for clinical opioid therapy? Trends in Molecular Medicine, 11, 82-89.

Luger, N. M., Mach, D. B., Sevcik, M. A., \& Mantyh, P. W. (2005). Bone cancer pain: From model to mechanism to therapy. Journal of Pain \& Symptom Management, 29, 32-46.

Luo, M. C., Zhang, D. Q., Ma, S. W., Huang, Y. Y., Shuster, S. J., Porreca, F., et al. (2005). An efficient intrathecal delivery of small interfering RNA to the spinal cord and peripheral neurons. Molecular Pain, 28, 29-37.

MacDermott, A. B., Role, L. W., \& Siegelbaum, S. A. (1999). Presynaptic ionotropic receptors and the control of transmitter release. Annual Review of Neuroscience, 22, 443-485.

Magni, G., Moreschi, C., Rigatti Luchini, S., \& Merskey, H. (1994). Prospective study on the relationship between depressive symptoms and chronic musculoskeletal pain. Pain, 56, 289-297.

Maihöfner, C., \& Handwerker, H. O. (2005). Differential coding of hyperalgesia in the human brain: A functional MRI study. NeuroImage, 28, 996-1006.

Maihöfner, C., Handwerker, H. O., \& Birklein, F. (2006). Functional imaging of allodynia in complex regional pain syndrome. Neurology, 66, 711-717.

Malmberg, A. B., Brandon, E. P., Idzerda, R. L., Liu, H., McKnight, G. S., \& Basbaum, A. I. (1997). Diminished inflammation and nociceptive pain with preservation of neuropathic pain in mice with a targeted mutation of the type I regulatory subunit of cAMP-dependent protein kinase. Journal of Neuroscience, 17, 7462-7470.

Malmberg, A. B., Chen, C., Tonegawa, S., \& Basbaum, A. I. (1997, October 10). Preserved acute pain and reduced neuropathic pain in mice lacking PKCgamma. Science, 278, 279-283.

Manfredi, M., Bini, G., Cruccu, G., Accornero, N., Berardelli, A., \& Medolago, L. (1981). Congenital absence of pain. Archives of Neurology, 38, 507-511.

Mantyh, P. W., Clohisy, D. R., Koltzenburg, M., \& Hunt, S. P. (2002). Molecular mechanisms of cancer pain. Nature Review of Cancer, 2, 201-209.

Marchettini, P., Simone, D. A., Caputi, G., \& Ochoa, J. L. (1996). Pain from excitation of identified muscle nociceptors in humans. Brain Research, 740, 109-116.

Mardy, S., Miura, Y., Endo, F., Matsuda, I., Sztriha, L., Frossard, P., et al. (1999). Congenital insensitivity to pain with anhidrosis: Novel mutations in the TRKA (NTRK1) gene encoding a high-affinity receptor for nerve growth factor. American Journal of Human Genetics, 64, 1570 1579.

Marks, R. (2001). Efficacy theory and its utility in arthritis rehabilitation: Review and recommendations. Disability and Rehabilitation, 23, 271280.

Matsuo, M., Kurokawa, T., Goya, N., \& Ohta, M. (1981). Congenital insensitivity to pain with anhidrosis in a 2-month-old boy. Neurology, 31, 1190-1192.

Matthes, H. W., Maldonado, R., Simonin, F., Valverde, O., Slowe, S., Kitchen, I., et al. (1996, October 31). Loss of morphine-induced analgesia, reward effect and withdrawal symptoms in mice lacking the $\mu$-opioid-receptor gene. Nature, 383, 819-823.

Maves, T. J., Pechman, P. S., Gebhart, G. F., \& Meller, S. T. (1993). Possible chemical contribution from chromic gut sutures produces disorders of pain sensation like those seen in man. Pain, 54, 57-69.

McBeth, J., Chiu, Y. H., Silman, A. J., Ray, D., Morriss, R., Dickens, C., et al. (2005). Hypothalamic-pituitary-adrenal stress axis function and the relationship with chronic widespread pain and its antecedents. Arthritis Research \& Therapy, 7, R992-R1000.

McCracken, L. M., Carson, J. W., Eccleston, C., \& Keefe, F. J. (2004). Acceptance and change in the context of chronic pain. Pain, 109, 4-7. 
McCracken, L. M., \& Eccleston, C. (2003). Coping or acceptance: What to do about chronic pain? Pain, 104, 197-204.

McCracken, L. M., \& Gross, R. T. (1998). The role of pain-related anxiety reduction in the outcome of multidisciplinary treatment for low back pain: Preliminary results. Journal of Occupational Rehabilitation, 8, 179-189.

McCracken, L. M., Gross, R. T., \& Eccleston, C. (2002). Multimethod assessment of treatment process in chronic low back pain: Comparison of reported pain-related anxiety with directly measured physical capacity. Behaviour Research and Therapy, 40, 585-594.

McCracken, L. M., Gross, R. T., Sorg, P. J., \& Edmands, T. A. (1993). Prediction of pain in patients with chronic low back pain: Effects of inaccurate prediction and pain-related anxiety. Behavior Research and Therapy, 31, 647-652.

McCracken, L. M., Vowles, K. E., \& Eccleston, C. (2005). Acceptancebased treatment for persons with complex, long standing chronic pain: A preliminary analysis of treatment outcome in comparison to a waiting phase. Behaviour Research and Therapy, 43, 1335-1346.

McEwen, B. S. (2001). Plasticity of the hippocampus: Adaptation to chronic stress and allostatic load. Annals of the New York Academy of Science, 933, 265-277.

McLean, S. A., Williams, D. A., Harris, R. E., Kop, W. J., Groner, K. H., Ambrose, K., et al. (2005). Momentary relationship between cortisol secretion and symptoms in patients with fibromyalgia. Arthritis \& Rheumatism, 52, 3660-3669.

Medhurst, S. J., Walker, K., Bowes, M., Kidd, B. L., Glatt, M., Muller, M., et al. (2002). A rat model of bone cancer pain. Pain, 96, 129-140.

Meller, S. T., Cummings, C. P., Traub, R. J., \& Gebhart, G. F. (1994). The role of nitric oxide in the development and maintenance of the hyperalgesia produced by intraplantar injection of carrageenan in the rat. Neuroscience, 60, 367-374.

Melzack, R. (2001). Pain and the neuromatrix in the brain. Journal of Dental Education, 65, 1378-1382.

Melzack, R. (2005). Evolution of the neuromatrix theory of pain. Pain Practice, 5, 85-94.

Melzack, R., \& Casey, K. L. (1968). Sensory, motivational and central control determinants of pain: A new conceptual model. In D. Kenshalo (Ed.), The skin senses (pp. 423-443). Springfield, IL: Charles C. Thomas.

Melzack, R., \& Wall, P. D. (1965, November 19). Pain mechanisms: A new theory. Science, 150, 971-979.

Melzack, R., \& Wall, P. D. (1996). The challenge of pain. New York: Penguin.

Mendell, L. M., \& Wall, P. D. (1965, April 3). Responses of single dorsal cord cells to peripheral cutaneous unmyelinated fibres. Nature, 206, 97-99.

Merskey, H. (1986). International association for the study of pain: Classification of chronic pain. Descriptions of chronic pain syndromes and definitions of pain terms. Pain, 3(Suppl.), 1-226.

Meyerovitch, J., Rothenberg, P., Shechter, Y., Bonner-Weir, S., \& Kahn, C. R. (1991). Vanadate normalizes hyperglycemia in two mouse models of non-insulin-dependent diabetes mellitus. Journal of Clinical Investigation, 87, 1286-1294.

Miampamba, M., Chery-Croze, S., Gorry, F., Berger, F., \& Chayvialle, J. A. (1994). Inflammation of the colonic wall induced by formalin as a model of acute visceral pain. Pain, 57, 327-334.

Michalet, X., Pinaud, F. F., Bentolila, L. A., Tsay, J. M., Doose, S., Li, J. J., et al. (2005, January 28). Quantum dots for live cells, in vivo imaging, and diagnostics. Science, 307, 538-544

Miller, L. D., Petrozzino, J. J., Mahanty, N. K., \& Connor, J. A. (1993). Optical imaging of cytosolic calcium, electrophysiology, and ultrastructure in pyramidal neurons of organotypic slice cultures from rat hippocampus. NeuroImage, 1, 109-120.

Miranda, C., Di Virgilio, M., Selleri, S., Zanotti, G., Pagliardini, S.,
Pierotti, M. A., et al. (2002). Novel pathogenic mechanisms of congenital insensitivity to pain with anhidrosis genetic disorder unveiled by functional analysis of neurotrophic tyrosine receptor kinase type 1/nerve growth factor receptor mutations. Journal of Biological Chemistry, 277, $6455-6462$.

Miura, Y., Hiura, M., Torigoe, K., Numata, O., Kuwahara, A., Matsunaga, M., et al. (2000). Complete paternal uniparental isodisomy for chromosome 1 revealed by mutation analyses of the TRKA (NTRK1) gene encoding a receptor tyrosine kinase for nerve growth factor in a patient with congenital insensitivity to pain with anhidrosis. Human Genetics, 107, 205-209.

Miura, Y., Mardy, S., Awaya, Y., Nihei, K., Endo, F., Matsuda, I., et al. (2000). Mutation and polymorphism analysis of the TRKA (NTRK1) gene encoding a high-affinity receptor for nerve growth factor in congenital insensitivity to pain with anhidrosis (CIPA) families. Human Genetics, 106, 116-124.

Mogil, J. S., Yu, L., \& Basbaum, A. I. (2000). Pain genes? Natural variation and transgenic mutants. Annual Review of Neuroscience, 23, $777-811$.

Moore, C. I., \& Nelson, S. B. (1998). Spatio-temporal subthreshold receptive fields in the vibrissa representation of rat primary somatosensory cortex. Journal of Neurophysiology, 80, 2882-2892.

Moore, J. E., Von Korff, M., Cherkin, D., Saunders, K., \& Lorig, K. (2000). A randomized trial of a cognitive-behavioral program for enhancing back pain self care in a primary care setting. Pain, 88, 145-153.

Morley, S., Eccleston, C., \& Williams, A. (1999). Systematic review and meta-analysis of randomized controlled trials of cognitive behavior therapy and behavior therapy for chronic pain in adults, excluding headache. Pain, 80, 1-13.

Mosconi, T., \& Kruger, L. (1996). Fixed-diameter polyethylene cuffs applied to the rat sciatic nerve induce a painful neuropathy: Ultrastructural morphometric analysis of axonal alterations. Pain, 64, 37-57.

Mosseri, R., Waner, T., Shefi, M., Shafrir, E., \& Meyerovitch, J. (2000). Gluconeogenesis in non-obese diabetic (NOD) mice: In vivo effects of vandadate treatment on hepatic glucose-6-phosphatase and phosphoenolpyruvate carboxykinase. Metabolism, 49, 321-325.

Müller, M., \& Netter, P. (2000). Relationship of subjective helplessness and pain perception after electric skin stimuli. Stress Medicine, 16 $109-115$.

Naatanen, R., Ilmoniemi, R. J., \& Alho, K. (1994). Magnetoencephalography in studies of human cognitive brain function. Trends in Neuroscience, 17, 389-395.

Nafe, J. P. (1934). The pressure, pain and temperature senses. In C. A. Murchison (Ed.), Handbook of general experimental psychology (pp. 1037-1087). Wooster, MA: Clark University.

Nair, D. G. (2005). About being BOLD. Brain Research Brain \& Research Review, 50, 229-243.

Neher, E., \& Sakmann, B. (1976, April 29). Single-channel currents recorded from membrane of denervated frog muscle fibres. Nature, 260, $799-802$.

Ness, T. J., Randich, A., \& Gebhart, G. F. (1991). Further behavioral evidence that colorectal distension is a "noxious" visceral stimulus in rats. Neuroscience Letters, 131, 113-116.

Ness, T. J., San Pedro, E. C., Richards, J. S., Kezar, L., Liu, H. G., \& Mountz, J. M. (1998). A case of spinal cord injury-related pain with baseline rCBF brain SPECT imaging and beneficial response to gabapentin. Pain, 78, 139-143.

Neugebauer, V., \& Schaible, H.-G. (1990). Evidence for a central component in the sensitization of spinal neurons with joint input during development of acute arthritis in cat's knee. Journal of Neurophysiology, 64, 299-311.

Newberg, A. B., LaRiccia, P. J., Lee, B. Y., Farrar, J. T., Lee, L., \& Alavi, A. (2005). Cerebral blood flow effects of pain and acupuncture: A 
preliminary single-photon emission computed tomography imaging study. Journal of Neuroimaging, 15, 43-49.

Nicol, G. D. \& Cui, M. (1994). Enhancement by prostaglandin $E_{2}$ of bradykinin activation of embryonic rat sensory neurones. Journal of Physiology (London), 480, 485-492.

Nolano, M., Crisci, C., Santoro, L., Barbieri, F., Casale, R., Kennedy, W. R., et al. (2000). Absent innervation of skin and sweat glands in congenital insensitivity to pain with anhidrosis. Clinical Neurophysiology, 111, 1596-1601.

Nomura, Y., Fujii, F., Sato, C., Nemoto, M., \& Tamura, M. (2000). Exchange transfusion with fluorocarbon for studying synaptically evoked optical signal in rat cortex. Brain Research Protocols, 5, 10-15. Nordenbras, W. (1959). Pain. Amsterdam: Elsevier.

Novy, D. M., Nelson, D. V., Hetzel, R. D., Squitieri, P., \& Kennington, M. (1998). Coping with chronic pain: Sources of intrinsic and contextual variability. Journal of Behavioral Medicine, 31, 19-34.

Nozaki-Taguchi, N., Chaplan, S. R., Higuera, E. S., Ajakwe, R. C., \& Yaksh, T. L. (2001). Vincristine-induced allodynia in the rat. Pain, 93, 69-76.

Numazaki, M., \& Tominaga, M. (2004). Nociception and TRP channels. Current Drug Targets - CNS \& Neurological Disorders, 3, 479-485.

Ochoa, J. L. \& Torebjörk, H. E. (1980). Paraesthesia from ectopic impulse generation in human sensory nerves. Brain, 103, 835-853.

Ochoa, J., \& Torebjörk, H. E. (1989). Sensations evoked by intraneural microstimulation of $\mathrm{C}$ nociceptor fibres in human skin nerves. Journal of Physiology, 415, 583-599.

Ochoa, J., Torebjörk, H. E., Culp, W. J., \& Schady, W. (1982). Abnormal spontaneous activity in single sensory nerve fibers in humans. Muscle and Nerve, 5(Suppl.), s74-s77.

Ogawa, S., Lee, T. M., Kay, A. R., \& Tank, D. W. (1990). Brain magnetic resonance imaging with contrast dependent on blood oxygenation. Proceedings of the National Academy of Sciences, USA, 87, 9868-9872.

Ogawa, S., Lee, T. M., Nayak, A. S., \& Glynn, P. (1990). Oxygenationsensitive contrast in magnetic resonance image of rodent brain at high magnetic fields. Magnetic Resonance Medicine, 14, 68-78.

Ogawa, S., Tank, D. W., Menon, R., Ellermann, J. M., Kim, S. G., Merkle, H., et al. (1992). Intrinsic signal changes accompanying sensory stimulation: Functional brain mapping with magnetic resonance imaging. Proceedings of the National Academy of Sciences, USA, 89, 5951-5955.

Okifuji, A., Turk, D. C., \& Curran, S. L. (1999). Anger in chronic pain: Investigations of anger targets and intensity. Journal of Psychosomatic Research, 61, 771-780.

Orbell, S., Johnston, M., Rowley, D., Davey, P., \& Espley, A. (2001). Self-efficacy and goal importance in the prediction of physical disability in people following hospitalization: A prospective study. British Journal of Health Psychology, 6, 25-40.

Oshiro, Y., Fuijita, N., Tanaka, H., Hirabuki, N., Nakamura, H., \& Yoshiya, I. (1998). Functional mapping of pain-related activation with echo-planar MRI: Significance of the SII-insular region. NeuroReport, 9 , 2285-2289.

Ovelmen-Levitt, J., Gorecki, J., Nguyen, K. T., Iskandar, B., \& Nashold, B. S. J. (1995). Spontaneous and evoked dysesthesias observed in the rat after spinal cordotomies. Stereotactic and Functional Neurosurgery, 65, 157-160.

Pagni, C. A., \& Canavero, S. (1995). Functional thalamic depression in a case of reversible central pain due to a spinal intramedullary cyst: Case report. Journal of Neurosurgery, 83, 163-165.

Palecek, J., Dougherty, P. M., Kim, S. H., Palecková, V., Lekan, H., Chung, J. M., et al. (1992). Responses of spinothalamic tract neurons to mechanical and thermal stimuli in an experimental model of peripheral neuropathy in primates. Journal of Neurophysiology, 68, 1951-1966.

Pan, Z. Z. (1998). $\mu$-Opposing actions of the kappa-opioid receptor. Trends in Pharmacological Sciences, 19, 94-98.

Pan, Z. Z., \& Fields, H. L. (1996). Endogenous opioid-mediated inhibition of putative pain-modulating neurons in rat rostral ventromedial medulla. Neuroscience, 74, 855-862.

Pan, Z. Z., Tershner, S. A., \& Fields, H. L. (1997, September 25). Cellular mechanism for anti-analgesic action of agonists of the kappa-opioid receptor. Nature, 389, 382-385.

Pavlin, D. J., Rapp, S. E., \& Pollisar, N. (1998). Factors affecting discharge time in adult outpatients. Anesthesia and Analgesia, 87, 816-826.

Pavlin, D. J., Sullivan, M. J., Freund, P. R., \& Roesen, K. (2005). Catastrophizing: A risk factor for postsurgical pain. Clinical Journal of Pain, 21, 83-90.

Peters, M. L., Vlaeyen, J. W. S., \& van Drunen, C. (2000). Do fibromyalgia patients display hypervigilance for innocuous somatosensory stimuli? Application of a body scanning reaction time paradigm. Pain, 86 , 283-292.

Peterson, R. A. \& Heilbronner, R. L. (1987). The Anxiety Sensitivity Index: Construct validity and factor analytic structure. Journal of Anxiety Disorders, 1, 117-121.

Peyron, R., Garcia-Larrea, L., Deiber, M. P., Cinotti, L., Convers, P., Sindou, M., et al. (1995). Electrical stimulation of precentral cortical area in the treatment of central pain: Electrophysiological and PET study. Pain, 62, 275-286.

Peyron, R., Garcia-Larrea, L., Gregoire, M. C., Convers, P., Lavenne, F., Veyre, L., et al. (1998). Allodynia after lateral-medullary (Wallenberg) infarct: A PET study. Brain, 121(Pt. 2), 345-356.

Phelps, M. E., \& Mazziotta, J. C. (1985, May 17). Positron emission tomography: Human brain function and biochemistry. Science, 228, 799-809.

Philips, H. C. (1987). Avoidance behaviour and its role in sustaining chronic pain. Behaviour Research and Therapy, 25, 273-279.

Picavet, H. S., Vlaeyen, J. W., \& Schouten, J. S. (2002). Pain catastrophizing and kinesiophobia: Predictors of chronic low back pain. American Journal of Epidemiology, 156, 1028-1034.

Pieper, G. M., Mizoguchi, H., Ohsawa, M., Kamei, J., Nagase, H., \& Tseng, L. F. (2000). Decreased opioid-induced antinociception but unaltered G-protein activation in the genetic-diabetic NOD mouse. European Journal of Pharmacology, 401, 375-379.

Pilowsky, I., \& Spence, N. (1976). Pain, anger, and illness behaviour. Journal of Psychosomatic Research, 20, 411-416.

Ploghaus, A., Tracey, I., Gati, J. S., Clare, S., Menon, R. S., Matthews, P. M., \& Rawlins, J. N. (1999, June 18). Dissociating pain from its anticipation in the human brain. Science, 284, 1979-1981.

Ploner, M., Gross, J., Timmermann, L., Pollok, B., \& Schnitzler, A. (2005). Pain suppresses spontaneous brain rhythms. Cerebral Cortex, 16, $537-$ 540.

Ploner, M., Schmitz, F., Freund, H. J., \& Schnitzler, A. (1999). Parallel activation of primary and secondary somatosensory cortices in human pain processing. Journal of Europhysiology, 81, 3100-3104.

Polatin, P. B. (1991). Predictors of low back pain. In A. White \& R. Anderson (Eds.), Conservative care of low back pain (pp. 321-336). Baltimore: Williams \& Wilkins.

Polomano, R. C., Mannes, A. J., Clark, U. S., \& Bennett, G. J. (2001). A painful peripheral neuropathy in the rat produced by the chemotherapeutic drug, paclitaxel. Pain, 94, 293-304.

Porro, C. A., Cettolo, V., Francescato, M. P., \& Baraldi, P. (1998). Temporal and intensity coding of pain in human cortex. Journal of Neurophysiology, 80, 3312-3320.

Porro, C. A., Lui, F., Facchin, P., Maieron, M., \& Baraldi, P. (2004). Percept-related activity in the human somatosensory system: Functional magnetic resonance imaging studies. Magnetic Resonance Imaging, 22, $1539-1548$

Price, D. D., Harkins, S. W., \& Baker, C. (1987). Sensory-affective relationships among different types of clinical and experimental pain. Pain, 28, 297-307.

Price, D. D., Staud, R., Robinson, M. E., Mauderli, A. P., Cannon, R., \& 
Vierck, C. J. (2002). Enhanced temporal summation of second pain and its central modulation in fibromyalgia patients. Pain, 99, 49-59.

Price, M. P., Lewin, G. R., McIlwrath, S. L., Cheng, C., Xie, J., Heppenstall, P. A., et al. (2000, October 26). The mammalian sodium channel BNC1 is required for normal touch sensation. Nature, 07, 1007-1011.

Price, M. P., McIlwrath, S. L., Xie, J., Cheng, C., Qiao, J., Tarr, D. E., et al. (2001). The DRASIC cation channel contributes to the detection of cutaneous touch and acid stimuli in mice. Neuron, 32, 1071-1083.

Price, M. P., Snyder, P. M., \& Welsh, M. J. (1996). Cloning and expression of a novel human brain $\mathrm{Na}+$ channel. Journal of Biological Chemistry, 271, 7879-7882.

Prichard, J. W., \& Brass, L. M. (1992). New anatomical and functional imaging methods. Annals of Neurology, 32, 395-400.

Pubols, L. M., \& Goldberger, M. E. (1980). Recovery of function in dorsal horn following partial deafferentation. Journal of Neurophysiology, 43, 102-117.

Radanov, B. P., di Stefano, G., Schnidrig, A., \& Ballinari, P. (1991, September 21). Role of psychosocial stress in recovery from common whiplash. Lancet, 338, 712-715.

Radhakrishnan, R., Moore, S. A., \& Sluka, K. A. (2003). Unilateral carrageenan injection into muscle or joint induces chronic bilateral hyperalgesia in rats. Pain, 104, 567-577.

Raij, T. T., Forss, N., Stancak, A., \& Hari, R. (2004). Modulation of motor-cortex oscillatory activity by painful Adelta- and C-fiber stimuli. NeuroImage, 23, 569-573.

Rainville, J., Carlson, N., Polatin, P., Gatchel, R. J., \& Indahl, A. (2000). Exploration of physicians' recommendations for activities in chronic low back pain. Spine, 25, 2210-2220.

Rainville, P., Duncan, G. H., Price, D. D., Carrier, B., \& Bushnell, M. C. (1997, August 15). Pain affect encoded in human anterior cingulate but not somatosensory cortex. Science, 277, 968-971.

Raja, S. N., Meyer, R. A., Ringkamp, M., \& Campbell, J. A. (1999). Peripheral neural mechanisms of nociception. In P. D. Wall \& R. Melzack (Eds.), Textbook of pain (4th ed., pp. 11-58). New York: Churchill Livingstone.

Ramachandran, V. S. (1998). Consciousness and body image: Lessons from phantom limbs, capgras syndrome and pain asymbolia. Philosophical Transactions of the Royal Society of London, 353, 1851-1859.

Ramachandran, V. S., \& Hirstein, W. (1998). The perception of phantom limbs. Brain, 121, 1603-1630.

Ray, Q. (2004). How the mind hurts and heals the body. American Psychologist, 59, 29-40.

Reichling, D. B., Kyrozis, A., Wang, J., \& MacDermott, A. B. (1994). Mechanisms of GABA and glycine depolarization-induced calcium transients in rat dorsal horn neurons. Journal of Physiology, 476, 411-421.

Reid, G., Scholz, A., Bostock, H., \& Vogel, W. (1999). Human axons contain at least five types of voltage-dependent potassium channel. Journal of Physiology, 518(Pt. 3), 681-696.

Reiss, S. (1991). Expectancy theory of fear, anxiety, and panic. Clinical Psychology Review, 11, 141-153.

Reiss, S., Peterson, R. A., Gursky, D. M., \& McNally, R. J. (1986). Anxiety sensitivity, anxiety frequency and the predictions of fearfulness. Behaviour Research and Therapy, 24, 1-8.

Ren, K., \& Dubner, R. (1993). NMDA receptor antagonists attenuate mechanical hyperalgesia in rats with unilateral inflammation of the hindpaw. Neuroscience Letters, 163, 22-26.

Ren, K., \& Dubner, R. (1996). Enhanced descending modulation of nociception in rats with persistent hindpaw inflammation. Journal of Neurophysiology, 76, 3025-3037.

Ren, K., Hylden, J. L., Williams, G. M., Ruda, M. A., \& Dubner, R. (1992). The effects of a non-competitive NMDA receptor antagonist, MK-801, on behavioral hyperalgesia and dorsal horn neuronal activity in rats with unilateral inflammation. Pain, 50, 331-344.

Ren, K., Williams, G. M., Hylden, J. L. K., Ruda, M. A., \& Dubner, R.
(1992). The intrathecal administration of excitatory amino acid receptor antagonists selectively attenuated carrageenan-induced behavioral hyperalgesia in rats. European Journal of Pharmacology, 219, 235-243.

Ren, K., Williams, G. M., Ruda, M. A., \& Dubner, R. (1994). Inflammation and hyperalgesia in rats neonatally treated with capsaicin: Effects on two classes of nociceptive neurons in the superficial dorsal horn. Pain, 59, 287-300.

Ritter, A. M. \& Mendell, L. M. (1992). Somal membrane properties of physiologically identified sensory neurons in the rat: effects of nerve growth factor. Journal of Neurophysiology, 68, 2033-2041.

Robinson, M. E., \& Riley, J. L. (1999). The role of emotion in pain. In R. J. Gatchel \& D. C. Turk (Eds.), Psychosocial factors in pain: Critical perspectives (pp. 74-88). New York: Guilford.

Romano, J., \& Turner, J. A. (1985). Chronic pain and depression: Does the evidence support a relationship? Psychological Bulletin, 97, 18-34.

Ruda, M. A., Ling, Q.-D., Hohmann, A. G., Peng, Y. B., \& Tachibana, T. (2000, July 28). Altered nociceptive neuronal circuits after neonatal peripheral inflammation. Science, 289, 628-631.

Rudomin, P., \& Schmidt, R. F. (1999). Presynaptic inhibition in the vertebrate spinal cord revisited. Experimental Brain Research, 129, $1-37$.

Rudy, T. E., Kerns, R. D., \& Turk, D. C. (1988). Chronic pain and depression: Toward a cognitive behavioral mediational model. Pain, 35, 129-140.

Rudy, T. E., Lieber, S. J., Boston, J. R., Gourley, L. M., \& Baysal, E. (2003). Psychosocial predictors of physical performance in disabled individuals with chronic pain. Clinical Journal of Pain, 19, 18-30.

Rusin, K. I., Jiang, M. C., Cerne, R., \& Randic, M. (1993). Interactions between excitatory amino acids and tachykinins in the rat spinal dorsal horn. Brain Research Bulletin, 30, 329-338.

Sadzot, B., Price, J. C., Mayberg, H. S., Douglass, K. H., Dannals, R. F., Lever, J. R. et al. (1991). Quantification of human opiate receptor concentration and affinity using high and low specific activity [11C]diprenorphine and positron emission tomography. Journal of Cerebral Blood Flow Metabolism, 11, 204-219.

Sadzot-Delvaux, C., Debrus, S., Nikkels, A., Piette, J., \& Rentier, B. (1995). Varicella-zoster virus latency in the adult rat is a useful model for human latent infection. Neurology, 45, S18-S20.

Sadzot-Delvaux, C., Merville-Louis, M. P., Delree, P., Marc, P., Piette, J., Moonen, G. et al. (1990). An in vivo model of varicella-zoster virus latent infection of dorsal root ganglia. Journal of Neuroscience Research, 26, 83-89.

Salomons, T. V., Johnstone, T., Backonja, M. M., \& Davidson, R. J. (2004). Perceived controllability modulates the neural response to pain. Journal of Neuroscience, 24, 7199-7203.

Samwel, H. J. A., Evers, A. W. M., Crul, B. J. P., \& Kraaimaat, F. W. (2006). The role of helplessness, fear of pain and passive pain-coping in chronic pain patients. Clinical Journal of Pain, 22, 245-251.

San Pedro, E. C., Mountz, J. M., Mountz, J. D., Liu, H. G., Katholi, C. R., \& Deutsch, G. (1998). Familial painful restless legs syndrome correlates with pain dependent variation of blood flow to the caudate, thalamus, and anterior cingulate gyrus. Journal of Rheumatology, 25, 2270-2275.

Sasaki, S., Yazawa, I., Miyakawa, N., Mochida, H., Shinomiya, K., Kamino, K., et al. (2002). Optical imaging of intrinsic signals induced by peripheral nerve stimulation in the in vivo rat spinal cord. NeuroImage, $17,1240-1255$.

Savoy, R. L. (2005). Experimental design in brain activation MRI: Cautionary tales. Brain Research Bulletin, 67, 361-367.

Scarfone, H., McComas, A. J., Pape, K., \& Newberry, R. (1999). Denervation and reinnervation in congenital brachial palsy. Muscle and Nerve, 22, 600-607.

Schaible, H. G., \& Grubb, B. D. (1993). Afferent and spinal mechanisms of joint pain. Pain, 55, 5-54.

Schaible, H. G., \& Schmidt, R. F. (1985). Effects of an experimental 
arthritis on the sensory properties of fine articular afferent units. Journal of Neurophysiology, 54, 1109-1122.

Schaible, H. G., \& Schmidt, R. F. (1988a). Direct observation of the sensitization of articular afferents during an experimental arthritis. In R. Dubner, G. F. Gebhart, \& M. R. Bond (Eds.), Proceedings of the 5th World Congress on Pain (pp. 44-50). Amsterdam: Elsevier.

Schaible, H. G., \& Schmidt, R. F. (1988b). Time course of mechanosensitivity changes in articular afferents during a developing experimental arthritis. Journal of Neurophysiology, 60, 2180-2195.

Scheier, M. F., \& Carver, C. S. (1985). Optimism, coping, and health: Assessment and implications of generalized outcome expectancies. Health Psychology, 4, 219-247.

Scheier, M. F., \& Carver, C. S. (1992). Effects of optimism on psychological and physical well-being: Theoretical overview and empirical update. Cognitive Therapy and Research, 16, 201-228.

Scheier, M. F., Carver, C. S., \& Bridges, M. W. (1994). Distinguishing optimism from neuroticism (and trait anxiety, self-mastery, and selfesteem): A reevaluation of the Life Orientation Test. Journal of Personality and Social Psychology, 67, 1063-1078.

Schmelz, M., Schmidt, R., Bickel, A., Handwerker, H. O., \& Torebjörk, H. E. (1997). Specific C-receptors for itch in human skin. Journal of Neuroscience, 17, 8003-8008.

Schmelz, M., Schmidt, R., Weidner, C., Hilliges, M., Torebjörk, H. E., \& Handwerker, H. O. (2003). Chemical response pattern of different classes of C-nociceptors to pruritogens and algogens. Journal of Neuroscience, $89,2441-2448$.

Schmidt, N. B., \& Cook, J. H. (1999). Effects of anxiety sensitivity on anxiety and pain during a cold pressor challenge in patients with panic disorder. Behaviour Research and Therapy, 37, 313-323.

Schmidt, R. F. (1971). Presynaptic inhibition in the vertebrate central nervous system. Ergebnisse der Physiologie, 63, 20-101.

Schneider, S. P., Eckert, W. A., \& Light, A. R. (1998). Opioid-activated postsynaptic, inward rectifying potassium currents in whole cell recordings in substantia gelatinosa neurons. Journal of Neurophysiology, 80, 2954-2962.

Scholten-Peeters, G. G., Verhagen, A. P., Bekkering, G. E., van der Windt, D. A., Barnsley, L., Oostendorp, R. A., \& Hendriks, E. J. (2003). Prognostic factors of whiplash-associated disorders: A systematic review of prospective cohort studies. Pain, 104, 303-322.

Scholz, A., Reid, G., Vogel, W., \& Bostock, H. (1993). Ion channels in human axons. Journal of Neurophysiology, 70, 1274-1279.

Schulman, H., Tsodikow, V., Einhorn, M., Levy, Y., Shorer, Z., \& Hertzanu, Y. (2001). Congenital insensitivity to pain with anhidrosis (CIPA): The spectrum of radiological findings. Pediatric Radiology, 31, 701-705.

Schwartz, L., Slater, M., Birchler, G., \& Atkinson, J. H. (1991). Depression in spouses of chronic pain patients: The role of patient pain and anger, and marital satisfaction. Pain, 44, 61-67.

Schwei, M. J., Honore, P., Rogers, S. D., Salak-Johnson, J. L., Finke, M. P., Ramnaraine, M. L. et al. (1999). Neurochemical and cellular reorganization of the spinal cord in a murine model of bone cancer pain. Journal of Neuroscience, 19, 10886-10897.

Schweinhardt, P., Glynn, C., Brooks, J., McQuay, H., Jack, T., Chessell, I., et al. (2006). An fMRI study of cerebral processing of brush-evoked allodynia in neuropathic pain patients. NeuroImage, 32, 256-265.

Seltzer, Z., Dubner, R., \& Shir, Y. (1990). A novel behavioral model of neuropathic pain disorders produced in rats by partial sciatic nerve injury. Pain, 43, 205-218.

Selye, H. (1950). Stress. Montreal, Canada: Acta Medical Publisher.

Seng, J. S., Graham-Bermann, S. A., Clark, M. K., McCarthy, A. M., \& Ronis, D. L. (2005). Posttraumatic stress disorder and physical comorbidity among female children and adolescents: Results from service-use data. Pediatrics, 116, 767-776.

Severeijns, R., Vlaeyen, J. W., \& van den Hout, M. A. (2004). Do we need a communal coping model of pain catastrophizing? An alternative explanation. Pain, 111, 226-229.

Severeijns, R., Vlaeyen, J. W., van den Hout, M. A., \& Picavet, H. S. (2005). Pain catastrophizing and consequences of musculoskeletal pain: A prospective study in the Dutch community. Journal of Pain, 6, $125-132$.

Shafrir, E., Spielman, S., Nachliel, I., Khamaisi, M., Bar-On, H., \& Ziv, E. (2001). Treatment of diabetes with vanadium salts: General overview and amelioration of nutritionally induced diabetes in the Psammomys obesus gerbil. Diabetes Metabolism Research Review, 17, 55-66.

Sharp, T. J. (2001). Chronic pain: A reformulation of the cognitivebehavioural model. Behaviour Research and Therapy, 39, 787-800.

Shatzky, S., Moses, S., Levy, J., Pinsk, V., Hershkovitz, E., Herzog, L., et al. (2000). Congenital insensitivity to pain with anhidrosis (CIPA) in Israeli-Bedouins: Genetic heterogeneity, novel mutations in the TRKA/ NGF receptor gene, clinical findings, and results of nerve conduction studies. American Journal of Medical Genetics, 92, 353-360.

Shimoyama, M., Tanaka, K., Hasue, F., \& Shimoyama, N. (2002). A mouse model of neuropathic cancer pain. Pain, 99, 167-174.

Shimoyama, M., Tatsuoka, H., Ohtori, S., Tanaka, K., \& Shimoyama, N. (2005). Change of dorsal horn neurochemistry in a mouse model of neuropathic cancer pain. Pain, 114, 221-230.

Shorer, Z., Moses, S. W., Hershkovitz, E., Pinsk, V., \& Levy, J. (2001). Neurophysiologic studies in congenital insensitivity to pain with anhidrosis. Pediatric Neurology, 25, 397-400.

Shorey, P., \& Lobo, G. (1990). Congenital corneal anesthesia: Problems in diagnosis. Journal of Pediatric Ophthalmology and Strabismus, 27, $143-147$.

Siddall, P. J., Taylor, D., \& Cousins, M. J. (1995). Pain associated with spinal cord injury. Current Opinion in Neurology, 8, 447-450.

Sima, A. (1980). Peripheral neuropathy in the spontaneously diabetic BB-Wistar-rat. An ultrastructural study. Acta Neuropathology (Berlin), $51,223-227$.

Simone, D. A., Baumann, T. K., \& LaMotte, R. H. (1989). Dose-dependent pain and mechanical hyperalgesia in humans after intradermal injection of capsaicin. Pain, 38, 99-107.

Simone, D. A., Marchettini, P., Caputi, G., \& Ochoa, J. L. (1994). Identification of muscle afferents subserving sensation of deep pain in humans. Journal of Neurophysiology, 72, 883-889.

Sinclair, D. C. (1955). Cutaneous sensation and the cotrine of specific nerve energies. Brain, 78, 584-614.

Singer, B., Friedman, E., Seeman, T., Fava, G. A., Ryff, C. D. (2005). Protective environments and health status: Cross-talk between human and animal studies. Neurobiology of Aging, 26(Suppl.), S113-S118.

Singer, T., Seymour, B., O’Doherty, J., Kaube, H., Dolan, R. J., \& Frith, C. D. (2004, February 20). Empathy for pain involves the affective but not sensory components of pain. Science, 303, 1157-1162.

Skyba, D. A., Radhakrishnan, R., \& Sluka, K. A. (2005). Characterization of a method for measuring primary hyperalgesia of deep somatic tissue. Journal of Pain, 6, 41-47.

Slifstein, M., \& Laruelle, M. (2001). Models and methods for derivation of in vivo neuroreceptor parameters with PET and SPECT reversible radiotracers. Nuclear Medicine Biology, 28, 595-608.

Sluka, K. A., Kalra, A., \& Moore, S. A. (2001). Unilateral intramuscular injections of acidic saline produce a bilateral, long-lasting hyperalgesia. Muscle Nerve, 24, 37-46.

Sluka, K. A., Rees, H., Chen, P. S., Tsuruoka, M., \& Willis, W. D. (1997). Capsaicin-induced sensitization of primate spinothalamic tract cells is prevented by a protein kinase C inhibitor. Brain Research, 772, 82-86.

Smeets, R. J. E. M., Vlaeyen, J. W. S., Kester, A. D. M., \& Knottnerus, J. A. (2006). Reduction of pain catastrophizing mediates the outcome of both physical and cognitive-behavioral treatment of chronic low back pain. The Journal of Pain, 7, 261-271.

Smith, W. B., Gracely, R. H., \& Safer, M. A. (1998). The meaning of pain: 
Cancer patients' rating and recall of pain intensity and affect. Pain, 78, 123-129.

Snyder, C. R., Berg, C., Woodward, J. T., Gum, A., Rand, K. L., Wrobleski, K. K., et al. (2005). Hope against the cold: Individual differences in trait hope and acute pain tolerance on the cold pressor task. Journal of Personality, 73, 287-312.

Snyder, C. R., Rand, K. L., \& Sigmond, D. R. (2005). Hope theory: A member of the positive psychology family. In C. R. Snyder \& S. J. Lopez (Eds.), Handbook of positive psychology (pp. 257-276). Oxford, England: Oxford University Press.

Social Security Administration. (n.d.). Social security basic facts. Retrieved August 15, 2005, from http://www.ssa.gov/pressoffice/ basicfact.htm

Sora, I., Funada, M., \& Uhl, G. R. (1997). The mu-opioid receptor is necessary for [D-Pen2,D-Pen5]enkephalin-induced analgesia. European Journal of Pharmacology, 324, R1-R2.

Spinhoven, P., Ter Kuile, M. N., Kole-Snijders, A. M. J., Hutten Mansfield, M., Den Outen, D. J., \& Vlaeyen, J. W. S. (2004). Catastrophizing and internal pain control as mediators of outcome in the multidisciplinary treatment of chronic low back pain. European Journal of Pain, $8,211-219$

Staud, R., Price, D. D., Robinson, M. E., Mauderli, A. P., \& Vierck, C. J. (2004). Maintenance of windup of second pain requires less frequent stimulation in fibromyalgia patients compared to normal controls. Pain, 110, 689-696.

Steedman, W. M., Molony, V., \& Iggo, A. (1985). Nociceptive neurones in the superficial dorsal horn of cat lumbar spinal cord and their primary afferent inputs. Experimental Brain Research, 58, 171-182.

Steen, K. H., Issberner, U., \& Reeh, P. W. (1995). Pain due to experimental acidosis in human skin: Evidence for non-adapting nociceptor excitation. Neuroscience Letters, 199, 29-32.

Stegen, K., Van Diest, I., Van de Woestijne, K. P., \& Van den Bergh, O. (2000). Negative affectivity and bodily sensations induced by $5.5 \%$ CO-sub-2 enriched air inhalation: Is there a bias to interpret bodily sensations negatively in persons with negative affect? Psychology and Health, 15, 513-525.

Stein, M. B., Jang, K. L., \& Livesley, W. J. (1999). Heritability of anxiety sensitivity: A twin study. American Journal of Psychiatry, 156, 246251.

Sternbach, R., Wolfe, S., Murphy, R., \& Akeson, W. (1973). Traits of pain patients: The low-back "loser." Psychosomatics, 14, 226-229.

Stoner, S., \& Spencer, B. (1987). Age and gender differences with the Anger Expression Scale. Educational and Psychological Measurement, 47, 487-492.

Sullivan, M. J., Feuerstein, M., Gatchel, R., Linton, S. J., \& Pransky, G. (2005). Integrating psychosocial and behavioral interventions to achieve optimal rehabilitation outcomes. Journal of Occupational Rehabilitation, 15, 475-489.

Sullivan, M. J. L., Thorn, B., Haythornthwaite, J. A., Keefe, F., Martin, M., Bradley, L. A., et al. (2001). Theoretical perspectives on the relation between catastrophizing and pain. Clinical Journal of Pain, 17, 52-64.

Summers, J. D., Rapoff, M. A., Varghese, G., Porter, K., \& Palmer, R. E. (1991). Psychosocial factors in chronic spinal cord injury pain. Pain, 47, 183-189.

Svensson, P., Minoshima, S., Beydoun, A., Morrow, T. J., \& Casey, K. L. (1997). Cerebral processing of acute skin and muscle pain in humans. Journal of Neurophysiology, 78, 450-460.

Sweet, W. H. (1981). Animal models of chronic pain: Their possible validation from human experience with posterior rhizotomy and congenital analgesia. Pain, 10, 275-295.

Szilagyi, A., Bloor, K., Orosz, I., Szantai, E., Szekely, A., Kalasz, H., et al. (2006). Contribution of serotonin transporter gene polymorphisms to pediatric migraine. Headache, 46, 478-485.

Sztriha, L., Lestringant, G. G., Hertecant, J., Frossard, P. M., \& Masouye,
I. (2001). Congenital insensitivity to pain with anhidrosis. Pediatric Neurology, 25, 63-66.

Taber, R. I., Greenhouse, D. D., \& Irwin, S. (1964, October 10). Inhibition of phenylquinone-induced writhing by narcotic antagonists. Nature, 204, 189-190.

Taber, R. I., Greenhouse, D. D., Rendell, J. K., \& Irwin, S. (1969). Agonist and antagonist interactions of opioids on acetic acid-induced abdominal stretching in mice. Journal of Pharmacology \& Experimental Therapeutics, 169, 29-38.

Tai, Y. F., \& Piccini, P. (2004). Applications of positron emission tomography (PET) in neurology. Journal of Neurology, Neurosurgery, \& Psychiatry, 75, 669-676.

Takeshita, N., \& Yamaguchi, I. (1998). Antinociceptive effects of morphine were different between experimental and genetic diabetes. Pharmacology, Biochemistry, \& Behavior, 60, 889-897.

Talbot, J. D., Marrett, S., Evans, A. C., Meyer, E., Bushnell, M. C., \& Duncan, G. H. (1991, March 15). Multiple representations of pain in human cerebral cortex. Science, 251, 1355-1358.

Tan, G., Jensen, M. P., Robinson Whelen, S., Thornby, J. I., \& Monga, T. (2002). Measuring control appraisals in chronic pain. Journal of Pain, 3, 385-393.

Tanaka, S., Osari, S., Ozawa, M., Yamanouchi, H., Goto, Y., Matsuda, H., et al. (1997). Recurrent pain attacks in a 3-year-old patient with myoclonus epilepsy associated with ragged-red fibers (MERRF): A singlephoton emission computed tomographic (SPECT) and electrophysiological study. Brain Development, 19, 205-208.

Tanner, K. D., Reichling, D. B., \& Levine, J. D. (1998). Nociceptor hyper-responsiveness during vincristine-induced painful peripheral neuropathy in the rat. Journal of Neuroscience, 18, 6480-6491.

Taylor, S. (1993). The structure of fundamental fears. Journal of Behavioral Therapy and Experimental Psychiatry, 24, 289-299.

Taylor, S. (1995). Anxiety sensitivity: Theoretical perspectives and recent findings. Behaviour Research and Therapy, 33, 243-258.

Tennen, H., \& Affleck, G. (2005). Benefit-finding and benefit-reminding. In C. R. Snyder \& S. J. Lopez (Eds.), Handbook of positive psychology (pp. 584-597). Oxford, England: Oxford University Press.

ter Laak, M. P., Hamers, F. P., Kirk, C. J., \& Gispen, W. H. (2000). rhGGF2 protects against cisplatin-induced neuropathy in the rat. Journal of Neuroscience Research, 60, 237-244.

Terrazas, A., \& McNaughton, B. L. (2000). Brain growth and the cognitive map. Proceedings of the National Academy of Sciences, USA, 97, 4414-4416.

Thompson, S. C. (1981). Will it hurt less if I can control it? A complex answer to a simple question. Psychological Bulletin, 90, 89-101.

Thorn, B. E. (2004). Cognitive therapy for chronic pain. New York: Guilford Press.

Thorn, B. E., Rich, M. A., \& Boothby, J. L. (1999). Pain beliefs and coping attempts. Pain Forum, 8, 169-171.

Todorovic, S., \& Anderson, E. G. (1990). 5- $\mathrm{HT}_{2}$ and 5- $\mathrm{HT}_{3}$ receptors mediate two distinct depolarizing responses in rat dorsal root ganglion neurons. Brain Research, 511, 71-79.

Tommerdahl, M., Simons, S. B., Chiu, J. S., Favorov, O., \& Whitsel, B. (2005). Response of SI cortex to ipsilateral, contralateral and bilateral flutter stimulation in the cat [Electronic version]. BMC Neuroscience, 6, $29-42$.

Torebjörk, H. E., \& Hallin, R. G. (1970). C-fibre units recorded from human sensory nerve fascicles in situ. A preliminary report. Acta Social Medicina Upsala, 75, 81-84.

Torebjörk, H. E., Lundberg, L. E. R., \& LaMotte, R. H. (1992). Central changes in processing of mechanoreceptive input in capsaicin-induced secondary hyperalgesia in humans. Journal of Physiology (London), 448, 765-780.

Torebjörk, H. E., Ochoa, J. L., \& McCann, F. V. (1979). Paresthesiae: 
Abnormal impulse generation in sensory nerve fibres in man. Acta Physiologica Scandinavica, 105, 518-520.

Torebjörk, H. E., Vallbo, A. B., \& Ochoa, J. L. (1987). Intraneural microstimulation in man: Its relation to specificity of tactile sensations. Brain, 110, 1509-1529.

Toscano, E., \& Andria, G. (2001). Congenital insensitivity to pain with anhidrosis: An NGF/TrkA-related disorder. American Journal of Medical Genetics, 99, 164-165.

Toscano, E., della Casa, R., Mardy, S., Gaetaniello, L., Sadile, F., Indo, Y., et al. (2000). Multisystem involvement in congenital insensitivity to pain with anhidrosis (CIPA), a nerve growth factor receptor(Trk A)-related disorder. Neuropediatrics, 31, 39-41.

Traub, R. J. (1996). The spinal contribution of substance P to the generation and maintenance of inflammatory hyperalgesia in the rat. Pain, 67, 151-161.

Traub, R. J., \& Mendell, L. M. (1988). The spinal projection of individual identified A-delta and C-fibers. Journal of Neurophysiology, 59, 41-55.

Traub, R. J., Sedivec, M. J., \& Mendell, L. M. (1986). The rostral projection of small diameter primary afferents in Lissauer's tract. Brain Research, 399, 185-189.

Treharne, G. J., Kitas, G. D., Lyons, A. C., \& Booth, D. A. (2005). Well-being in rheumatoid arthritis: The effects of disease duration and psychosocial factors. Journal of Health Psychology, 10, 457-474.

Trevino, D. L., Coulter, J. D., \& Willis, W. D. (1973). Location of cells of origin of spinothalamic tract in lumbar enlargement of the monkey. Journal of Neurophysiology, 36, 750-761.

Tschannen, T. A., Duckro, P. N., Margolis, R. B., \& Tomazic, T. J. (1992). The relationship of anger, depression, and perceived disability among headache patients. Headache, 32, 501-503.

Tucker, K. L. (2005). Stress and nutrition in relation to excess development of chronic disease in Puerto Rican adults living in the northeastern USA. The Journal of Medical Investigation, 52(Suppl.), 252-258.

Turk, D. C., \& Monarch, E. S. (2002). Biopsychosocial perspective on chronic pain. In D. C. Turk \& R. J. Gatchel (Ed.), Psychological approaches to pain management: A practitioner's handbook (2nd ed., pp. 3-30). New York: Guilford Press.

Turk, D. C., Okifuji, A., \& Scharff, L. (1995). Chronic pain and depression: Role of perceived impact and perceived control in different age cohorts. Pain, 61, 93-101.

Turk, D. C., Robinson, J. P., \& Burwinkle, T. (2004). Prevalence of fear of pain and activity in fibromyalgia syndrome patients. Journal of Pain, 5 , 483-490.

Turner, J. A., \& Aaron, L. A. (2001). Pain-related catastrophizing: What is it? Clinical Journal of Pain, 17, 65-71.

Turner, J. A., Jensen, M. P., \& Romano, J. M. (2000). Do beliefs, coping, and catastrophizing independently predict functioning in patients with chronic pain? Pain, 85, 115-125.

Turner, J. A., Mancl, L., Aaron, L. A. (2006). Short- and long-term efficacy of brief cognitive-behavioral therapy for patients with chronic temporomandibular disorder pain: A randomized, controlled trial. Pain, 121, 181-194.

Uchino, H., Elmer, E., Uchino, K., Lindvall, O., \& Siesjo, B. K. (1995). Cyclosporin A dramatically ameliorates CA1 hippocampal damage following transient forebrain ischaemia in the rat. Acta Physiologica Scandinavica, 155, 469-471.

Unruh, A. M. (1996). Gender variations in clinical pain experience. Pain, 65, 123-167.

Uttal, W. R. (2001). The new phrenology: The limits of localizing cognitive processes in the brain. Cambridge, MA: MIT Press.

Vallbo, A. B., Hagbarth, K. E., Torebjörk, H. E., \& Wallin, B. G. (1979). Somatosensory, proprioceptive, and sympathetic activity in human peripheral nerves. Physiological Reviews, 59, 919-957.

Vancleef, L. M. G., Peters, M. L., \& de Jong, P. J. (in press). Understanding the role of injury/illness sensitivity and anxiety sensitivity in (auto- matic) pain processing: An examination using the Extrinsic Affective Simon Task. Journal of Pain.

Vancleef, L. M. G., Peters, M. L., Roelofs, J., \& Asmundson, G. J. G. (2006). Do fundamental fears differentially contribute to pain-related fear and pain catastrophizing? An evaluation of the Sensitivity Index. European Journal of Pain, 10, 527-536.

Van Hees, J. \& Gybels, J. M. (1972). Pain related to single afferent C fibers from human skin. Brain Research, 48, 397-400.

Vasko, M. R., Campbell, W. B., \& Waite, K. J. (1994). Prostaglandin E2 enhances bradykinin-stimulated release of neuropeptides from rat sensory neurons in culture. Journal of Neuroscience, 4, 4987-4997.

Verdu, E., Vilches, J. J., Rodriguez, F. J., Ceballos, D., Valero, A., \& Navarro, X. (1999). Physiological and immunohistochemical characterization of cisplatin-induced neuropathy in mice. Muscle Nerve, 22, 329-340.

Verhaak, P. F., Kerssens, J. J., Dekker, J., Sorbi, M. J., \& Bensing, J. M. (1998). Prevalence of chronic benign pain disorder among adults: A review of the literature. Pain, 77, 231-239.

Viane, I., Crombez, G., Eccleston, C., Poppe, C., Devulder, J., Van Houdenhove, B., et al. (2003). Acceptance of pain is an independent predictor of mental well-being in patients with chronic pain: Empirical evidence and reappraisal. Pain, 106, 65-72.

Vierck, C. J., Greenspan, J. D., \& Ritz, L. A. (1990). Long-term changes in purposive and reflexive responses to nociception stimulation following anterolateral chordotomy. Journal of Neuroscience, 10, 2077-2095.

Vierck, C. J. J., \& Light, A. R. (1999). Effects of combined hemotoxic and anterolateral spinal lesions on nociceptive sensitivity. Pain, 83, 447457.

Vincent, A. L., Rodrick, G. E., \& Sodeman, W. A., Jr. (1979). The pathology of the Mongolian gerbil (Meriones unguiculatus): A review. Laboratory Animal Science, 29, 645-651.

Vital, A., Fontan, D., Julien, J., Julien, J., Heron, B., Routon, M. C., et al. (1998). Congenital insensitivity to pain with anhydrosis. Report of two unrelated cases. Journal of the Peripheral Nervous System, 3, 125-132.

Vlaeyen, J. W. S., \& Crombez, G. (1999). Fear of movement/(re)injury, avoidance and pain disability in chronic low back pain patients. Manual Therapy, 4, 187-195.

Vlaeyen, J. W., de Jong, J., Geilen, M., Heuts, P. H., \& van Breukelen, G. (2002). The treatment of fear of movement/(re)injury in chronic low back pain: Further evidence on the effectiveness of exposure in vivo. Clinical Journal of Pain, 18, 251-261.

Vlaeyen, J. W., de Jong, J. R., Onghena, P., Kerckhoffs Hanssen, M., \& Kole Snijders, A. M. (2002). Can pain-related fear be reduced? The application of cognitive-behavioural exposure in vivo. Pain Research and Management, 7, 144-153.

Vlaeyen, J. W. S., Kole-Snijders, A. M., Boeren, R. G. B., \& van Eek, H. (1995). Fear of movement/(re)injury in chronic low back pain and its relation to behavioral performance. Pain, 62, 363-372.

Vlaeyen, J. W. S., Kole-Snijders, A., Rotteveel, A., Ruesink, R., \& Heuts, P. (1995). The role of fear of movement/(re)injury in pain disability. Journal of Occupational Rehabilitation, 5, 235-252.

Vlaeyen, J. W. S., \& Linton, S. J. (2000). Fear-avoidance and its consequences in chronic musculoskeletal pain: A state of the art review. Pain, $85,317-332$.

Vlaeyen, J. W. S., Seelen, H. A. M., Peters, M., de Jong, P., Aretz, E., Beisiegel, E., et al. (1999). Fear of movement/(re)injury and muscular reactivity in chronic low back pain patients: An experimental investigation. Pain, 82, 297-304.

Von Korff, M., Crane, P., Lane, M., Miglioretti, D. L., Simon, G., Saunders, K., et al. (2005). Chronic spinal pain and physical-mental comorbidity in the United States: Results from the National Comorbidity Survey Replication. Pain, 113, 331-339.

Von Korff, M., \& Simon, G. (1996). The relationship between pain and depression. British Journal of Psychiatry, 168(Suppl. 30), 101-108. 
Voura, E. B., Jaiswal, J. K., Mattoussi, H., \& Simon, S. M. (2004). Tracking metastatic tumor cell extravasation with quantum dot nanocrystals and fluorescence emission-scanning microscopy. Nature Medicine, 10, 993-998.

Waddell, G. (1987). A new clinical method for the treatment of low back pain. Spine, 12, 632-644.

Wade, J. B., Price, D. D., Hamer, R. M., Schwartz, S. M., \& Hart, R. P. (1990). An emotional component analysis of chronic pain. Pain, 40, 303-310.

Waldrop, D., Lightsey, O. R., Jr., Ethington, C. A., Woemmel, C. A., \& Coke, A. L. (2001). Self-efficacy, optimism, health competence, and recovery from orthopedic surgery. Journal of Counseling Psychology, 48, 233-238.

Walker, K., Medhurst, S. J., Kidd, B. L., Glatt, M., Bowes, M., Patel, S., et al. (2002). Disease modifying and anti-nociceptive effects of the bisphosphonate, zoledronic acid in a model of bone cancer pain. Pain, 100, 219-229.

Wall, P. D. (1960). Cord cells responding to touch, damage and temperature of skin. Journal of Neurophysiology, 23, 197-210.

Wall, P. D. (1967). The laminar organization of dorsal horn and effects of descending impulses. Journal of Physiology, 188, 403-423.

Wall, P. D., Devor, M., Inbal, R., Scadding, J. W., Schonfeld, D., Seltzer, Z., et al. (1979). Autotomy following peripheral nerve lesions: Experimental anaesthesia dolorosa. Pain, 7, 103-111.

Wallace, V. C., Cottrell, D. F., Brophy, P. J., \& Fleetwood-Walker, S. M. (2003). Focal lysolecithin-induced demyelination of peripheral afferents results in neuropathic pain behavior that is attenuated by cannabinoids. Journal of Neuroscience, 23, 3221-3233.

Watson, D., Clark, L. A., \& Harkness, A. R. (1994). Structures of personality and their relevance to psychopathology. Journal of Abnormal Psychology, 103, 18-31.

Watson, D., \& Pennebaker, J. W. (1989). Health complaints, stress, and distress: Exploring the central role of negative affectivity. Psychology Review, 96, 234-254.

Weddell, G. (1955). Somesthesis and the chemical senses. Annual Review of Psychology, 6, 119-136.

Weinreich, D., \& Wonderlin, W. F. (1987). Inhibition of calciumdependent spike after-hyperpolarization increases excitability of rabbit visceral sensory neurones. Journal of Physiology, 394, 415-427.

Weisenberg, M. (1998). Cognitive aspects of pain and pain control. International Journal of Clinical and Experimental Hypnosis, 46, 44-61.

Welsh, M. J., Price, M. P., \& Xie, J. (2002). Biochemical basis of touch perception: Mechanosensory function of degenerin/epithelial Na+ channels. Journal of Biological Chemistry, 277, 2369-2372.

Weng, H. R., \& Dougherty, P. M. (2002). Tuning of membrane properties regulates subliminal synapses in dorsal horn neurons of intact rats. Experimental Neurology, 175, 209-215.

Weng, H., Lee, J. I., Lenz, F. A., Schwartz, A., Vierck, C., Rowland, L., Dougherty, P. M. (2000). Functional plasticity in primate somatosensory thalamus following chronic lesion of the ventral lateral spinal cord. Neuroscience, 101, 393-401.

Werner, E. L., Ihlebaek, C., Skouen, J. S., \& Laerum, E. (2005). Beliefs about low back pain in the Norwegian general population: Are they related to pain experiences and health professionals? Spine, 30, 17701776.

Wesselmann, U., Czakanski, P. P., Affaitati, G., \& Giamberardino, M. A. (1998). Uterine inflammation as a noxious visceral stimulus: Behavioral characterization in the rat. Neuroscience Letters, 246, 73-76.

Weydert, J. A., Ball, T. M., \& Davis, M. F. (2003). Systematic review of treatments for recurrent abdominal pain. Pediatrics, 111, e1-11.

White, J. C., Sweet, W. H., Hawkins, R., \& Nilges, R. G. (1950). Anterolateral cordotomy: Results, complications and causes of failure. Brain, $73,346-367$.
Willenbring, S., Beauprie, I. G., \& DeLeo, J. A. (1995). Sciatic cryoneurolysis in rats: A model of sympathetically independent pain: Part 1. Effects of sympathectomy. Anesthesia and Analgesia, 81, 544-548.

Williams, A., \& McCracken, L. M. (2004). Cognitive-behavioral therapy for chronic pain: An overview with specific reference to fear and avoidance. In G. J. Asmundson, J. W. S. Vlaeyen, \& G. Crombez (Eds.), Understanding and treating fear of pain (pp. 293-312). Oxford, England: Oxford University Press.

Willis, W. D. (1999). Dorsal root potentials and dorsal root reflexes: A double-edged sword. Experimental Brain Research, 124, 395-421.

Willis, W. D. (2002). Possible mechanisms of central neuropathic pain. In K. J. Burchiel \& R. P. Yezierski (Eds.), Spinal cord injury pain: Assessment, mechanisms, management. Vol. 23: Pain research and management (pp. 85-115). Seattle, WA: International Association for the Study of Pain.

Willis, W. D., Trevino, D. L., Coulter, J. D., \& Maunz, R. A. (1974). Responses of primate spinothalamic tract neurons to natural stimulation of hindlimb. Journal of Neurophysiology, 37, 358-372.

Willis, W. D., Weir, M. A., Skinner, R. D., \& Bryan, R. N. (1973). Differential distribution of spinal cord field potentials. Experimental Brain Research, 17, 169-176.

Woby, S. R., Watson, P. J., Roach, N. K., \& Urmston, M. (2005). Coping strategy use: Does it predict adjustment to chronic back pain after controlling for catastrophic thinking and self-efficacy for pain control? Journal of Rehabilitation Medicine, 37, 100-107.

Wolfe, F., Smythe, H. A., Yunus, M. B., Bennett, R. M., Bombardier, C., Goldenberg, D. L., et al. (1990). The American College of Rheumatology 1990 criteria for the classification of fibromyalgia: Report of the Multicenter Criteria Committee. Arthritis and Rheumatism, 33, 160172 .

Woolf, C. J. (1996). Windup and central sensitization are not equivalent. Pain, 66, 105-108.

Woolf, C. J., \& King, A. E. (1990). Dynamic alterations in the cutaneous mechanoreceptive fields of dorsal horn neurons in the rat spinal cord. Journal of Neuroscience, 10, 2717-2726.

Woolf, C. J., \& Wall, P. D. (1982). Chronic peripheral nerve section diminishes the primary afferent A-fibre mediated inhibition of rat dorsal horn neurones. Brain Research, 242, 77-85.

Wu, C. L., Tella, P., Staats, P. S., Vaslav, R., Kazim, D. A., Wesselmann, U., et al. (2002). Analgesic effects of intravenous lidocaine and morphine on postamputation pain: A randomized double-blind, active placebo-controlled, crossover trial. Anesthesiology, 96, 841-848.

Wuarin-Bierman, L., Zahnd, G. R., Kaufmann, F., Burcklen, L., \& Adler, J. (1987). Hyperalgesia in spontaneous and experimental animal models of diabetic neuropathy. Diabetologia, 30, 653-658.

Xie, Y., Zhang, J. X., Petersen, M., \& LaMotte, R. H. (1995). Functional changes in dorsal root ganglion cells after chronic nerve constriction in the rat. Journal of Neurophysiology, 73, 1811-1820.

Xu, X., Fukuyama, H., Yazawa, S., Mima, T., Hanakawa, T., Magata, Y., Kanda, M., Fujiwara, N., Shindo, K., Nagamine, T., \& Shibasaki, H. (1997). Functional localization of pain perception in the human brain studied by PET. NeuroReport, 8, 555-559.

Xu, X.-J., Hao, J.-X., Aldskogius, H., Seiger, A., \& Wiesenfeld-Hallin, Z. (1992). Chronic pain-related syndrome in rats after ischemic spinal cord lesion: A possible animal model for pain in patients with spinal cord injury. Pain, 48, 279-290.

Yezierski, R. P., Liu, S., Ruenes, G. L., Kajander, K. J., \& Brewer, K. L. (1998). Excitotoxic spinal cord injury: Behavioral and morphological characteristics of a central pain model. Pain, 75, 141-155.

Yezierski, R. P., \& Park, S. H. (1993). The mechanosensitivity of spinal sensory neurons following intraspinal injections of quisqualic acid in the rat. Neuroscience Letters, 157, 115-119.

Yezierski, R. P., Santana, M., Park, S. H., \& Madsen, P. W. (1993). 
Neuronal degeneration and spinal cavitation following intraspinal injections of quisqualic acid in the rat. Journal of Neurotrauma, 10, 445-456.

Yoon, Y. W., Na, H. S., \& Chung, J. M. (1996). Contributions of injured and intact afferents to neuropathic pain in an experimental rat model. Pain, 64, 27-36.

Yoshimura, M., Doi, A., Mizuno, M., Furue, H., \& Katafuchi, T. (2005). In vivo and in vitro patch-clamp recording analysis of the process of sensory transmission in the spinal cord and sensory cortex. Journal of Physiological Anthropology \& Applied Human Science, 24, 93-97.

Yoshimura, M., \& Nishi, S. (1993). Blind patch-clamp recordings from substantia gelatinosa neurons in adult rat spinal cord slices: Pharmacological properties of synaptic currents. Neuroscience, 53, 519-526.
Yotsumoto, S., Setoyama, M., Hozumi, H., Mizoguchi, S., Fukumaru, S., Kobayashi, K., et al. (1999). A novel point mutation affecting the tyrosine kinase domain of the TRKA gene in a family with congenital insensitivity to pain with anhidrosis. Journal of Investigational Dermatology, 112, 810-814.

Zhang, L., Hoff, A. O., Wimalawansa, S. J., Cote, G. J., Gagel, R. F., \& Westlund, K. N. (2001). Arthritic calcitonin/alpha calcitonin generelated peptide knockout mice have reduced nociceptive hypersensitivity. Pain, 89, 265-273.

Received February 16, 2006

Revision received June 7, 2006

Accepted July 6, 2006

\section{Members of Underrepresented Groups: Reviewers for Journal Manuscripts Wanted}

If you are interested in reviewing manuscripts for APA journals, the APA Publications and Communications Board would like to invite your participation. Manuscript reviewers are vital to the publications process. As a reviewer, you would gain valuable experience in publishing. The P\&C Board is particularly interested in encouraging members of underrepresented groups to participate more in this process.

If you are interested in reviewing manuscripts, please write to the address below. Please note the following important points:

- To be selected as a reviewer, you must have published articles in peer-reviewed journals. The experience of publishing provides a reviewer with the basis for preparing a thorough, objective review.

- To be selected, it is critical to be a regular reader of the five to six empirical journals that are most central to the area or journal for which you would like to review. Current knowledge of recently published research provides a reviewer with the knowledge base to evaluate a new submission within the context of existing research.

- To select the appropriate reviewers for each manuscript, the editor needs detailed information. Please include with your letter your vita. In the letter, please identify which APA journal(s) you are interested in, and describe your area of expertise. Be as specific as possible. For example, "social psychology" is not sufficient-you would need to specify "social cognition" or "attitude change" as well.

- Reviewing a manuscript takes time (1-4 hours per manuscript reviewed). If you are selected to review a manuscript, be prepared to invest the necessary time to evaluate the manuscript thoroughly.

Write to Journals Office, American Psychological Association, 750 First Street, NE, Washington, DC 20002-4242. 